\title{
ESTILO, ICONOGRAFÍA Y FUNCIÓN DE LAS INKUÑAS PREHISPÁNICAS DEL NORTE DE CHILE DURANTE EL PERIODO INTERMEDIO TARDÍO (1.000-1.470 D.C.)
}

\author{
STYLE, ICONOGRAPHY AND FUNCTION OF THE PREHISPANIC \\ INKUÑA IN NORTHERN CHILE DURING THE LATE \\ INTERMEDIATE PERIOD (AD 1,000-1,470)
}

\author{
Helena Horta Tricallotis ${ }^{1}$ y Carolina Agüero Piwonka ${ }^{2}$
}

\begin{abstract}
En este artículo analizamos un grupo de 147 inkuñas procedentes de cementerios del valle de Azapa (Azapa-3, Azapa-6, Azapa-8, Azapa-71, Azapa-75 y Azapa-140), así como de la costa de Arica (Playa Miller-2, Playa Miller-3, Playa Miller-4, Playa Miller-8, Playa Miller-9 y Chacalluta-3), las que son clasificadas tipológicamente con el objeto de definir la inkuña arqueológica en cuanto a su forma y función; al mismo tiempo, y en base al análisis iconográfico y estilístico nos proponemos definir varios estilos textiles contemporáneos durante el periodo Intermedio Tardío, lo cual avala -y es coherente con- la ocupación multiétnica formulada para la zona.
\end{abstract}

Palabras claves: textiles arqueológicos, estilos textiles, inkuña, tari, coca, textiles etnográficos, Arica, extremo norte de Chile, periodo Intermedio Tardío.

In this article a total of 147 inkuñas originating from cemeteries in the Azapa Valley (Azapa-3, Azapa-6, Azapa-8, Azapa-71, Azapa-75 and Azapa-140), and those of the coast of Arica (Playa Miller-2, Playa Miller-3, Playa Miller-4, Playa Miller-8, Playa Miller-9 and Chacalluta-3) are analyzed and classified according to their form and function. Also, based on iconographic and stylistic analysis we propose a definition of various contemporary textile styles during the Late Intermediate Period which confirms - and is coherent with - the multiethnic occupation of the zone.

Key words: Archaeological textiles, textile styles, inkuña, tari, coca, etnographic textiles, Arica, Northern Chile, Late Intermediate Period.

El estudio de los contextos de diferentes cementerios de la costa de Arica y del valle de Azapa, que cronológicamente pertenecen al período Intermedio Tardío, ha permitido la observación de diferentes textiles ofrendados en las tumbas ${ }^{1}$. Destacan entre ellos las inkuñas o taris - palabras quechua y aymara-pacaje, respectivamente- y denominadas tradicionalmente "paños rituales" por los arqueólogos, que en la gran mayoría de los casos contienen hojas de coca, conformando pequeños bultos al amarrar las asas de sus esquinas. Estos atados fueron depositados en el entorno del difunto, a veces entre los pliegues del fardo, formando parte de su ofrenda. Este uso y disposición es común tanto en cementerios de la costa como del valle.

Con este trabajo nos hemos propuesto establecer una adecuada definición de la inkuña arqueológica en cuanto a sus rasgos formales y técnicos. Para ello procedimos a clasificar tipológicamente la muestra en estudio, lo cual nos condujo a la detección de varios estilos diferentes conviviendo en el universo textil del período; suponemos que esta situación obedece a la presencia multiétnica de la zona, que es avalada por testimonios documentales del siglo XVI. La información etnohistórica en forma de títulos de encomiendas del siglo XVI, da cuenta de la presencia de pescadores foráneos en la costa de Arica, provenientes de Tacna, Ilo y Tarapacá (Hidalgo y Focacci 1986); al mismo tiempo, entrega información acerca de poblaciones Caranga (en el valle de Azapa y en la costa) y Pacajes (en la costa), así como Lupaca (en el valle de Lluta), que mezclados con la población yunga local, compartían espacios de valle y costa, y por

\footnotetext{
Programa de Doctorado en Historia, mención Etnohistoria, Universidad de Chile, Santiago, Chile. horta.helena@gmail.com 2 Instituto de Investigaciones Arqueológicas y Museo R. P. Gustavo Le Paige s. j., Universidad Católica del Norte, San Pedro de Atacama, Casilla 17, Correo San Pedro de Atacama, II Región, Chile. maguero@ucn.cl
} 
ende los recursos de cada ecosistema (Durston e Hidalgo 1997; Hidalgo 2004; Hidalgo y Durston 1998; Murra 1972, 1976).

Al mismo tiempo, nos interesó definir a cada uno de estos estilos, en base a criterios de composición espacial, paleta cromática utilizada, diseños específicos de la decoración y terminaciones, todos rasgos que evidencian diferencias culturales específicas. Por otra parte, en base a la muestra estudiada hemos definido la función primordial que parece haber cumplido en tiempos prehispánicos este particular textil de forma cuadrangular.

Hasta aquí se contaba con un número limitado de descripciones breves para la inkuña arqueológica (Bird 1943; Brugnoli y Hoces de la Guardia 1989; Cassman 1997; Clark 1993; Hoces de la Guardia y Brugnoli 2006; Santoro y Ulloa 1985; Skottsberg 1924; Ulloa 1981a), y las menciones en general sobre ella habían sido aisladas o escuetas (Adelson y Tracht 1983; Focacci 1982, 1990; Mostny 1942, 1944). En los años sesenta estas prendas textiles eran denominadas comúnmente "pañuelos", "paños" o "delantales", y en no pocas ocasiones fueron confundidas con taparrabos; esto se debe a que hacia fines del Intermedio Tardío y comienzos del Tardío se observa una tendencia a convertir inkuñas preexistentes en taparrabos, y se las reutiliza agregándoles cuerdas laterales que facilitan su amarre a la cintura del individuo portador ${ }^{2}$. Las causas de este fenómeno esperan ser esclarecidas, al igual que otras reutilizaciones textiles observadas en el registro arqueológico de la zona.

Por otra parte, con frecuencia los detalles sobre la ubicación de la inkuña en el contexto funerario fueron omitidos o no observados por los arqueólogos. El presente estudio pretende llenar estos vacíos de información en base al análisis de la muestra textil y a una subsecuente revisión bibliográfica sobre el tema.

\section{Material Utilizado}

La muestra utilizada en este análisis contempló piezas provenientes de cementerios de valle (Figura 1: Az-3, Az-6, Az-8, Az-71, Az-75 y Az-140) y costa (Figura 1: PLM-2, PLM-3, PLM-4, PLM-8, PLM-9 y ChLL-3). No todos los cementerios mencionados fueron analizados íntegramente desde el punto de vista del material textil; esto sólo ocurrió con los textiles de Azapa-8 de la colección Manuel Blanco Encalada (en adelante CMBE) y los tejidos de
Playa Miller-3 pertenecientes en su mayor parte a la colección del Museo Arqueológico San Miguel de Azapa (en adelante MASMA), y en una mucho menor parte a la colección CMBE. El resto de las inkuñas sólo fueron observadas individualmente, en la medida en que aparecieron durante la revisión del material que realizamos durante 20 días en el Laboratorio Textil del MASMA (agosto de 1996). Por tanto, sólo los ajuares y ofrendas de los cementerios de Azapa-8 y Playa Miller-3 fueron estudiados contextualmente, vale decir, en toda su complejidad funeraria, que incluye ceramios y otros objetos de diversas materias primas (madera, hueso, metal, fibra vegetal, piedra). Esto obedeció al hecho de que nuestra investigación de aquel entonces se enmarcaba dentro de los objetivos establecidos para el proyecto FONDECYT 1960113, y nos encontrábamos buscando información complementaria que permitiese establecer diferencias entre los desarrollos culturales de la costa de Arica y el valle de Azapa. El análisis cerámico de dicho proyecto fue realizado por Mauricio Uribe y Oscar Espoueys tomó las muestras para fechar (Espoueys et al. 1995; Uribe 1995); ambos géneros de información han sido incluidos en los cuadros que contienen los ejemplares de cada grupo de inkuñas. Los fechados radiocarbónicos sirven para reforzar las adcripciones culturales que se desprenden del análisis estilístico e iconográfico aplicado al tipo de textil inkuña, y no tienen valor en sí mismos, tal como se verá más adelante.

Debido a la gran cantidad del registro material proveniente del cementerio de Playa Miller-3 (233 tumbas con contexto) fue necesario reducir la muestra por medio de una selección al azar centrada en aquellas tumbas, cuyos ajuares presentaban tanto elementos cerámicos como textiles; de esta forma, analizamos 94 inkuñas de un total de 225, vale decir, se estudió un $40 \%$ de este tipo de textil; para Azapa-8 analizamos un número menor, 16 piezas, pero en realidad corresponde al $80 \%$ de las inkuñas preservadas como material textil de este sitio en la CMBE.

Considerando también en el recuento a dos ejemplares sin referencias, se logró clasificar a 147 inkuñas en 19 tipos, de acuerdo a variaciones observadas en sus respectivas composiciones espaciales, colores utilizados, elementos iconográficos $\mathrm{y}$ terminaciones.

A su vez, un número menor de inkuñas no pudo ser incluida en ninguno de los 19 tipos por 


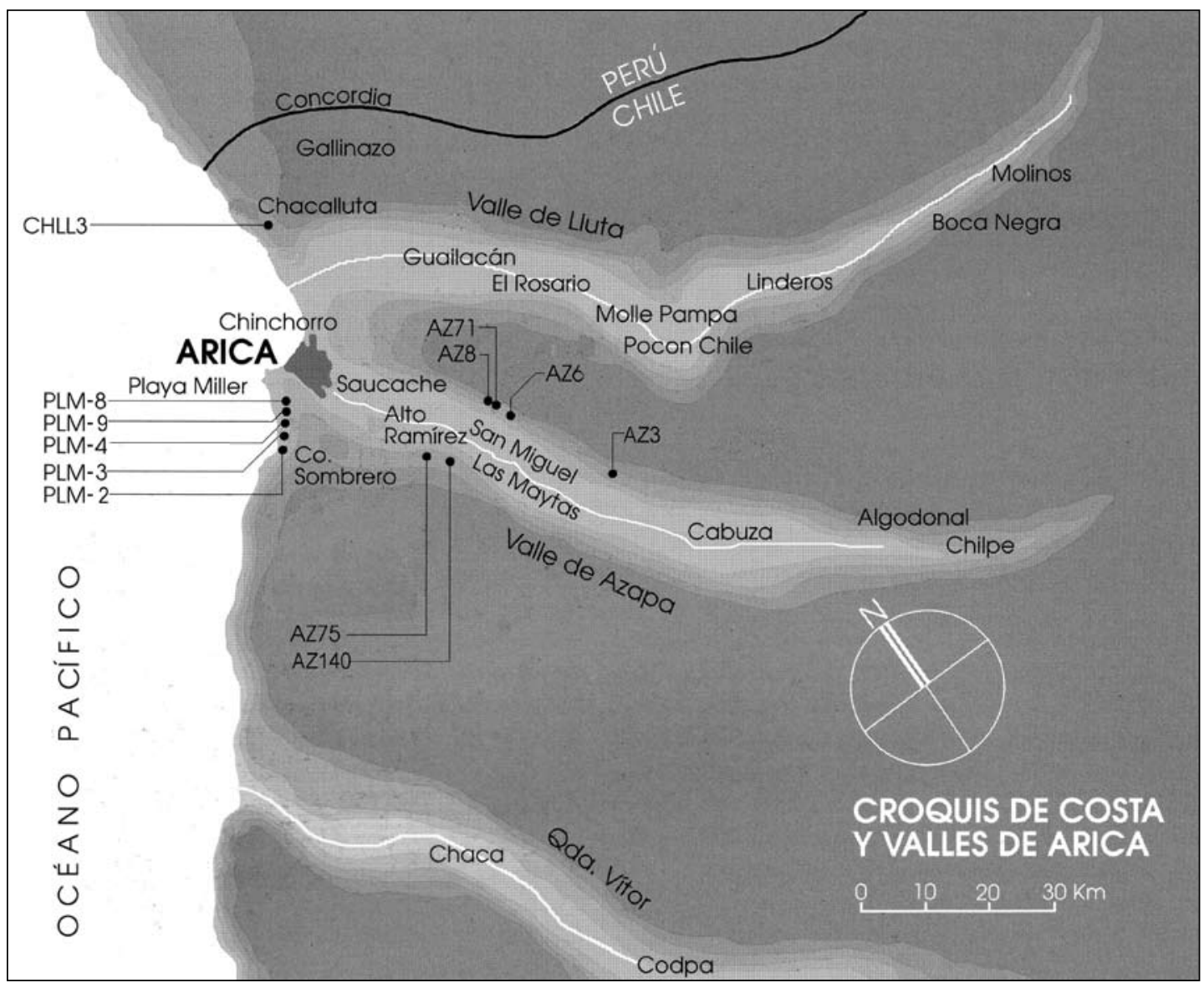

Figura 1. Mapa con los cementerios considerados en el análisis; del valle de Azapa: Az-3, Az-6, Az-8, Az-71, Az-75 y Az-140; de la costa de Arica: PLM-2, PLM-3, PLM-4, PLM-8, PLM-9 y Chll-3 (adaptado de Espoueys et al. 1995).

Map with cemeteries considered in this analysis; from the Azapa Valley: Az-3, Az-6, Az-8, Az-71, Az-75, and Az-140; from the coast of Arica: PLM-2, PLM-3, PLM-4, PLM-8, PLM-9, and Chll-3 (adapted from Espoueys et al. 1995).

presentar características particulares, o debido a su escaso número, lo cual no permitió formar con ellas grupos significativos. También hubo que descartar material fragmentado, cuyo nivel de deterioro no hacía posible el reconocimiento de su forma original. En la Tabla 1 se puede observar la distribución por sitios de la muestra utilizada.

\section{Características Técnicas}

Al igual que lo que ocurre con el resto de las prendas textiles del Intermedio Tardío, también en el caso de las inkuñas la técnica dominante es la faz de urdimbre para las partes lisas o sin decoración, y la técnica de urdimbres complementarias para las decoradas. No obstante esto, pudimos observar que el cementerio de Azapa-6 presenta mayoritariamente inkuñas decoradas por medio de la técnica de urdimbres flotantes; por su parte, algunas de las inkuñas de Azapa-71 también exhiben dicha técnica, aunque aisladamente junto a la técnica de urdimbres complementarias. Tal como se verá en detalle más adelante, tanto Azapa-6 como Azapa71 evidencian estilos textiles provenientes de una tradición diferente a la local o azapeña. En conjunto, podemos afirmar que en lo referente a atributos técnicos diagnósticos, las inkuñas arqueológicas de Arica se caracterizan por:

(1) la terminación de tramas en torzal que se prolonga en "asas" en las orillas de urdimbre,

(2) la forma siempre rectangular, más corta en sentido de la urdimbre y más ancha en el sentido de la trama, 
Tabla 1. Distribución por sitios de la muestra utilizada en el análisis.

Distribution of samples analyzed by site.

Número de Inkuñas Provenientes

de Cementerios Costeros de Arica

\begin{tabular}{lr}
\hline PLM-3 & 94 \\
PLM-9 & 7 \\
PLM-4 & 8 \\
PLM-2 & 1 \\
PLM-8 & 1 \\
Chll-3 & 1 \\
TOTAL & 112 \\
\hline
\end{tabular}

Número de Inkuñas Provenientes

de Cementerios del Valle de Azapa

Az-8

Az-6

Az-71a y b

Az-3

Az-75

Az-140

TOTAL

(3) el tamaño estándar que oscila entre $45 \times 50 \mathrm{~cm}$; se conocen también algunos ejemplares muy excepcionales de 70x80 cm,

(4) por ser una prenda tejida de una sola pieza, por tanto no presenta costura en el centro (lo cual sí ocurre con algunos taparrabos de la zona),

(5) la utilización mayoritaria de colores artificiales, aunque también hay combinaciones de éstos con colores naturales, o piezas que presentan sólo colores naturales.

\section{Variabilidad de las composiciones espaciales}

La gran variedad de tipos de inkuñas arqueológicas es sólo el reflejo de la extraordinaria variabilidad que presenta dicha prenda textil en cuanto a composición espacial, colores y diseños característicos. Esta situación es especialmente interesante, puesto que ya ha sido advertida en relación con ejemplares etnográficos usados actualmente por pastores andinos (Zorn 1987:501). Más adelante volveremos sobre este punto.

La decoración del espacio textil de las inkuñas se logra por medio de dos maneras: una de ellas es introducir listas de diferentes colores, y la otra es incluir franjas con diseños (ocasionalmente ambas soluciones también pueden ser combinadas en una misma pieza). En base a esta diferencia básica detectada en el tratamiento del espacio textil, es como llegamos a establecer dos grandes grupos.

El Grupo 1 ha sido conformado por diez tipos $(1 \mathrm{~A}, 1 \mathrm{~B}, 1 \mathrm{C}, 1 \mathrm{D}, 1 \mathrm{E}, 1 \mathrm{~F}, 1 \mathrm{G}, 1 \mathrm{H}, 1 \mathrm{I}, 1 \mathrm{~J})$ que corresponden a inkuñas sólo listadas, sin diseño figurativo alguno, mientras que otros nueve tipos comprenden el Grupo 2 con inkuñas decoradas estructuralmente con diseños figurativos o abstractos (tipos 2A, 2A', 2B, 2C, 2D, 2E, 2F, 2G, 2H).

Basándonos en las diferencias observadas en relación con las variadas composiciones espaciales que exhibían las inkuñas, fue posible clasificarlas en los dos grupos mencionados, cada uno con sus diferentes tipos, como una primera aproximación al análisis estilístico. Prosiguió la observación de los colores empleados por cada uno de los grupos que se habían logrado establecer según sus composiciones espaciales, para luego estudiar en detalle los íconos asociados a cada grupo de inkuñas con similares composiciones espaciales, colores y terminaciones.

Son tantas las posibilidades de combinación entre formas de listar y de disponer franjas en el tejido, que -como una forma de hacerlas más comprensibles- hemos definido algunos términos relacionados con el tema, tal como los usamos operativamente en este estudio.

Lista: espacio textil de color liso sin diseños, más angosto que la franja.

Bloque de listas: conjunto de listas de ancho variable, que se repite un número indeterminado de veces a lo ancho de la pieza, de acuerdo a una secuencia preestablecida.

Franja: espacio textil con diseños, más ancho que la lista.

Listado lateral diferencial: secuencia de listas lisas de diferentes colores dispuestas paralelamente a las orillas de trama, cuyo color de fondo es distinto al del resto del textil.

Listado lateral San Miguel: secuencia pautada de tres listas lisas en morado, amarillo ocre y azul oscuro o negro sobre fondo rojo.

Listado Pocoma: secuencia pautada de tres listas pares en morado, amarillo ocre y azul oscuro o negro sobre rojo o granate. Este tipo de listado puede ser 
lateral, y también cubrir las pampas intermedias de todo el cuerpo de la inkuña.

Lista con cría: secuencia de dos listas café oscuro, una ancha seguida por una muy delgada, en fuerte contraste sobre un fondo café claro. El nombre -utilizado por Cereceda- alude a la idea de que la lista mayor funcionaría como "madre" de la menor o "hija" (Cereceda 1990, s/f).

Pampa: todo espacio continuo del tejido, que no contiene diseño; sector liso o llano de color natural o de color teñido (Cereceda 1990, s/f).

También consignamos las abreviaturas usadas en las definiciones cerámicas de los cuadros que se verán en el texto:

SMA= San Miguel Grupo A o San Miguel Temprano (según denominación de Uribe 1999)

$\mathrm{SMB}=$ San Miguel Grupo B o San Miguel Clásico (según denominación de Uribe 1999)

$\mathrm{MCH}=$ Maytas-Chiribaya

$\mathrm{CA}=$ Cabuza

$\mathrm{PO}=$ Pocoma

$\mathrm{GE}=$ Gentilar

NO DEC.$=$ No decorada

\section{Grupo 1}

Reúne inkuñas decoradas con listas lisas, punteadas, ajedrezadas o con peinecillo, es decir, con diseños no figurativos simples logrados únicamente por medio de la técnica de faz de urdimbre. La descripción se inicia con inkuñas que muestran un amplio espacio central sin decorar, o pampa lisa monocroma, prosigue con aquellas que lo decoran, pero dejan espacios en que aún es posible apreciarlo como fondo, hasta llegar a inkuñas que lo cubren por completo con listas o franjas decoradas.

\section{A (número total = 4)}

Inkuñas con orillas de urdimbre sin terminaciones (12106/Az-6), o terminadas en tramas en torzal que se prolongan en asas y conforman una línea ondulada morada delimitada por líneas paralelas rojas, o bien, rombos blancos con centro morado, sobre rojo (inkuña $\mathrm{S} / \mathrm{N}^{\circ}$ de Az-71). La decoración del cuerpo se organiza según la Composición Espacial 1 (Figura 2), la cual consiste en dos sectores laterales de 6 a $10 \mathrm{~cm}$ de ancho, adyacentes a la orilla de trama, listados con: tres listas separadas morado oscuro, azul piedra y ocre sobre fondo rojo; o bien, rojo, verde, morado, terracota y rojo (sin fondo) como el caso de la inkuña 2587 de PLM-3. El resto del espacio tejido es una amplia pampa de color café claro.

Inkuñas Grupo 1A

\begin{tabular}{lccl}
\hline \multicolumn{1}{c}{ Zona/Sitio } & $\mathrm{N}^{\circ}$ Pieza & Tumba & \multicolumn{1}{c}{ Asociaciones } \\
\hline $\begin{array}{l}\text { Costa/PLM-3 } \\
\text { (CMBE) }\end{array}$ & 2587 & 15 & $\begin{array}{l}\text { SM.G3-G7/PO.G1-G2/ } \\
\text { Indet / NO DEC. }\end{array}$ \\
$\begin{array}{l}\text { Valle/Az-6 } \\
\text { (CMBE) }\end{array}$ & 12081 & 14 & MCH.G3 \\
$\begin{array}{l}\text { Valle/Az-71a } \\
\text { (MASMA) }\end{array}$ & $46 ?$ & 22 & Sin cerámica \\
$\begin{array}{l}\text { Valle/Az-71a } \\
\text { (MASMA) }\end{array}$ & 4712 & 40 & $\begin{array}{l}\text { CA.G3/SMB.G5/NO } \\
\text { DEC. }\end{array}$ \\
\hline
\end{tabular}

\section{$1 B$ (número total = 3)}

Inkuñas con orillas de urdimbre terminadas en tramas en torzal que se prolongan en asas y forman una línea ondulada amarillo ocre sobre morado delimitada por listas rojas. La inkuña 2814 de PLM-3 presenta, además, las orillas de urdimbre festoneadas en anillado doble (ejemplar de la Figura 3). La decoración se organiza según la Composición Espacial 2, que consiste en una pampa central de 6 a $10 \mathrm{~cm}$ de ancho, café claro o roja que divide a la pieza en dos sectores. Desde la orilla de trama, hay un sector de $4 \mathrm{~cm}$ de ancho, listado con listas pares en morado, ocre y azul oscuro sobre rojo, al cual hemos denominado "listado Pocoma" (tal como ya lo adelantáramos, se trata de un "listado lateral diferencial", puesto que es diferente en número de listas y colores al resto del espacio textil). Luego, continúa un sector completamente listado con listas lisas de colores naturales o artificiales (ocre, azul y blanco sobre concho de vino).

Inkuñas Grupo 1B

\begin{tabular}{lccl}
\hline \multicolumn{1}{c}{ Zona/Sitio } & $\mathrm{N}^{\circ}$ Pieza & Tumba & \multicolumn{1}{c}{ Asociaciones } \\
\hline $\begin{array}{l}\text { Costa/PLM-3 } \\
\text { (CMBE) }\end{array}$ & 2814 & Sup. & \\
$\begin{array}{l}\text { Costa/PLM-3 } \\
\text { (MASMA) }\end{array}$ & S/N & 142 & $\begin{array}{l}\text { CHILPE? } \\
\text { Valle/Az-8 }\end{array}$ \\
(CMBE) & 113 & N2/2 & $\begin{array}{l}\text { SM.G5/indet./NO DEC. } \\
\text { (fechado TL: } 1.310 \pm 75 \text { d.C. })\end{array}$ \\
\hline
\end{tabular}




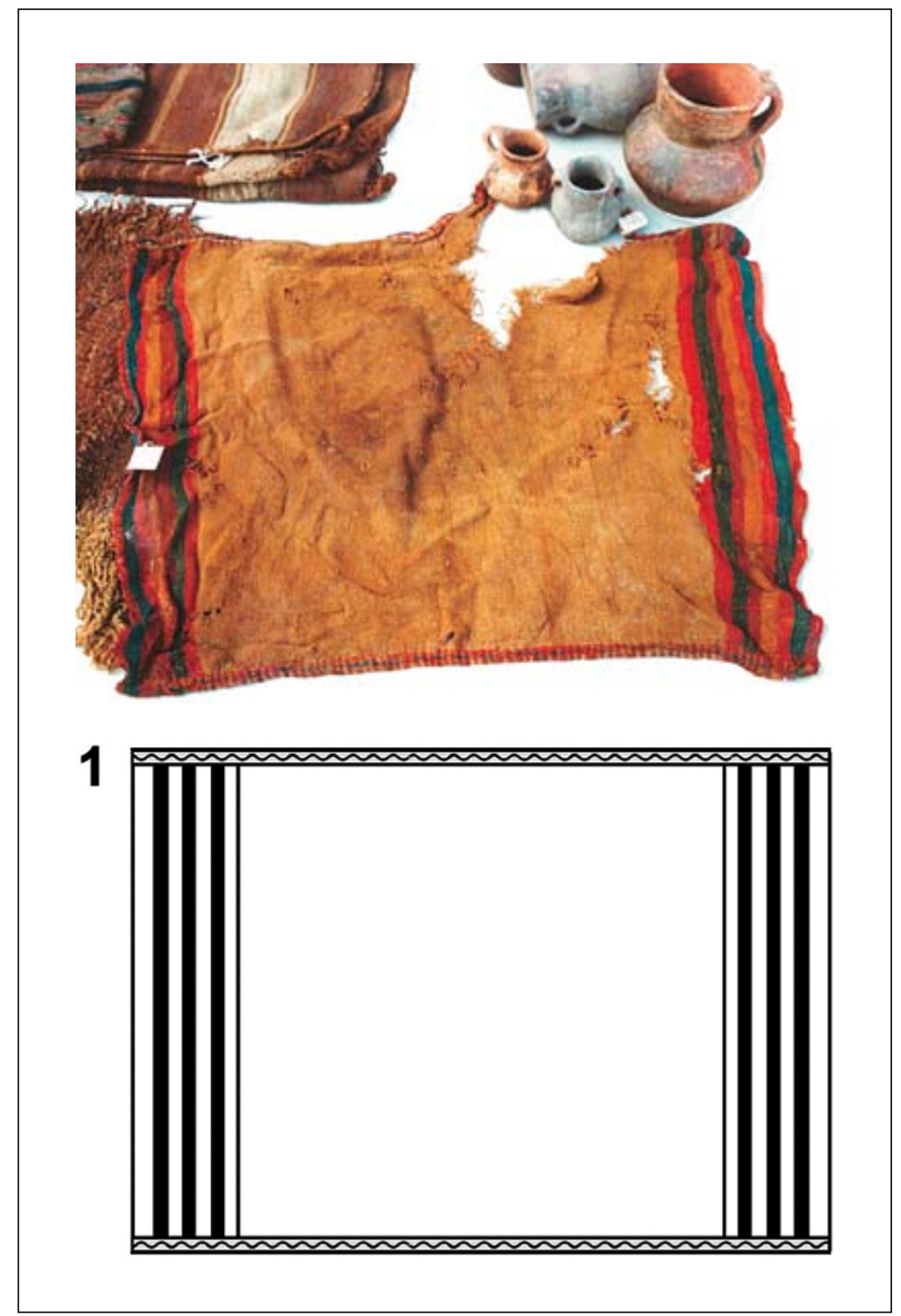

Figura 2. Composición Espacial 1. Inkuña del Grupo 1A, procedente del cementerio Az-71a, tumba 40, № 4712. Colección MASMA.

Spacial Composition 1. Inkuña from Group 1A, coming from cemetery Az-71a, grave 40, $N^{o} .4712$, MASMA Collection.

\section{C (número total = 5)}

Inkuñas con orillas de urdimbre sin terminaciones (pieza 1245 de Az-71) o terminadas en tramas en torzal que se prolongan en asas y forman rombos amarillo ocre sobre morado delimitados por líneas paralelas rojas. El cuerpo se organiza según la Composición Espacial 3 (Figura 4) que, en este caso, consiste en dos sectores listados de $6 \mathrm{~cm}$, adyacentes a las orillas de trama, en colores azul, rojo, ocre y café rojizo; en el centro de la inkuña existe un sector de $10 \mathrm{~cm}$ de ancho, listado con líneas punteadas blanco sobre rojo y azul sobre café rojizo. Los espacios que quedan entre los sectores listados del centro y el de los costados son de color café claro o café natural. 


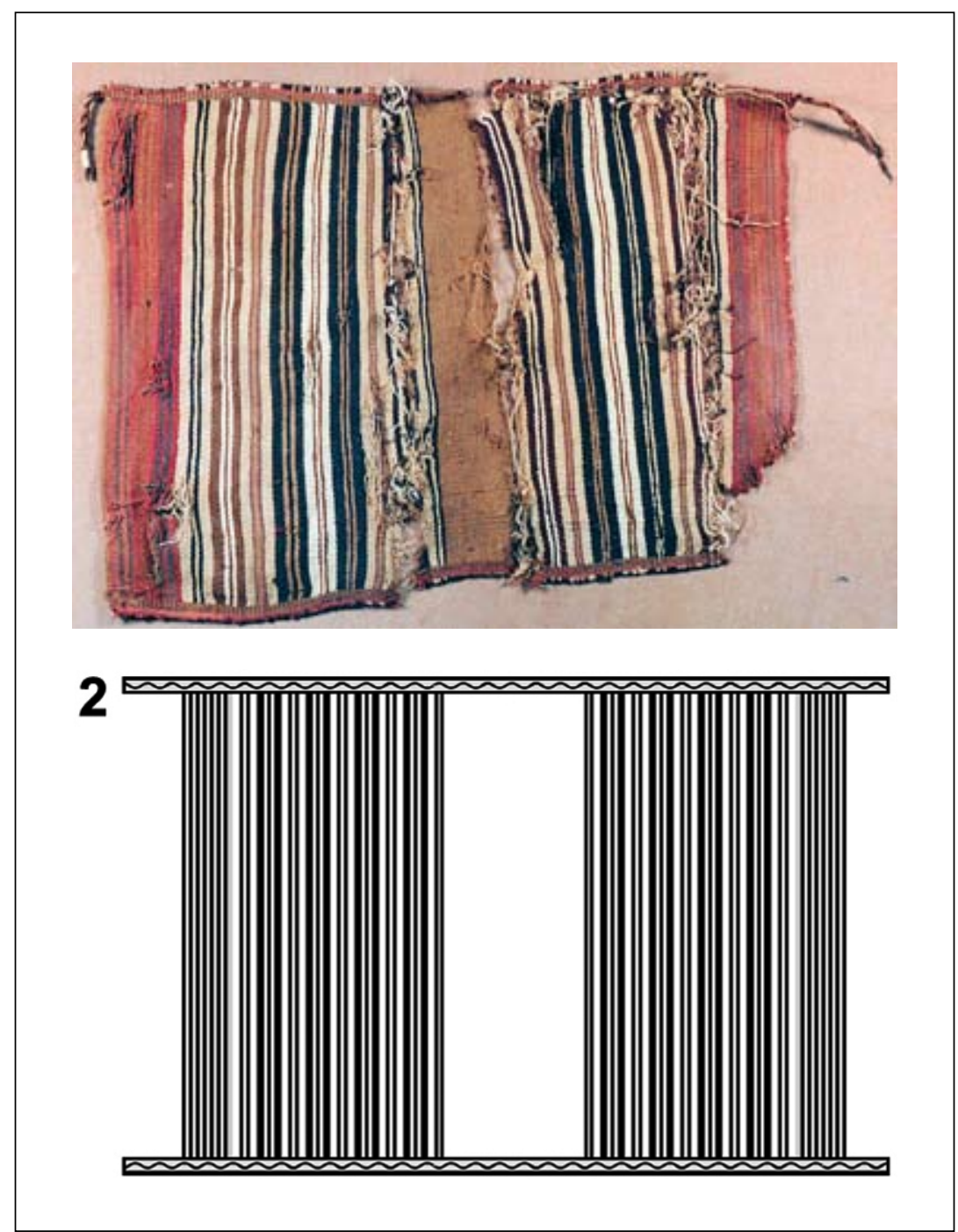

Figura 3. Composición Espacial 2. Inkuña del Grupo 1B, procedente del cementerio PLM-3, recolección de superficie, № 2814. Colección MBE.

Spacial Composition 2. Inkuña from Group 1B, coming from cemetery PLM-3, surface collection sample. MBE Collection.

Inkuñas Grupo 1C

\begin{tabular}{lrrll}
\hline \multicolumn{1}{c}{ Zona/Sitio } & N $^{\circ}$ Pieza & Tumba & \multicolumn{1}{c}{ Asociaciones } \\
\hline $\begin{array}{l}\text { Costa/PLM-9 } \\
\text { (MASMA) }\end{array}$ & 65 & 21 & $?$ \\
$\begin{array}{l}\text { Costa/PLM-3 } \\
\text { (MASMA) }\end{array}$ & 1662 & 136 & SMB.G2-G5/NO DEC. \\
$\begin{array}{l}\text { Valle/Az-6 } \\
\text { (CMBE) }\end{array}$ & 12572 & 139 & MCH.G3 \\
$\begin{array}{l}\text { Valle/Az-71b } \\
\text { (MASMA) }\end{array}$ & 1245 & 189 & CA. ? \\
$\begin{array}{l}\text { Valle/Az-71b } \\
\text { (MASMA) }\end{array}$ & 179 & 37 & $?$ \\
\hline
\end{tabular}

\section{D (número total $=7$ )}

Inkuñas con tramas en torzal en las orillas de urdimbre que forman rombos rojos sobre fondo azul verdoso, delimitados por listas concho de vino, o bien, rombos azul verdoso sobre fondo rojo, delimitados por listas rojas que en las esquinas se prolongan formando asas. El cuerpo se organiza según la Composición Espacial 4 (Figura 5), que consiste en tres bloques equidistantes de listas punteadas blanco sobre concho de vino y rojo sobre negro separadas por bloques de listas lisas de 


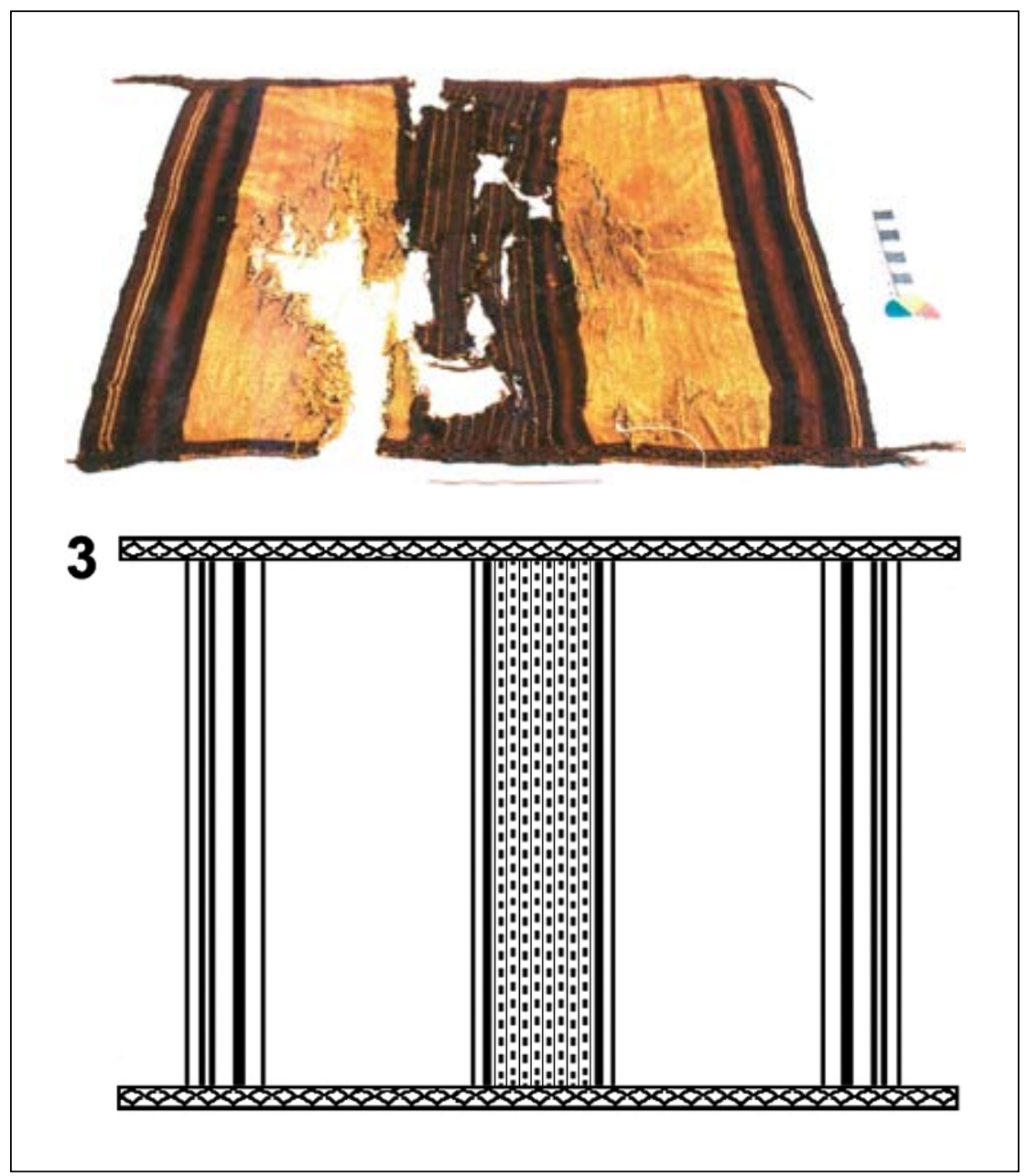

Figura 4. Composición Espacial 3. Inkuña del Grupo 1C, procedente del cementerio PLM-9, tumba 21, N 65. Colección MASMA. Spacial Composition 3. Inkuña from Group 1C, coming from cemetery PLM-9, grave 21, $N^{o}$. 65, MASMA Collection.

colores concho de vino, negro, azul verdoso y rojo; o bloques de listas punteadas blanco sobre rojo o café oscuro sobre un fondo café claro, separadas por listas lisas ocre oscuro y café oscuro. Otros dos bloques de listas lisas se sitúan cada uno adyacente a las orillas de trama.

\section{E (número total $=14)$}

Inkuñas con orillas de urdimbre terminadas en tramas en torzal que forman rombos ocre sobre morado delimitados por líneas paralelas rojas. En ocasiones, las cuatro orillas están terminadas, además, en festón anillado doble. El cuerpo de estas inkuñas se organiza según la Composición Espacial 5 (Figura 6), que consiste en tres o cuatro
Inkuñas Grupo 1D

\begin{tabular}{|c|c|c|c|}
\hline Zona/Sitio & $\mathrm{N}^{\circ}$ Pieza & Tumba & Asociaciones \\
\hline $\begin{array}{l}\text { Costa/PLM-3 } \\
\text { (MASMA) }\end{array}$ & 43 & 3 & $\begin{array}{l}\text { PO.G1/GB.G1-G2/NO } \\
\text { DEC. }\end{array}$ \\
\hline $\begin{array}{l}\text { Costa/PLM-4 } \\
\text { (MASMA) }\end{array}$ & 7673 & 57 & SMB.G? \\
\hline $\begin{array}{l}\text { Costa/PLM-9 } \\
\text { (MASMA) }\end{array}$ & 69 (b) & 22 & MCH.G2/NO DEC. \\
\hline $\begin{array}{l}\text { Valle/Az-3 } \\
\text { (CMBE) }\end{array}$ & 1133 & N14/1 & Sin cerámica \\
\hline $\begin{array}{l}\text { Valle/Az-71 } \\
\text { (CMBE) }\end{array}$ & $4315 \mathrm{~A}$ & $\mathrm{G} 1 / 1$ & Indeterminada \\
\hline $\begin{array}{l}\text { Valle/Az-71b } \\
\text { (MASMA) }\end{array}$ & $?$ & 400 & $?$ \\
\hline $\begin{array}{l}\text { Valle/Az-75 } \\
\text { (CMBE) }\end{array}$ & $1774 \mathrm{~A}$ & 101 & $\begin{array}{l}\text { MCH.G3. (fechado TL: } \\
1.215 \pm 60 \text { d.C.) }\end{array}$ \\
\hline
\end{tabular}




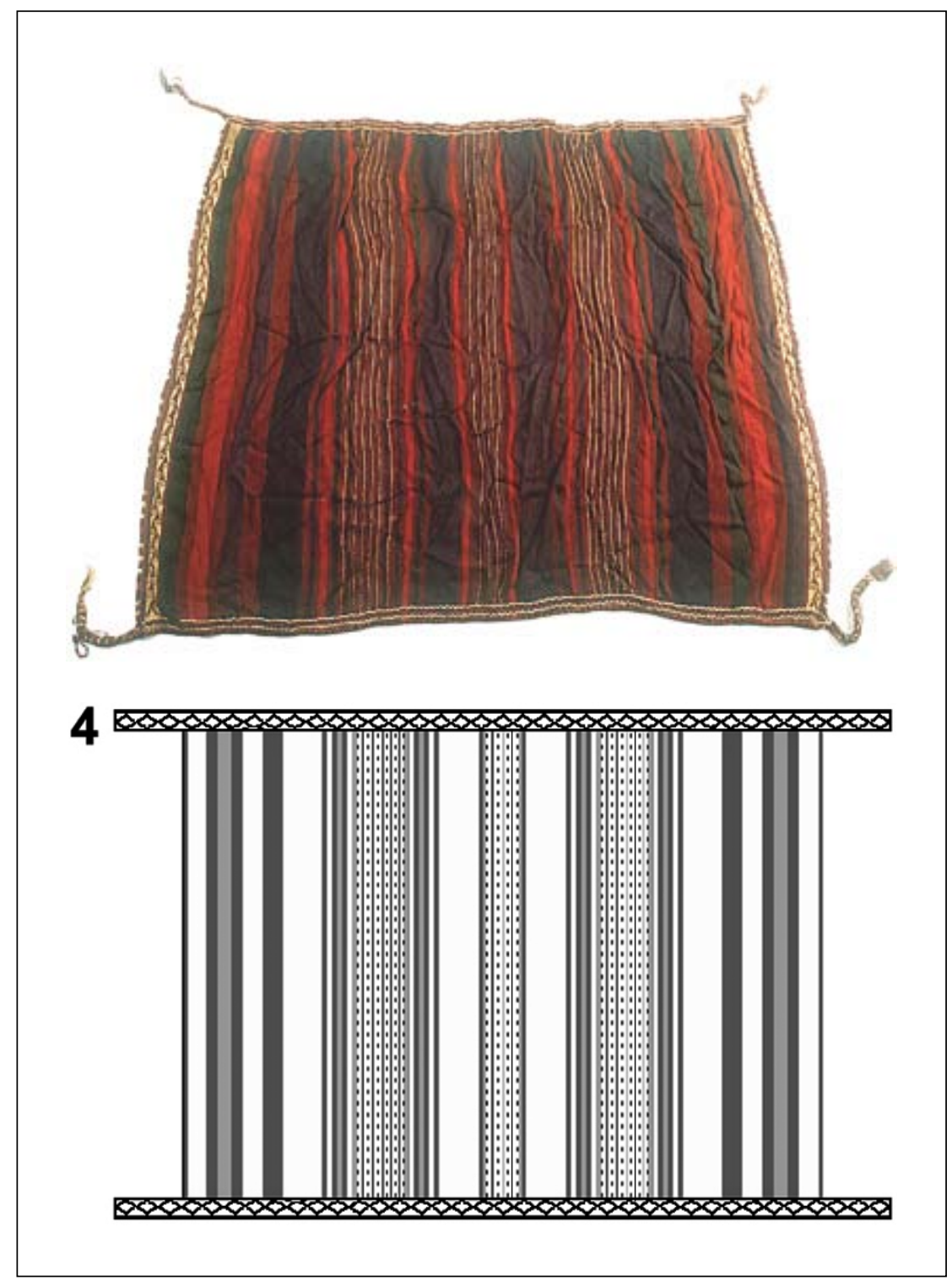

Figura 5. Composición Espacial 4. Inkuña del Grupo 1D, ejemplar № 2000 sin contexto, colección Museo de Artes Visuales (MAVI), Santiago.

Spacial Composition 4. Inkuña from Group 1D, $N^{\circ} 2000$ without context. MAVI Collection.

bloques de listas lisas de $2 \mathrm{~cm}$ de ancho (rojo, blanco, rojo, negro, rojo, ocre, rojo, morado oscuro, rojo, blanco, rojo); éstos se disponen como un bloque (o dos) al centro de la inkuña, y uno al centro de cada mitad, separados por sectores lisos de color café natural, en cuyo centro se ubica un bloque de $1 \mathrm{~cm}$ de ancho de listas finas rojo/blanco/rojo. Adyacentes a cada orilla de trama hay dos sectores con listado lateral San Miguel (morado, amarillo ocre y azul oscuro o negro sobre rojo) de $3,5 \mathrm{~cm}$ de ancho.

\section{$1 F$ (número total $=4$ )}

Inkuñas con orillas de urdimbre terminadas en tramas en torzal que se prolongan en asas y conforman una línea ondulada amarillo ocre sobre morado delimitada por líneas paralelas rojas. El 


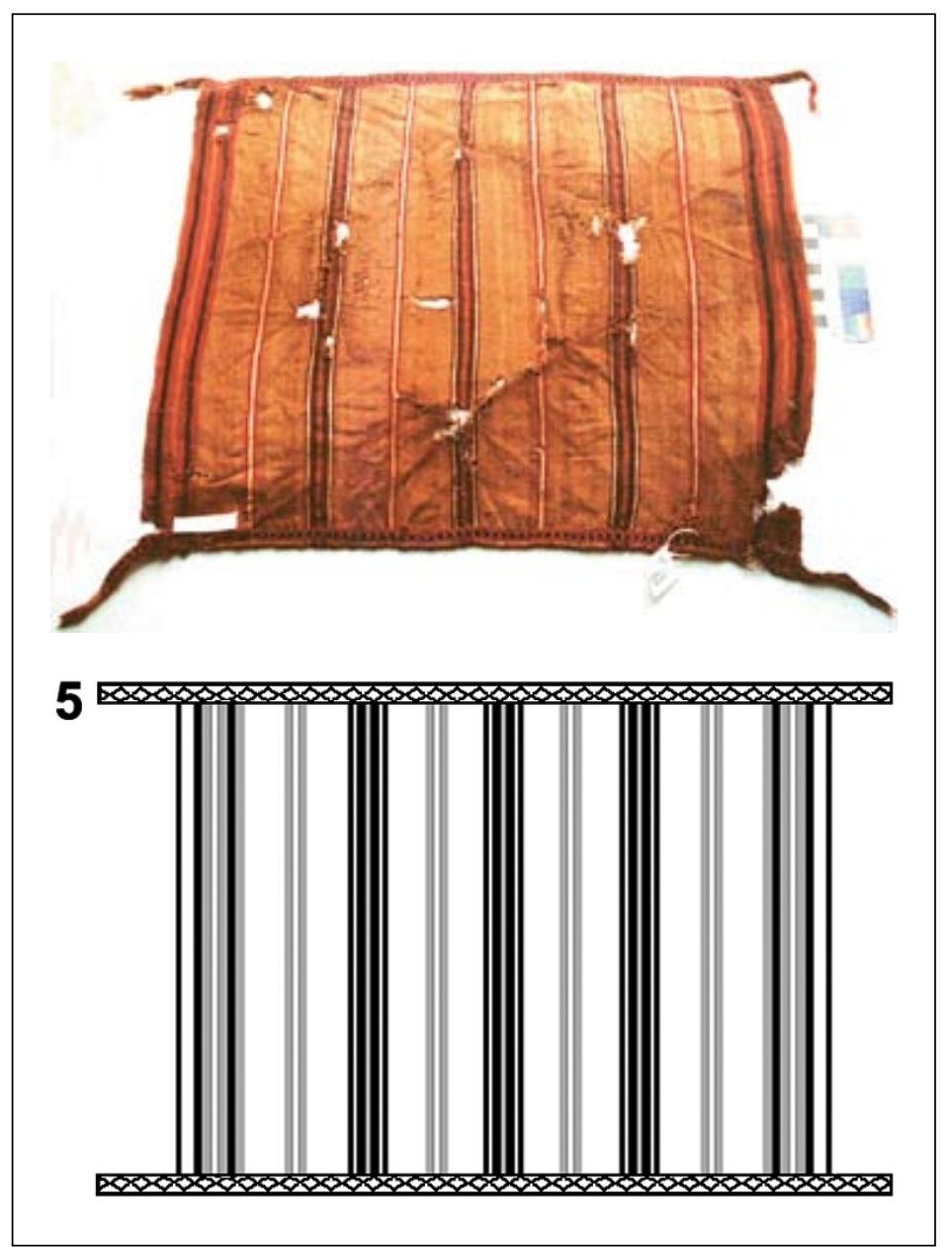

Figura 6. Composición Espacial 5. Inkuña del Grupo 1E, procedente del cementerio PLM-4, tumba 173, No 9514. Colección MASMA. Spacial Composition 5. Inkuña from Group 1E, coming from cemetery PLM-4, grave 173, $N^{\circ}$ 9514. MASMA Collection.

Inkuñas Grupo $1 \mathrm{E}$

\begin{tabular}{lccl}
\hline \multicolumn{1}{c}{ Zona/Sitio } & N $^{\circ}$ Pieza & Tumba & \multicolumn{1}{c}{ Asociaciones } \\
\hline Costa/PLM-9 (MASMA) & $69(\mathrm{~A})$ & 22 & MCH.G2/NO DEC. \\
Costa/PLM-9 (MASMA) & 23 & 8 & NO DEC. \\
Costa/PLM-4 (MASMA) & 9514 & 173 & $?$ \\
Costa/PLM-3 (MASMA) & 635 & 47 & SMB.G2-G4/NO DEC. \\
Costa/PLM-3 (MASMA) & 1749 & 140 & PO.G1/NO DEC. \\
Costa/PLM-3 (MASMA) & 1318 & 102 & NO DEC./PO? \\
Costa/PLM-3 (MASMA) & 335 & 26 & PO.G2/NO DEC. \\
Costa/PLM-3 (MASMA) & 2776 & 214 & NO DEC. \\
Costa/PLM-3 (MASMA) & 1468 & 122 & NO DEC. \\
Costa/PLM-3 (CMBE) & 983 & Sup. & \\
Costa/PLM-3 (CMBE) & 982 & Sup. & \\
Valle/Az-71a (MASMA) & $?$ & 13 & CA.G3 \\
Valle/Az-8 (CMBE) & 1519 & E'2/1 & PO.G4/NO DEC. \\
Valle/Az-6 (MASMA) & $?$ & $?$ & S/R \\
\hline
\end{tabular}


cuerpo se organiza según la Composición Espacial 6 (Figura 7), que consiste en tres bloques equidistantes de listas, uno angosto al centro de la inkuña y uno ancho en el centro de cada mitad; la lista central de cada uno de estos bloques es decorada con una franja ajedrezada o jaspeada; el fondo de la inkuña es café claro y los colores de las listas son negro, verde, rojo, morado claro y blanco; en los laterales hay sectores listados de $8 \mathrm{~cm}$ de ancho adyacentes a las orillas de trama, con tres o cuatro pares de listas separadas por una lista fina en colores morado y verde, rojo y morado, verde y morado.
Inkuñas Grupo $1 \mathrm{~F}$

\begin{tabular}{lccc}
\hline \multicolumn{1}{c}{ Zona/Sitio } & N $^{\text {o }}$ Pieza & Tumba & Asociaciones \\
\hline $\begin{array}{l}\text { Costa/PLM-3 } \\
\text { (CMBE) }\end{array}$ & 988 & Sup. & \\
$\begin{array}{l}\text { Costa/PLM-3 } \\
\text { (CMBE) }\end{array}$ & 993 & Sup. & \\
$\begin{array}{l}\text { Costa/PLM-3 } \\
\text { (CMBE) }\end{array}$ & 995 & Sup. & \\
$\begin{array}{l}\text { Costa/PLM-3 } \\
\text { (MASMA) }\end{array}$ & 640 & 47 & SMB.G2-G4/NO DEC. \\
\hline
\end{tabular}

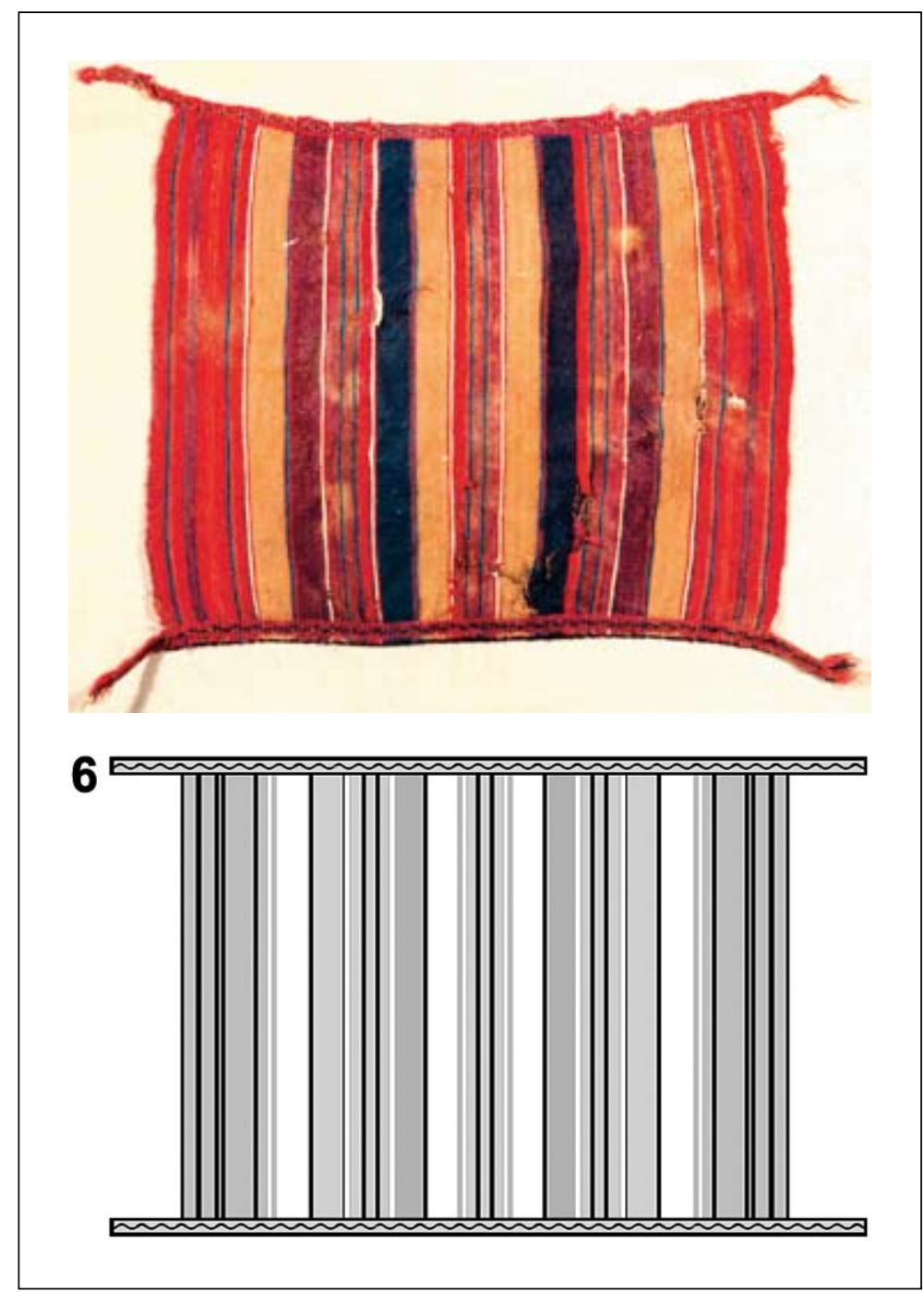

Figura 7. Composición Espacial 6. Inkuña del Grupo 1F, procedente del cementerio PLM-3, recolección de superficie, Nº 993. Colección MBE.

Spacial Composition 6. Inkuña from Group 1F, coming from cemetery PLM-3, surface collection sample, $N^{o} 993$. MBE Collection. 


\section{$1 G$ (número total = 9)}

Inkuñas con orillas de urdimbre terminadas en tramas en torzal conformando rombos o una línea ondulada ocre sobre morado, delimitada por líneas paralelas rojas. Estas inkuñas se organizan según la Composición Espacial 7 (Figura 8), que consiste en un cuerpo decorado con bloques de líneas punteadas por faz de urdimbre en rojo/ crema, y amarillo ocre/morado oscuro sobre fondo café claro, o en su defecto con listas individuales igualmente punteadas; en ambos casos, dichas líneas punteadas son suficientemente angostas como para permitir que se aprecie por debajo de ellas el color café claro de fondo. También pueden presentar un sector listado diferencialmente (sin punteado) adyacente a las orillas de trama en una gran gama de posibilidades: tres listas llanas (listado lateral San Miguel), listas en pares (listado Pocoma), o listados impares. La inkuña 2555 de PLM-3 es una miniatura (18 x $26 \mathrm{~cm}$ ) y fue reutilizada como bolsa-faja.

\section{$1 \mathrm{H}($ número total = 12)}

Inkuñas con orillas de urdimbre terminadas en tramas en torzal que forman una línea ondulada verde sobre morado, ocre sobre verde o rojo sobre morado, delimitada por líneas paralelas rojas. El

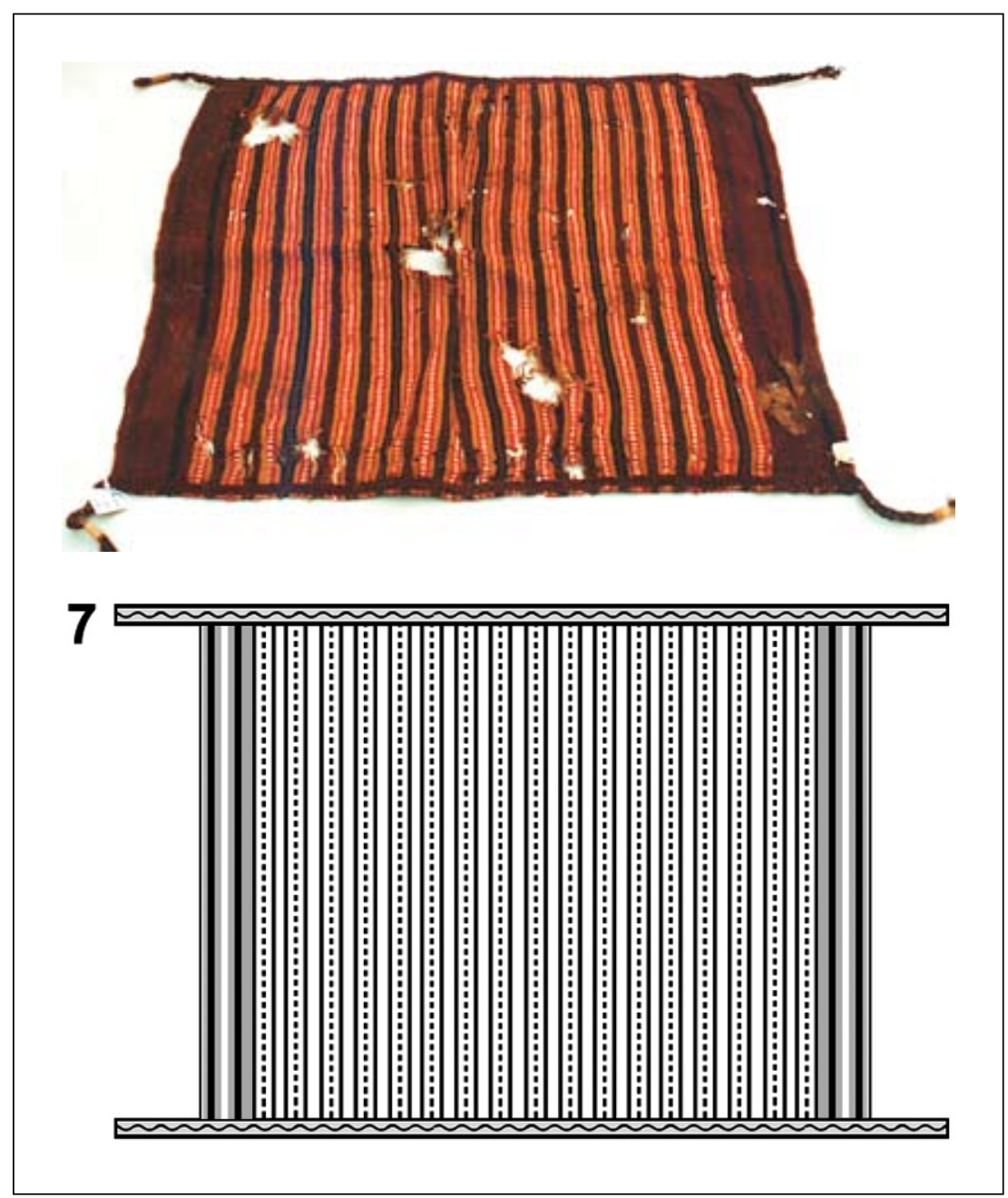

Figura 8. Composición Espacial 7. Inkuña del Grupo 1G, procedente del cementerio PLM-3, tumba 122, No 1472. Colección MASMA.

Spacial Composition 7. Inkuña from Group 1G, coming from cemetery PLM-3, grave 122, $N^{o}$. 1472. MASMA Collection. 
Inkuñas Grupo $1 \mathrm{G}$

\begin{tabular}{|c|c|c|c|}
\hline Zona/Sitio & $\mathrm{N}^{\mathrm{o}}$ Pieza & Tumba & Asociaciones \\
\hline $\begin{array}{l}\text { Costa/PLM-3 } \\
\text { (CMBE) }\end{array}$ & 2555 & 13 & $\begin{array}{l}\text { SM?/PO.G1-G2/ Indet./ } \\
\text { NO DEC. }\end{array}$ \\
\hline $\begin{array}{l}\text { Costa/PLM-3 } \\
\text { (MASMA) }\end{array}$ & 1471 & 122 & NO DEC. \\
\hline $\begin{array}{l}\text { Costa/PLM-3 } \\
\text { (MASMA) }\end{array}$ & 1472 & 122 & NO DEC. \\
\hline $\begin{array}{l}\text { Costa/PLM-3 } \\
\text { (MASMA) }\end{array}$ & 658 & 49 & $\begin{array}{l}\text { SMB.G2/ PO.G1-G2/ } \\
\text { GB.G2 }\end{array}$ \\
\hline $\begin{array}{l}\text { Costa/PLM-3 } \\
\text { (MASMA) }\end{array}$ & 959 & 71 & SMB.G5/ PO.G4/NO DEC \\
\hline $\begin{array}{l}\text { Costa/CHLL-3 } \\
\text { (CMBE) }\end{array}$ & 956 & 2 & SMB.G2, G4 \\
\hline $\begin{array}{l}\text { Valle/Az-71b } \\
\text { (MASMA) }\end{array}$ & $\mathrm{S} / \mathrm{N}^{\circ}$ & 174 & $?$ \\
\hline $\begin{array}{l}\text { Valle/Az-6 } \\
\text { (MASMA) }\end{array}$ & 1180 & 128 & Sin cerámica \\
\hline $\begin{array}{l}\text { Valle/Az-8 } \\
(\mathrm{CMBE})\end{array}$ & 55 & $\mathrm{~J} 1{ }^{\prime} / 1$ & SM.G5-G8/NO DEC. \\
\hline
\end{tabular}

Inkuñas Grupo $1 \mathrm{H}$

\begin{tabular}{|c|c|c|c|}
\hline Zona/Sitio & $\mathrm{N}^{\mathrm{o}}$ Pieza & Tumba & Asociaciones \\
\hline $\begin{array}{l}\text { Costa/PLM-9 } \\
\text { (CMBE) }\end{array}$ & $4825 \mathrm{~A}$ & 8 & SMB.G8 (PO). \\
\hline $\begin{array}{l}\text { Costa/PLM-3 } \\
\text { (MASMA) }\end{array}$ & $636 \mathrm{~A}$ & 47 & SMB.G2, G4/NO DEC. \\
\hline $\begin{array}{l}\text { Costa/PLM-3 } \\
\text { (MASMA) }\end{array}$ & 637 & 47 & SMB.G2, G4/NO DEC. \\
\hline $\begin{array}{l}\text { Costa/PLM-3 } \\
\text { (MASMA) }\end{array}$ & $937 \mathrm{~A}$ & 69 & SMB.G3, G7/NO DEC. \\
\hline $\begin{array}{l}\text { Costa/PLM-3 } \\
\text { (MASMA) }\end{array}$ & $?$ & 182 & PO.G2 \\
\hline $\begin{array}{l}\text { Costa/PLM-3 } \\
\text { (MASMA) }\end{array}$ & 2298 & 182 & PO.G2 \\
\hline $\begin{array}{l}\text { Costa/PLM-3 } \\
\text { (MASMA) }\end{array}$ & 1449 & 121 & NO DEC. \\
\hline $\begin{array}{l}\text { Costa/PLM-3 } \\
\text { (CMBE) }\end{array}$ & 989 & Sup. & \\
\hline $\begin{array}{l}\text { Costa/PLM-3 } \\
\text { (CMBE) }\end{array}$ & 994 & Sup. & \\
\hline $\begin{array}{l}\text { Costa/PLM-4 } \\
\text { (MASMA) }\end{array}$ & $?$ & 217 & $?$ \\
\hline $\begin{array}{l}\text { Valle/Az-8 } \\
\text { (CMBE) }\end{array}$ & 1493 & $\mathrm{P} 1 / 1$ & $\begin{array}{c}\text { MCH.G2/SM.G5, G6, } \\
\text { G7/Indet. }\end{array}$ \\
\hline $\begin{array}{l}\text { Valle/Az-8 } \\
\text { (CMBE) }\end{array}$ & 3592B & $\mathrm{R} 11 / 1$ & SMB.G4/NO DEC. \\
\hline
\end{tabular}

cuerpo de estas inkuñas se organiza según las composiciones espaciales 8 y 8 a (Figura 9), de manera que pueden o no presentar dos sectores laterales de 4 a $5 \mathrm{~cm}$ de ancho adyacentes a las orillas de trama, listados en verde, ocre y morado oscuro sobre rojo; excepcionalmente, estas inkuñas presentan listado lateral diferencial de variados tipos: tres listas llanas de diferentes colores; cuatro listas pares; tres listas pares en ocre, morado y azul oscuro. En tanto, el resto es completamente listado por listas lisas de $1 \mathrm{~cm}$ de ancho de color café oscuro en contraste con el café claro de fondo, con una lista delgada adyacente en el mismo tono oscuro (tal como ya se señaló, este tipo de listado se conoce de textiles etnográficos y es denominado "lista con cría"). La pieza 4825 de Playa Miller-9 constituye en realidad una inkuña reutilizada como bolsa.

\section{1 ( $($ número total = 5)}

Inkuñas con terminación en orillas de urdimbre de tramas en torzal que se prolongan en asas y conforman una línea ondulada amarillo ocre sobre morado, o blanca sobre café claro delimitada por líneas paralelas café oscuro, o en un solo lado por una lista roja. En este tipo de inkuñas la línea ondulada es mucho más frecuente que en el resto. El cuerpo está completamente cubierto por finas listas mayoritariamente de colores naturales, organizadas según la Composición Espacial 9 (Figura 10); sólo en la inkuña 2881 se agregan el rojo, azul y concho de vino. La inkuña se compone de cuatro sectores oscuros alternados por tres más claros, todos más o menos del mismo ancho, o bien, de cinco sectores claros alternados por cuatro oscuros, todos del mismo ancho. El listado consiste en listas de $1 \mathrm{~cm}$ de ancho y la utilización diferencial de colores claros y oscuros. Los sectores laterales muestran un listado diferente al del resto del cuerpo.

\section{J $($ número total = 11)}

Inkuñas con orillas de urdimbre terminadas en tramas en torzal que se prolongan en asas y forman una línea ondulada amarillo ocre sobre morado delimitada por líneas paralelas rojas; la pieza 1907A termina en un zigzag azul/amarillo/ azul confeccionado en puntada corrida doble en zigzag, que se prolonga formando asas trenzadas. El cuerpo de la inkuña se organiza según la Composición Espacial 10 (Figura 11), que consiste 


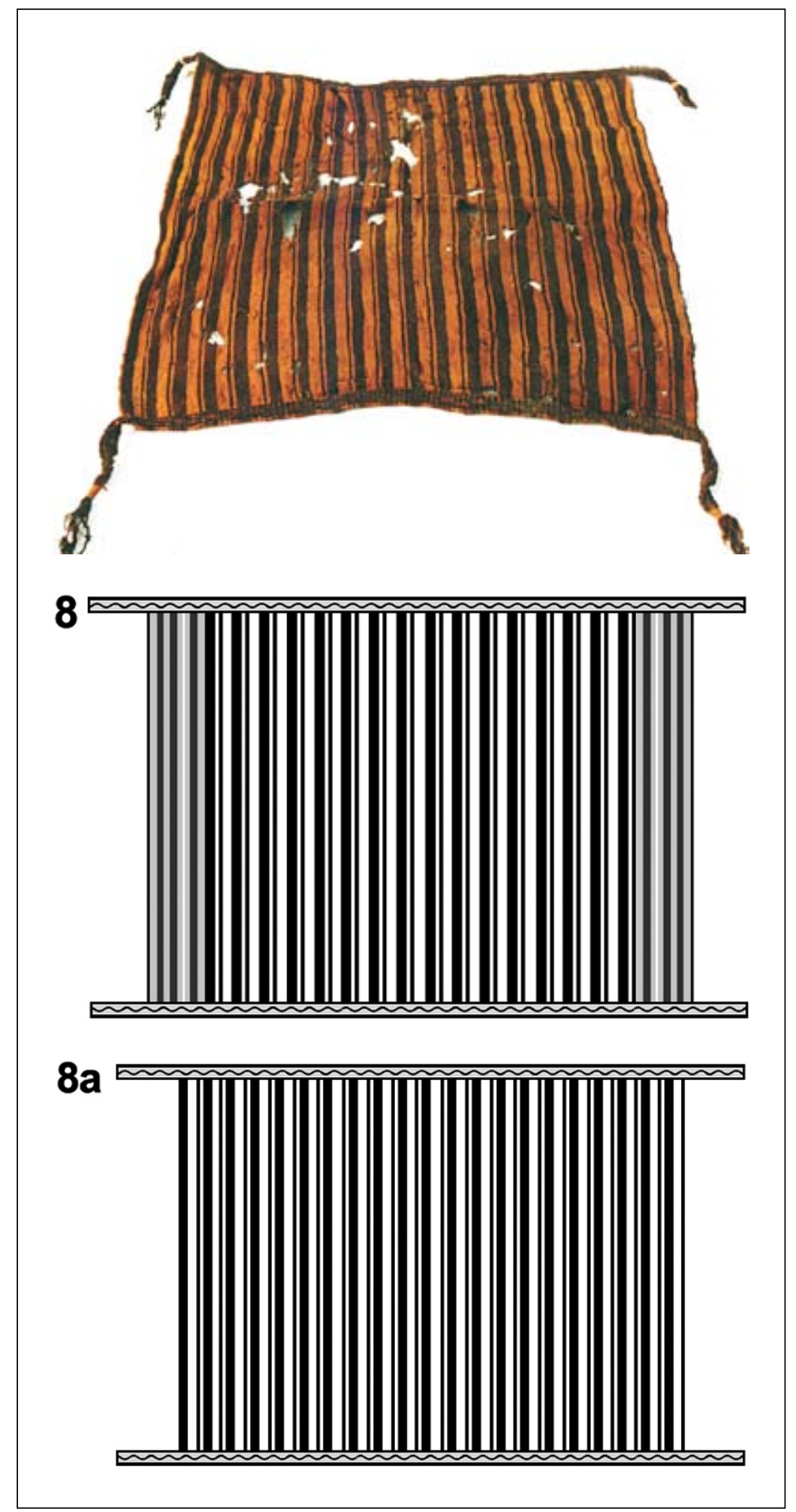

Figura 9. Composición Espacial 8 y 8a. Inkuña del Grupo 1H, procedente del cementerio PLM-3, tumba 182, N²298. Colección MASMA.

Spacial Composition 8 and 8 . Inkuña from Group 1H, coming from cemetery PLM-3, grave 182, $N^{o}$. 2298. MASMA Collection. 


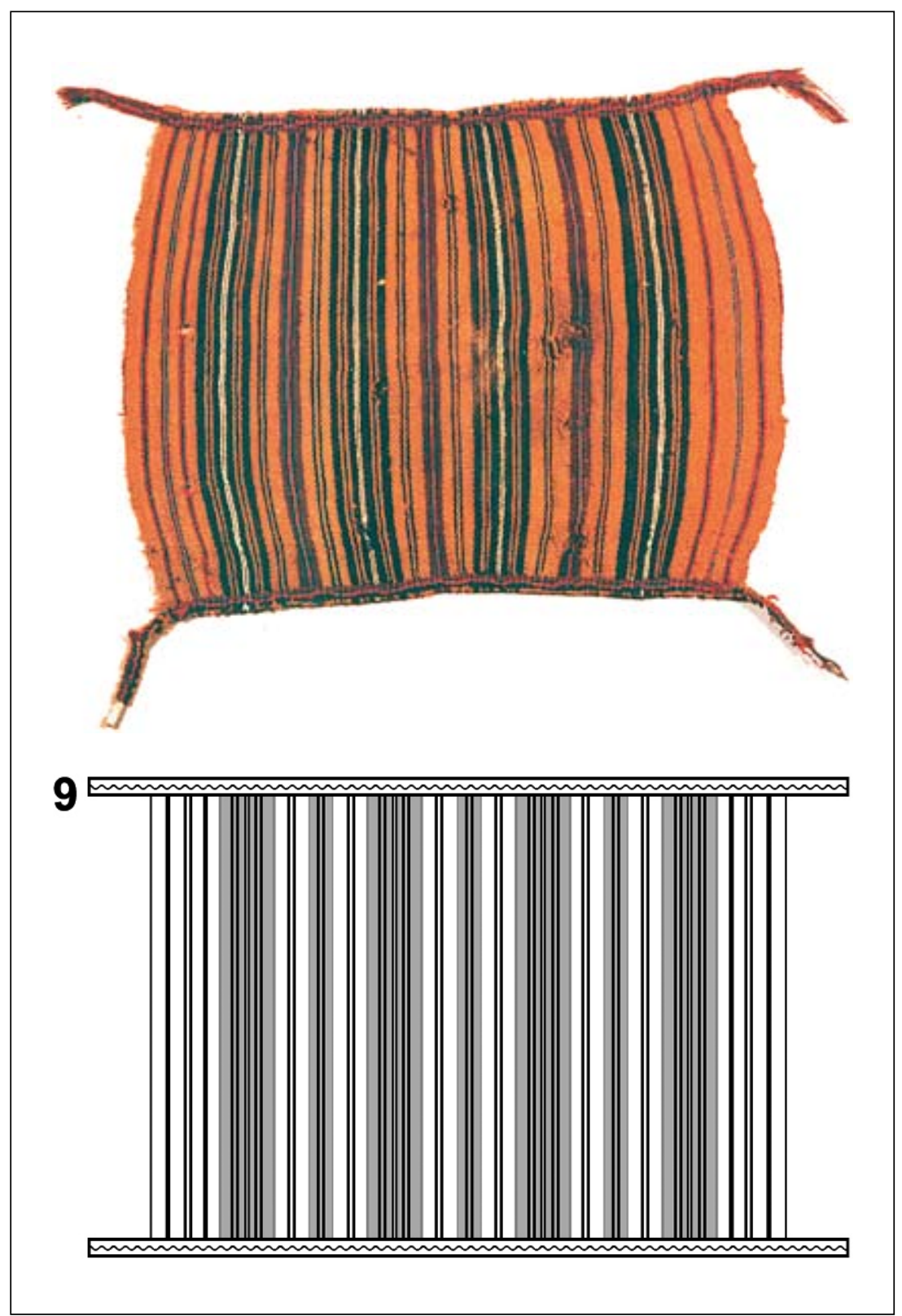

Figura 10. Composición Espacial 9. Inkuña del Grupo 1I, procedente del cementerio PLM-3, tumba 14, No 2881. Colección MBE. Spacial Composition 9. Inkuña from Group 1I, coming from cemetery PLM-3, grave 14, $N^{o}$. 2881. MBE Collection.

INKUÑAS GRUPO 1I

\begin{tabular}{lrrl}
\hline \multicolumn{1}{c}{ Zona/Sitio } & N $^{\text {P }}$ Pieza & Tumba & \multicolumn{1}{c}{ Asociaciones } \\
\hline Costa/PLM-3 (CMBE) & 2881 & 14 & PO.G4/GE.G1-G6/Indet./NO DEC. (fechado TL: 1.470 \pm 55 d.C.) \\
Costa/PLM-3 (CMBE) & 996 & Sup. & \\
Costa/PLM-3 (MASMA) & 333 & 26 & PO.G2/NO DEC. \\
Costa/PLM-3 (MASMA) & 641 & 47 & SMB.G2-G4/NO DEC. \\
Costa/PLM-3 (MASMA) & 1152 & 85 & SMB.G6/PO.G1-G2/NO DEC. \\
\hline
\end{tabular}




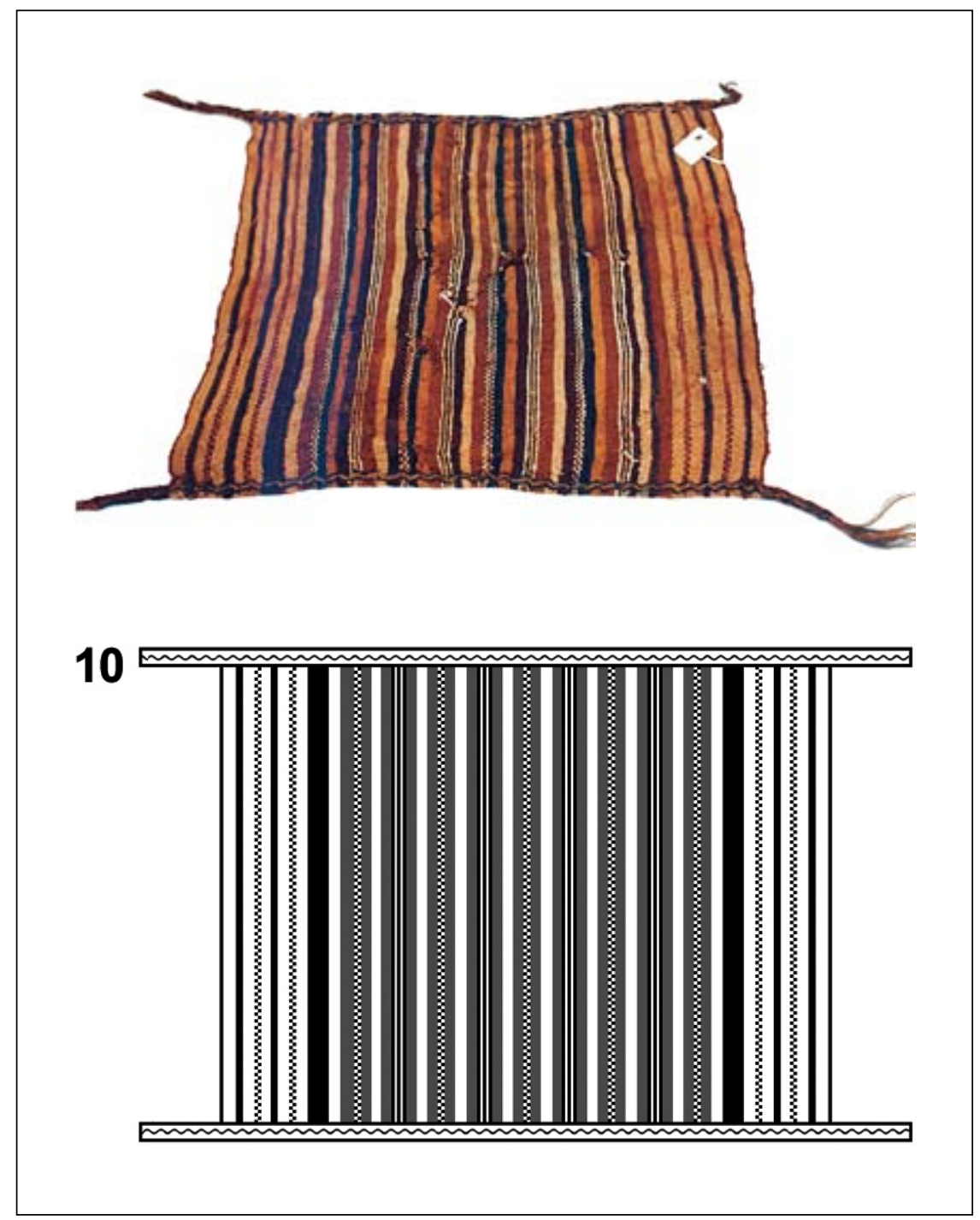

Figura 11. Composición Espacial 10. Inkuña del Grupo 1J, procedente del cementerio PLM-3, tumba 149, N 1907. Colección MASMA.

Spacial Composition 10. Inkuña from Group 1J, coming from cemetery PLM-3, grave 149, $N^{o}$. 1907. MASMA Collection.

Inkuñas Grupo 1J

\begin{tabular}{lccl}
\hline \multicolumn{1}{c}{ Zona/Sitio } & N $^{\text {P Pieza }}$ & Tumba & \multicolumn{1}{c}{ Asociaciones } \\
\hline Costa/PLM-3 (MASMA) & 2838 & 218 & NO DEC. \\
Costa/PLM-3 (MASMA) & 43 & 3 & PO.G1-G2/GB.G2/NO DEC. \\
Costa/PLM-3 (MASMA) & 1907 & 149 & GB.G10/NO DEC. \\
Costa/PLM-3 (MASMA) & 1315 & 102 & NO DEC. \\
Costa/PLM-3 (MASMA) & $1656 \mathrm{~A}$ & 136 & SMB.G2-G5/NO DEC. \\
Costa/PLM-3 (MASMA) & 1583 & 130 & NO DEC. \\
Costa/PLM-3 (MASMA) & 63 & 4 & PO/NO DEC. \\
Costa/PLM-3 (CMBE) & 992 & Sup. & \\
Costa/PLM-3 (CMBE) & 991 & Sup. & SMB \\
Valle/Az-6 (MASMA) & $?$ & 203 & \\
Valle/Az-8 (CMBE) & 1035 & $?$ & \\
\hline
\end{tabular}


en dos sectores de $7 \mathrm{~cm}$ de ancho adyacentes a las orillas de trama, listados en azul piedra y rojo sobre café claro; en rigor, el listado lateral diferencial tiende a desaparecer, ya que se utiliza en dicho sector los mismos colores que en el resto de la pieza. El resto es completamente decorado con listas lisas en tonos café naturales, a los que se suma blanco, azul piedra, amarillo y en menor proporción rojo. Estas inkuñas tienen un centro punteado, ajedrezado, con peinecillo, o peinecillo doble de 0,5 a $2 \mathrm{~cm}$ de ancho, y más o menos al centro de cada mitad otro sector punteado, ajedrezado o con peinecillo, de 0,5 a $2 \mathrm{~cm}$ de ancho.

\section{Grupo 2}

Reúne a aquellas inkuñas que incluyen franjas decoradas con motivos figurativos logrados principalmente por medio de la técnica de urdimbres complementarias y eventualmente, por urdimbres flotantes y urdimbres transpuestas (esta última siempre es acompañada de urdimbres complementarias). La descripción se inicia con inkuñas que presentan un sector central monocromo o pampa lisa de un color, mientras el resto es decorado de variadas formas; luego, continúa con aquellas que decoran dicho sector, y al mismo tiempo dejan espacios intermedios lisos en los que aún es posible apreciar un color de fondo, hasta llegar a piezas que cubren por completo el espacio textil con franjas decoradas y listas, en una enorme variedad de diferentes anchos y secuencias cromáticas.

\section{A $($ número total $=16)$}

Inkuñas con las orillas de urdimbre terminadas en tramas en torzal, conformando rombos delimitados por listas finas. En ocasiones, las cuatro orillas llevan además un festón anillado doble. El cuerpo se organiza según la Composición Espacial 11 (Figura 12), que consiste en una pampa central roja o morada oscura que divide a la pieza en mitades; cada mitad presenta dos franjas decoradas por urdimbres complementarias crema sobre un color oscuro (café o rojo), separadas por tres pares de listas moradas, ocres y azules o negras sobre fondo rojo o concho de vino (listado Pocoma). Los diseños de este tipo de inkuña se pueden observar en la Figura $12 \mathrm{a}^{3}$. Como dato adicional podemos agregar que la pieza 5125 de la tumba N2/5 de Azapa-8 se encuentra asociada a un ceramio no decorado fechado en $1.325 \pm 70$ d.C. Por otra parte, la inkuña 66 de Playa Miller-9 fue fechada por C14 en 975 d.C. (Cassman 1997).

\section{A' (número total = 3)}

Esta variedad la conforman prendas que presentan variaciones, ya sea en el número de las franjas decoradas, o bien, en la ubicación de éstas dentro del espacio textil. Se mantiene el centro vacío, pero no hay listado en pares en los espacios intermedios entre las franjas decoradas, de tal forma que se destaca el color de fondo natural, no teñido (Figura 13 con esquema de la Composición Espacial 11a). En consecuencia, este tipo de inkuñas presentan listado

Inkuñas Grupo 2A

\begin{tabular}{lcrll}
\hline \multicolumn{1}{c}{ Zona/Sitio } & N $^{\circ}$ Pieza & Tumba & Asociaciones \\
\hline Costa/PLM-9 (MASMA) & 66 & 21 & $?$ \\
Costa/PLM-9 (MASMA) & 73 o 15167 & 25 & NO DEC. \\
Costa/PLM-4 (CMBE) & 974 & Sup. & & \\
Costa/PLM-4 (MASMA) & 9505 & 173 & $?$ \\
Costa/PLM-4 (MASMA) & 10221.6 & 166 & $?$ /NODEC. \\
Costa/PLM-3 (MNHN) & S/N & 49 & $?$ \\
Costa/PLM-3 (MASMA) & 800 & 60 & SMB.G2/NO DEC. \\
Costa/PLM-3 (MASMA) & 833 & 61 & No dec. \\
Costa/PLM-3 (MASMA) & $1657 b$ & 136 & SMB.G2-G5/NO DEC. \\
Costa/PLM-3 (MASMA) & 334 & 26 & PO.G2/NO DEC. \\
Costa/PLM-3 (MASMA) & $1468 \mathrm{a}$ & 122 & NO DEC. \\
Costa/PLM-3 (MASMA) & 805 & 60 & SMB.G2/ NO DEC. \\
Costa/PLM-3 (MASMA) & 2300 & 182 & PO.G2 \\
Costa/PLM-3 (MASMA) & 674 & 50 & PO/ NO DEC. \\
Valle/Az-8 (CMBE) & 5125 & N2/5 & SMB.G3, G5/NO DEC. (fechado TL: $1.325 \pm 70$ d.C.; fechado C14: 1.282 d.C.) \\
Valle/Az-8 (CMBE) & 1451 & M4/1 & SM.G2, G3, G4, G5, G8/NO DEC (fechado por TL: 960 \pm 80 d.C.) \\
\hline
\end{tabular}




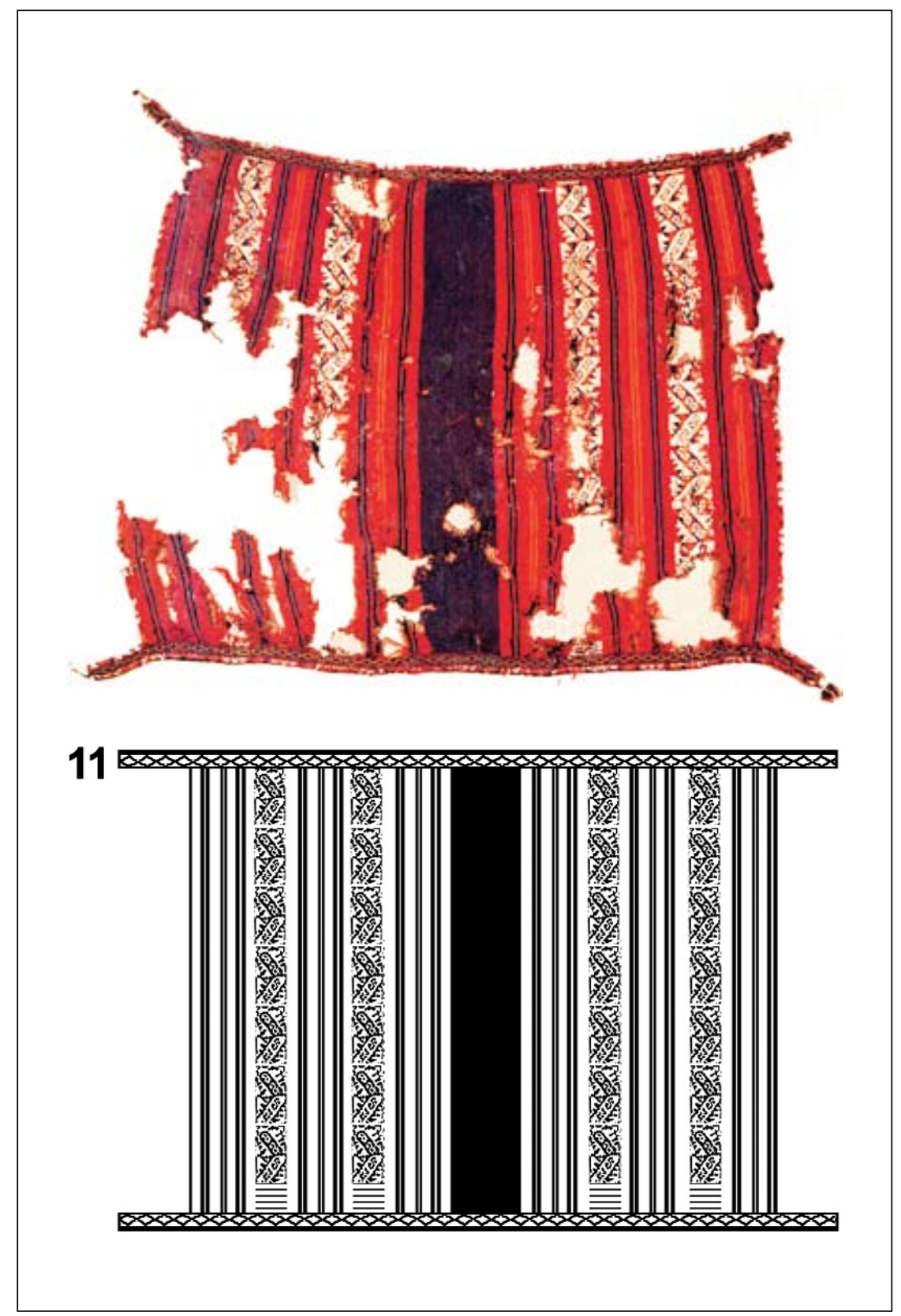

Figura 12. Composición Espacial 11. Inkuña del Grupo 2A, procedente del cementerio Az-8, tumba N2/5, N 5125. Colección MBE.

Spacial Composition 11. Inkuña from Group 2A, coming from cemetery Az-8, grave N2/5, $N^{o}$. 5125. MBE Collection.

lateral diferencial de tres listas llanas en morado, amarillo ocre y azul oscuro (listado lateral San Miguel), así como bloques intermedios de listas, en cuyos centros se ubican angostas franjas con diseños. Estos últimos suelen ser geométricos simples: voluta "S" individual, aserrado, letra " $Z$ ".
Grupo 2A'

\begin{tabular}{crrl}
\hline Zona/Sitio & $\mathrm{N}^{\circ}$ Pieza & Tumba & \multicolumn{1}{c}{ Asociaciones } \\
\hline Costa/PLM-3 (MASMA) & 806 & 60 & SMB.G2/NO DEC. \\
Costa/PLM-3 (MASMA) & 1470 & 122 & NO DEC. \\
Costa/PLM-2 (MASMA) & 3778 & $?$ & \\
\hline
\end{tabular}




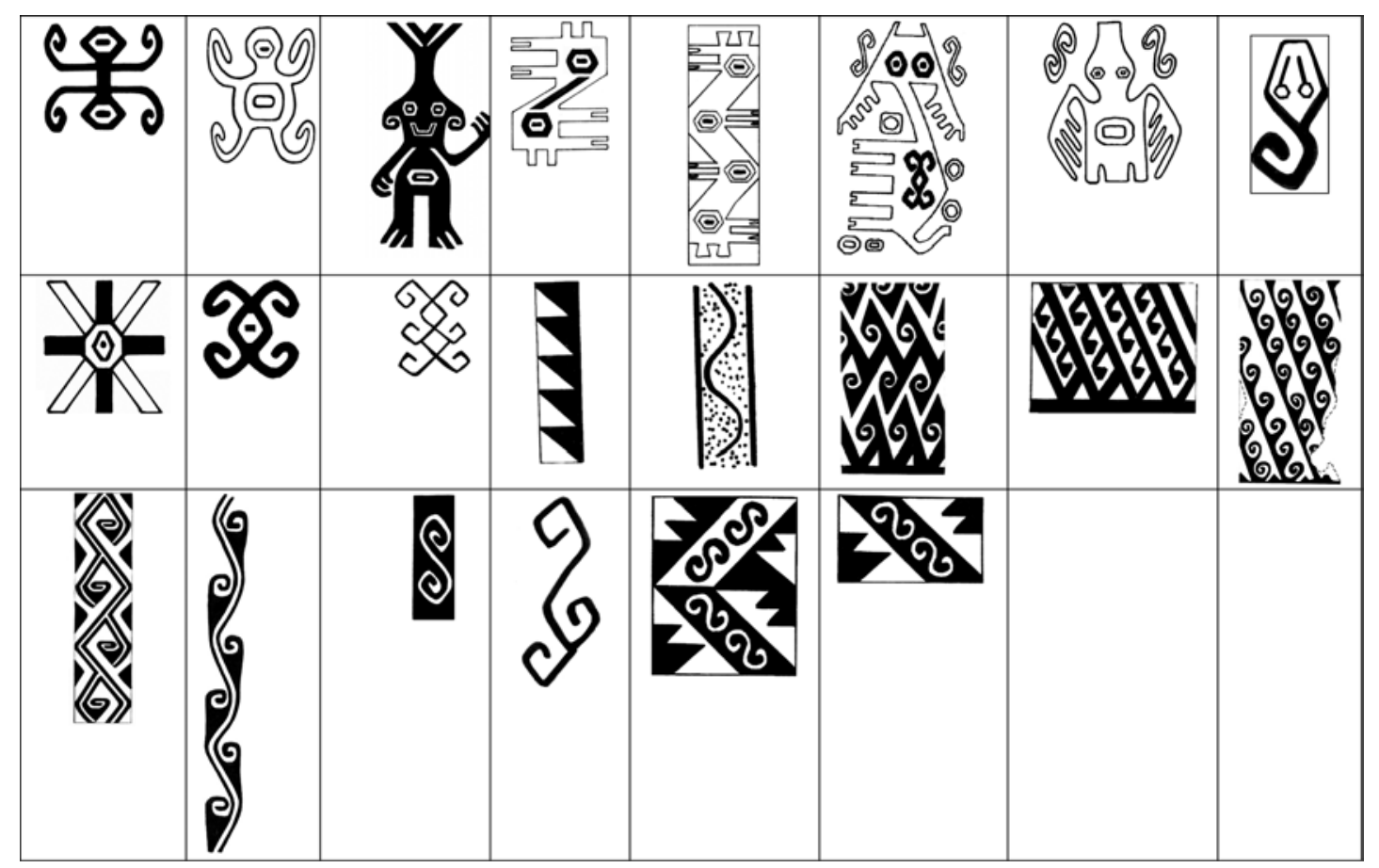

Figura 12a. Motivos decorativos más frecuentes de las inkuñas del Grupo 2A. Most frequent decorative motifs of inkuñas from Group $2 \mathrm{~A}$.

Los números entre paréntesis corresponden a la numeración aplicada en la definición iconográfica elaborada por una de las autoras del presente artículo, en el libro titulado Arte Textil Prehispánico. Diseños de los Tejidos de la Cultura Arica (1000-1470 d. C.), Horta (2005).

- figura antropomorfa con extremidades terminadas en ganchos (Figura 87)

- figura antropomorfa con extremidades terminadas en ganchos (Figura 80)

- figura antropomorfa erguida sobre piernas (Figura 47)

- camélido sin extremidades (Figura 175)

- camélido sin extremidades (Figura 176)

- camélido de cuatro patas (Figura 182)

- pájaro (Figura 158)

- cabeza de serpiente sin cuerpo (Figura 126)

- hexágono radiado de ocho ejes (Figura 212)

- rombo con cuatro ganchos (Figura 206)

- rombos con cuatro ganchos y apéndices (Figura 209)

- aserrado (Figura 228)

- línea ondulada (Figura 241)

- ganchos (Figura 284)

- ganchos (Figura 289)

- ganchos (Figura 288)

- ganchos (Figura 271)

- ganchos (Figura 262)

- voluta "S" individual (Figura 296)

- voluta "S" con prolongación (Figura 304)

- franja diagonal aserrada con voluta individual en pares (Figura 319)

- franja diagonal aserrada en módulo con voluta individual en pares (Figura 324) 


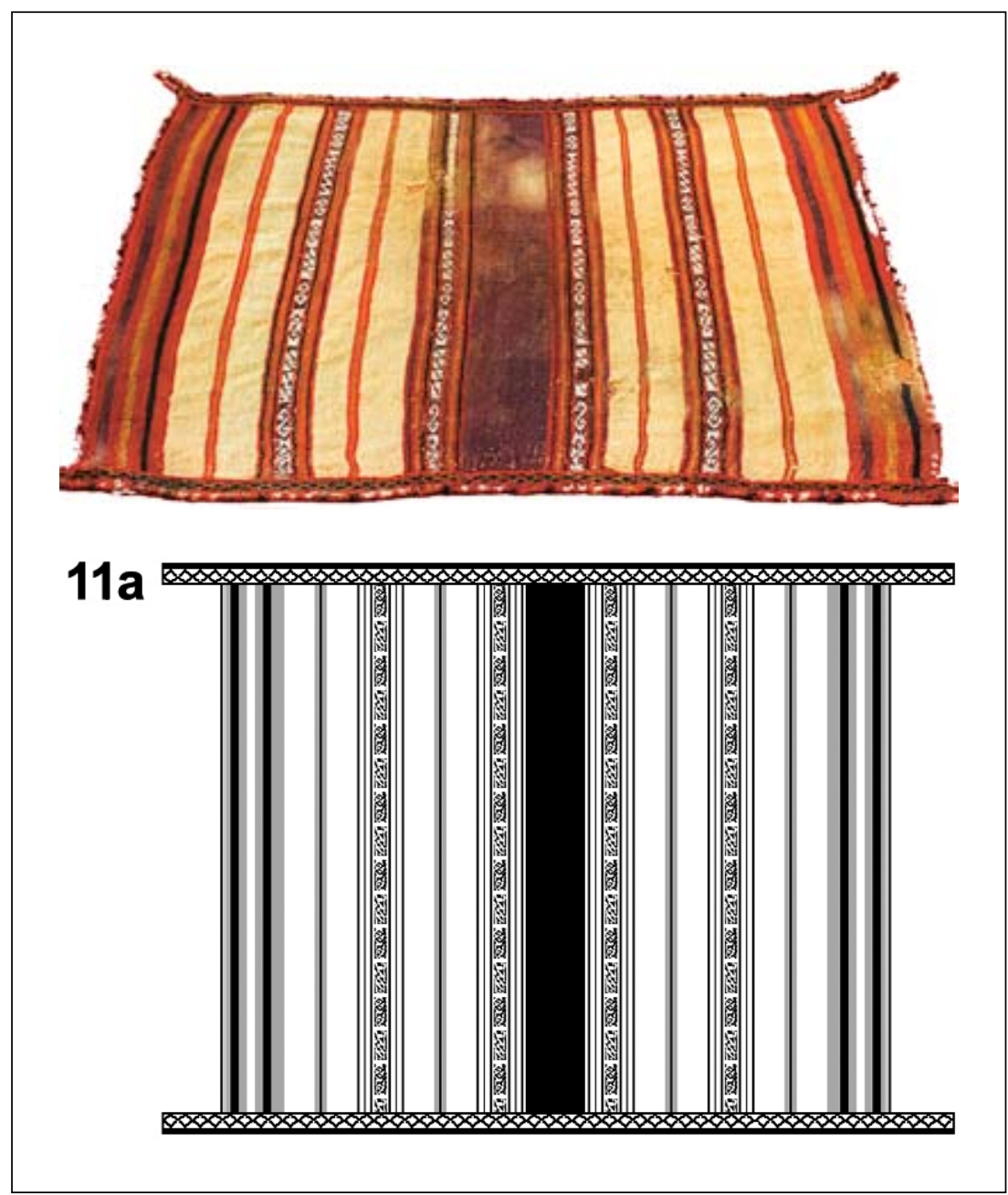

Figura 13. Composición Espacial 11a. Inkuña del Grupo 2A', procedente del cementerio PLM-2, sin contexto, № 3778. Colección MASMA.

Spacial Composition 11a. Inkuña from Group 2A', coming from cemetery PLM-2, without context, $N^{o}$. 3778. MASMA Collection.

\section{B (número total = 8)}

Inkuñas con las orillas de urdimbre terminadas en tramas en torzal, conformando rombos en amarillo ocre sobre morado, delimitados por líneas paralelas rojas. La inkuña 1750B de PLM-3 lleva además festón simple en las orillas de trama. El cuerpo se organiza según la Composición Espacial 12 y 12a (Figura 14), que consiste en dos sectores laterales de 4 a $5 \mathrm{~cm}$ de ancho adyacentes a las orillas de trama listados en morado, amarillo ocre y azul oscuro o negro (listado lateral San Miguel); hacia el centro existen tres franjas decoradas de 3 a $5 \mathrm{~cm}$ de ancho, una central y dos a los lados, dispuestas en forma equidistante sobre un fondo rojo intenso, granate o café oscuro. La decoración de estas franjas se realiza por medio de urdimbres complementarias en crema sobre rojo, amarillo ocre, azul oscuro o morado oscuro. En general, estas inkuñas concentran la mayor utilización de patrones y motivos geométricos, dispuestos en módulos que se repiten verticalmente. Los diseños de este tipo de inkuña se pueden observar en la Figura 14a. Como dato adicional podemos agregar que las inkuñas 500 y 501 de la tumba N2/4 del cementerio Azapa-8 están asociadas, entre otros ceramios, a una vasija PO.G4 fechada en $1215 \pm 80$ d.C. 
Inkuñas Grupo 2B

\begin{tabular}{lccl}
\hline \multicolumn{1}{c}{ Zona/Sitio } & No Pieza & Tumba & \multicolumn{1}{c}{ Asociaciones } \\
\hline S/R (CMBE) & 1036 & S/R & S/R \\
Costa/PLM-3 (CMBE) & 2823 & Sup. & \\
Costa/PLM-3 (MASMA) & $3177 \mathrm{~B}$ & 218 & NO DEC. \\
Costa/PLM-3 (MASMA) & $1750 \mathrm{~B}$ & 140 & PO.G1/NO DEC. \\
Valle/Az-8 (CMBE) & $792 \mathrm{~A}$ & $\mathrm{M} 2 / 2$ & SM.G2-G5?/NO DEC. \\
Valle/Az-8 (CMBE) & 500 & $\mathrm{~N} 2 / 4$ & SM.G4, G5/PO.G4 (fechado TL: $1.215 \pm 80$ d.C.) \\
Valle/Az-8 (CMBE) & 501 & $\mathrm{~N} 2 / 4$ & SM.G4, G5/PO.G4 \\
Valle/Az-8 (CMBE) & $1535 \mathrm{~A}$ & $\mathrm{~K} 1$ '/3 & SMB.G5, G6, G7, G8/PO.G2, G4 \\
\hline
\end{tabular}

\section{C (número total = 9)}

Inkuñas con las orillas de urdimbre terminadas en tramas en torzal que se prolongan en asas y conforman un diseño de rombos rojos sobre morado con o sin líneas que los delimiten; también pueden estar terminadas en festón anillado doble en las cuatro orillas (piezas 807 de Playa Miller-3 y 969 de Azapa-8). El cuerpo de la inkuña se organiza según la Composición Espacial 13 (Figura 15), que consiste en tres, cuatro o cinco bloques de listas lisas de 3 a $5 \mathrm{~cm}$ de ancho en colores rojo, verde botella, terracota y morado, en cuyo centro hay una franja con diseños logrados por urdimbres flotantes o por urdimbres complementarias; estos bloques se ubican repartidos en forma equidistante en el cuerpo de la inkuña. Adyacentes a cada orilla de trama, hay un sector de $3 \mathrm{~cm}$ de ancho con listas lisas en morado, amarillo ocre y azul oscuro sobre rojo (listado lateral San Miguel). El fondo de estas inkuñas es de color café claro. Los diseños de este tipo de inkuña se pueden observar en la Figura 15a.

\section{D (número total = 9)}

Inkuñas con las orillas de urdimbre terminadas en tramas en torzal conformando una línea ondulada ocre sobre morado delimitada por líneas paralelas rojas. El cuerpo de estas inkuñas se organiza según las composiciones 14 y 14a (Figura 16), que consisten en tres (o cuatro) franjas con diseños, una central y otras dos al centro de cada mitad sobre un fondo completamente listado por listas pares de color morado, ocre y azul oscuro, sobre granate (listado Pocoma); cada tres pares de listas hay una franja decorada por urdimbres complementarias -crema sobre rojo, morado oscuro y ocre, o por crema sobre rojo y crema sobre café- logrando motivos decorativos organizados en módulos verticales. El ancho de la franja central es variable; en ocasiones, es más ancho que el de las franjas laterales, o también puede ser del mismo ancho. En el primer caso, la franja central se destaca además por medio de un diseño particular, diferente al de las franjas laterales. No hay sectores laterales listados diferencialmente. Los diseños de este tipo de inkuña se pueden observar en la Figura 16a.

Inkuñas Grupo 2C

\begin{tabular}{lccl}
\hline \multicolumn{1}{c}{ Zona/Sitio } & N $^{\text {Pieza }}$ & Tumba & \multicolumn{1}{c}{ Asociaciones } \\
\hline Costa/PLM-3 (MASMA) & $636 \mathrm{~b}$ & 47 & SMB.G2-G4/NODEC. \\
Costa/PLM-3 (MASMA) & 481 & 35 & SMB.G4-G5-G6/NO DEC. \\
Costa/PLM-3 (MASMA) & 807 & 60 & SMB.G2/NO DEC. \\
Costa/PLM-3 (MASMA) & 801 & 60 & SMB.G2/NO DEC. \\
Costa/PLM-3 (MASMA) & 2837 & 218 & SMB.G2/NO DEC. \\
Costa/PLM-3 (MASMA) & 1748 & 140 & PO.G1/NO DEC. \\
Valle/Az-8 (CMBE) & 969 & Sup. & $?$ \\
Valle/Az-8 (CMBE) & 1699 & Sup. & $?$ \\
Valle/Az-71a (MASMA) & 5049 & 126 & CA.G2 \\
\hline
\end{tabular}




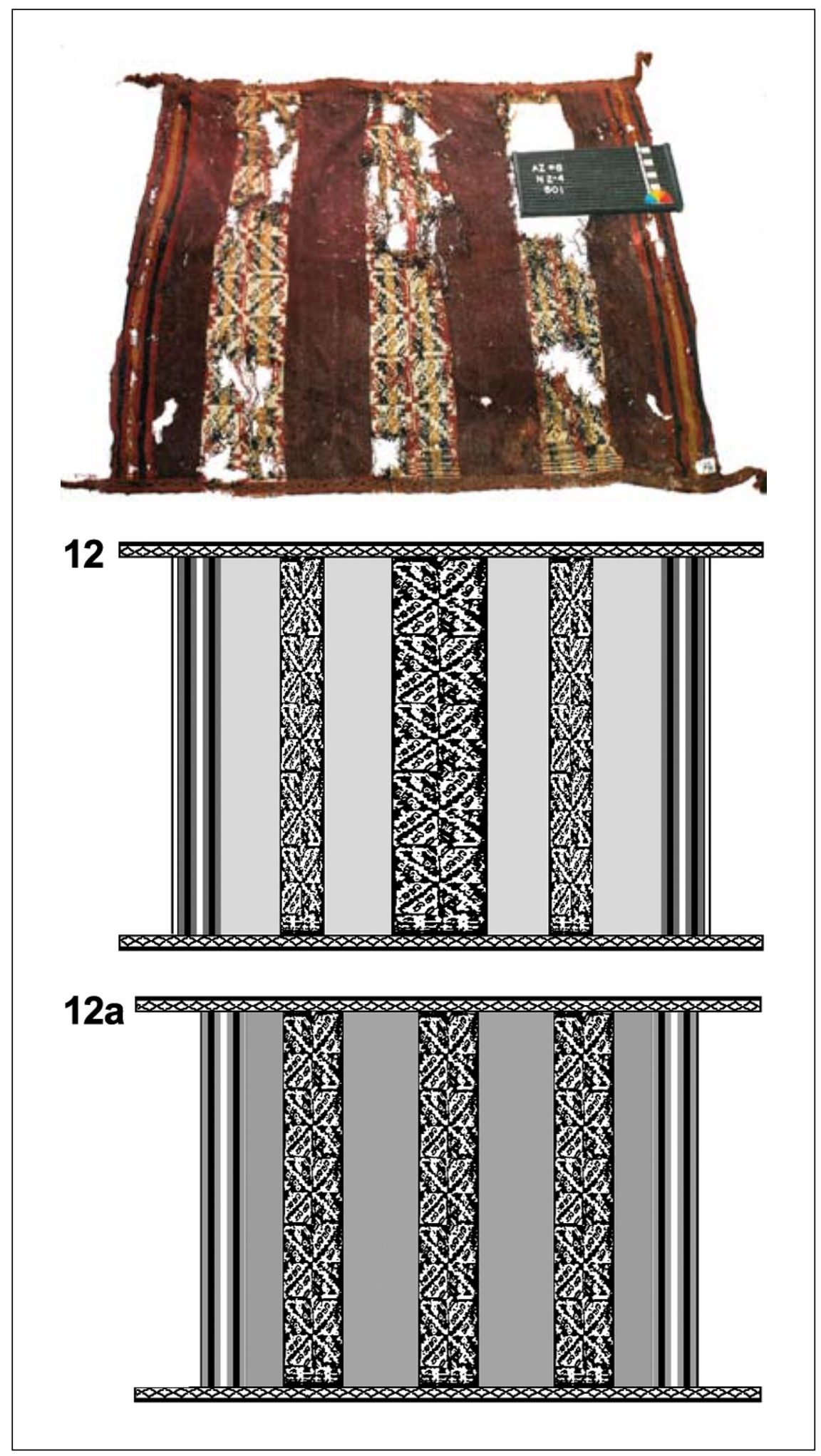

Figura 14. Composición Espacial 12 y 12a. Inkuña del Grupo 2B, procedente del cementerio Az-8, tumba N2/4, No 501. Colección MBE. Spacial Composition 12 and $12 a$. Inkuña from Group $2 B$, coming from cemetery Az-8, grave N2/4, $N^{o}$. 501. MBE Collection. 


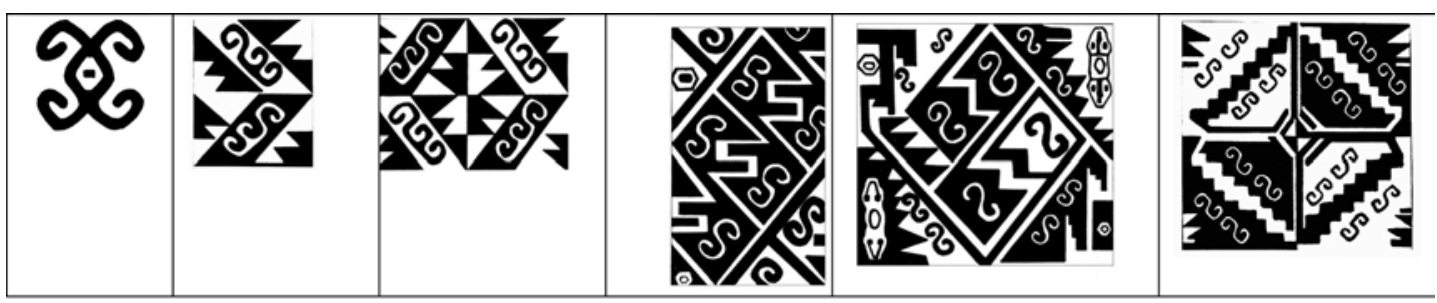

Figura 14a. Motivos decorativos más frecuentes de las inkuñas del Grupo 2B. Most frequent decorative motifs of inkuñas from Group $2 B$.

La numeración de las Figuras entre paréntesis corresponde a Horta (2005).

- rombo con cuatro ganchos (Figura 206)

- franja diagonal aserrada con voluta triple (Figura 321)

- franja diagonal aserrada con voluta triple en imagen espejo (Figura 326)

- serpiente bicéfala de cuerpo diagonal (Figura 111)

- serpiente bicéfala de cuerpo diagonal al interior de composición geométrica (Figura 113)

- patrón geométrico cuatripartito con volutas "S" individuales (Figura 355)

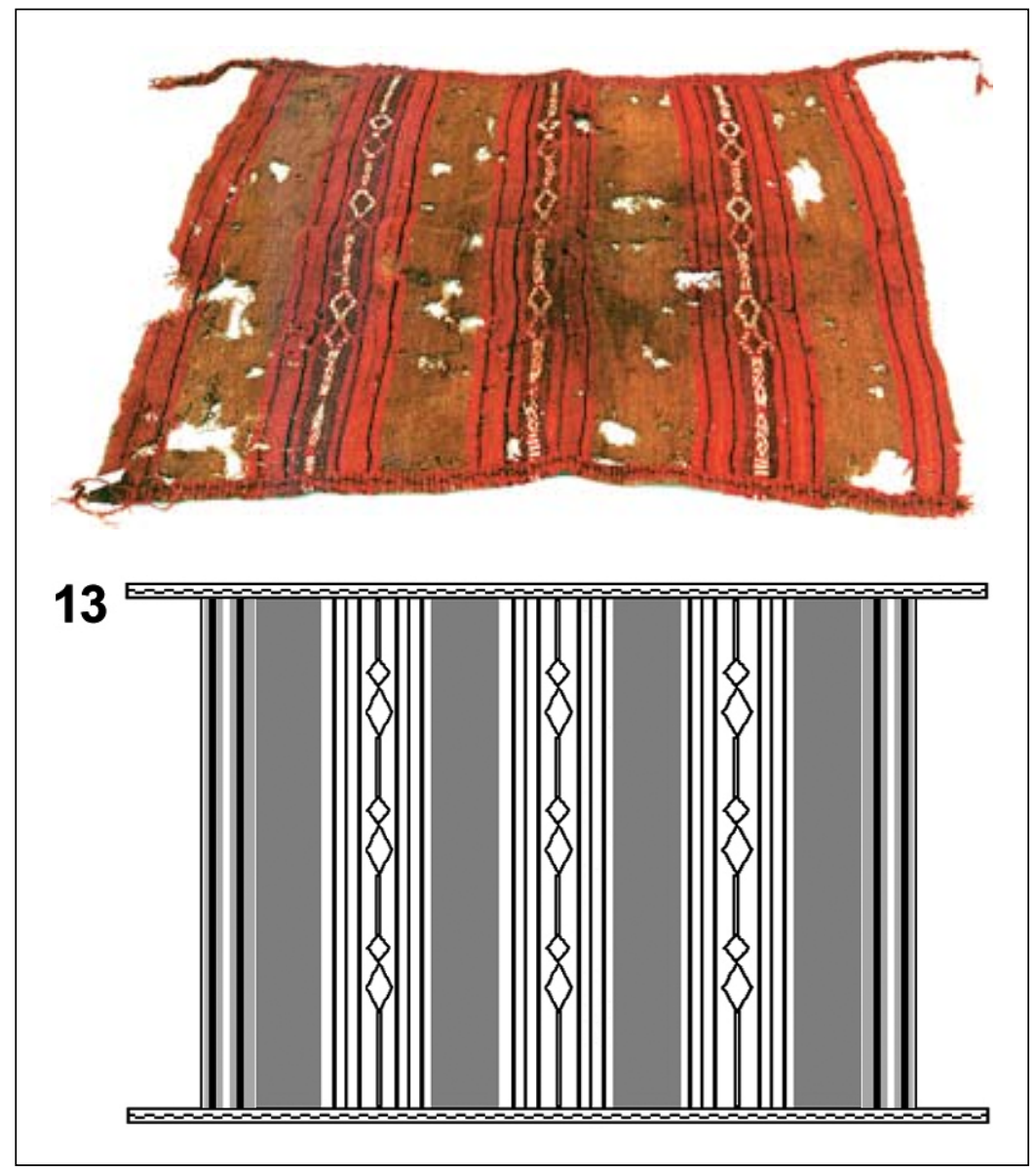

Figura 15. Composición Espacial 13. Inkuña del Grupo 2C, procedente del cementerio PLM-3, tumba 60, № 801. Colección MASMA.

Spacial Composition 13. Inkuña from Group 2C, coming from cemetery PLM-3, grave 60, $N^{o}$ 801. MASMA Collection. 


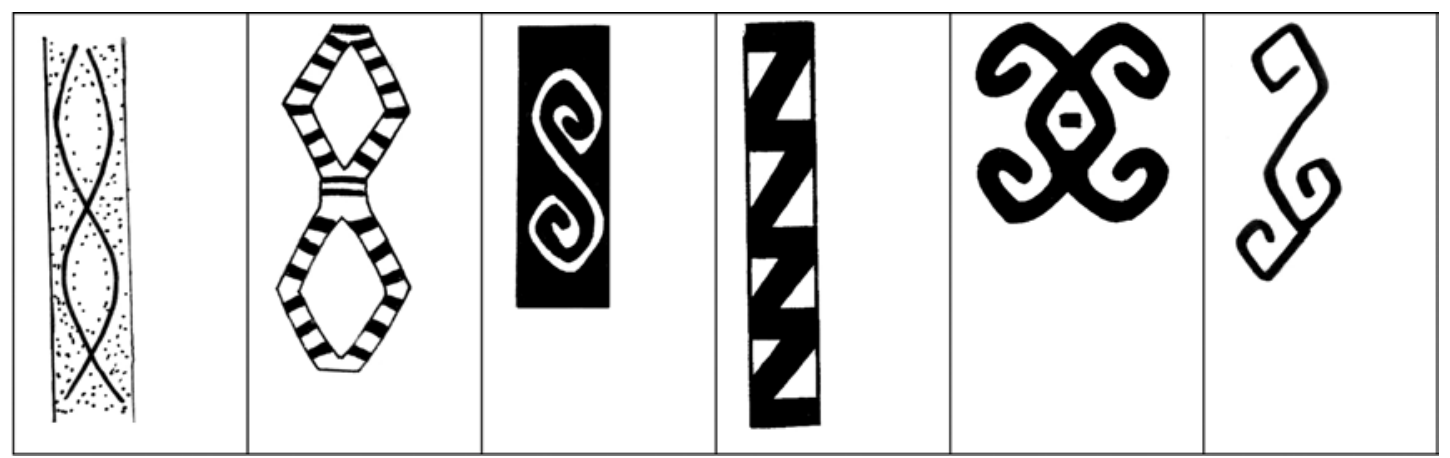

Figura 15a. Motivos decorativos más frecuentes de las inkuñas del Grupo 2C.

Most frequent decorative motifs of inkuñas from Group $2 C$.

La numeración de las Figuras entre paréntesis corresponde a Horta (2005).

- línea ondulada doble (Figura 242)

- rombo de borde segmentado (Figura 249)

- letra “Z” (Figura 226)

- voluta "S" individual (Figura 296)

- rombo con cuatro ganchos (Figura 206)

- voluta "S" con prolongación (Figura 304)

Inkuñas Grupo 2D

\begin{tabular}{lrrl}
\hline \multicolumn{1}{c}{ Zona/Sitio } & N $^{\text {P Pieza }}$ & Tumba & \multicolumn{1}{c}{ Asociaciones } \\
\hline Costa/PLM-3 (CMBE) & 1419 & M4/6 & SMB.G2, G5, G6, G8/PO.G4/NO DEC. (fechado TL: 1.355 \pm 55 d.C.) \\
Costa/PLM-3 (CMBE) & 1452 & M4/1 & SMB. G2, G4, G5, G8/Indet./NO DEC. (fechado TL: 960 \pm 80$)$ \\
Costa/PLM-3 (CMBE) & 499 & N2/4 & SMB.G4, G5/PO.G4/NO DEC. (fechado TL: 1.215 \pm 80 d.C.) \\
Costa/PLM-3 (MASMA) & 2022 & 156 & NO DEC./Aríbalo miniatura \\
Costa/PLM-3 (MASMA) & 23999 & 215 & PO.G1/NO DEC. \\
Costa/PLM-3 (MASMA) & 804 & 60 & SMB.G2/NO DEC. \\
Costa/PLM-4 (MASMA) & S/N & Sup. & \\
S/R (CMBE) & 1034 & S/R & \\
Valle/Az-140 (MASMA) & 15353 & 1 & $?$ \\
\hline
\end{tabular}

\section{E (número total $=8$ )}

Inkuñas con orillas de urdimbre terminadas en tramas en torzal que se prolongan en asas y forman una línea ondulada delimitada por paralelas. El cuerpo de la inkuña se organiza según la Composición Espacial 15 (Figura 17) que consiste en dos sectores de $4 \mathrm{~cm}$ de ancho adyacentes a las orillas de trama, listados generalmente con listas pares morado, ocre y azul oscuro sobre rojo (listado Pocoma); el resto del cuerpo es decorado con una franja central y una al centro de cada mitad, de 1 a $3 \mathrm{~cm}$ de ancho, con diseños logrados por urdimbres transpuestas o complementarias crema y rojo sobre morado, rojo y crema en positivo-negativo, o crema sobre rojo, siendo esta última combinación la más frecuente. El color de fondo del cuerpo es café claro, sobre el cual se disponen líneas punteadas crema sobre rojo y rojo sobre morado; esto quiere decir que en esta composición espacial todavía prevalece el rol jugado por el color de fondo de la pieza. Los diseños de este tipo de inkuña se pueden observar en la Figura 17a.

\section{F (número total $=10$ )}

Inkuñas con orillas de urdimbre terminadas en tramas en torzal que se prolongan en asas y forman rombos o una línea ondulada delimitada por paralelas. El cuerpo de la inkuña se organiza según las Composiciones Espaciales 16 y 16a (Figura 18), que consisten en dos sectores de $4 \mathrm{~cm}$ de ancho adyacentes a las orillas de trama, 


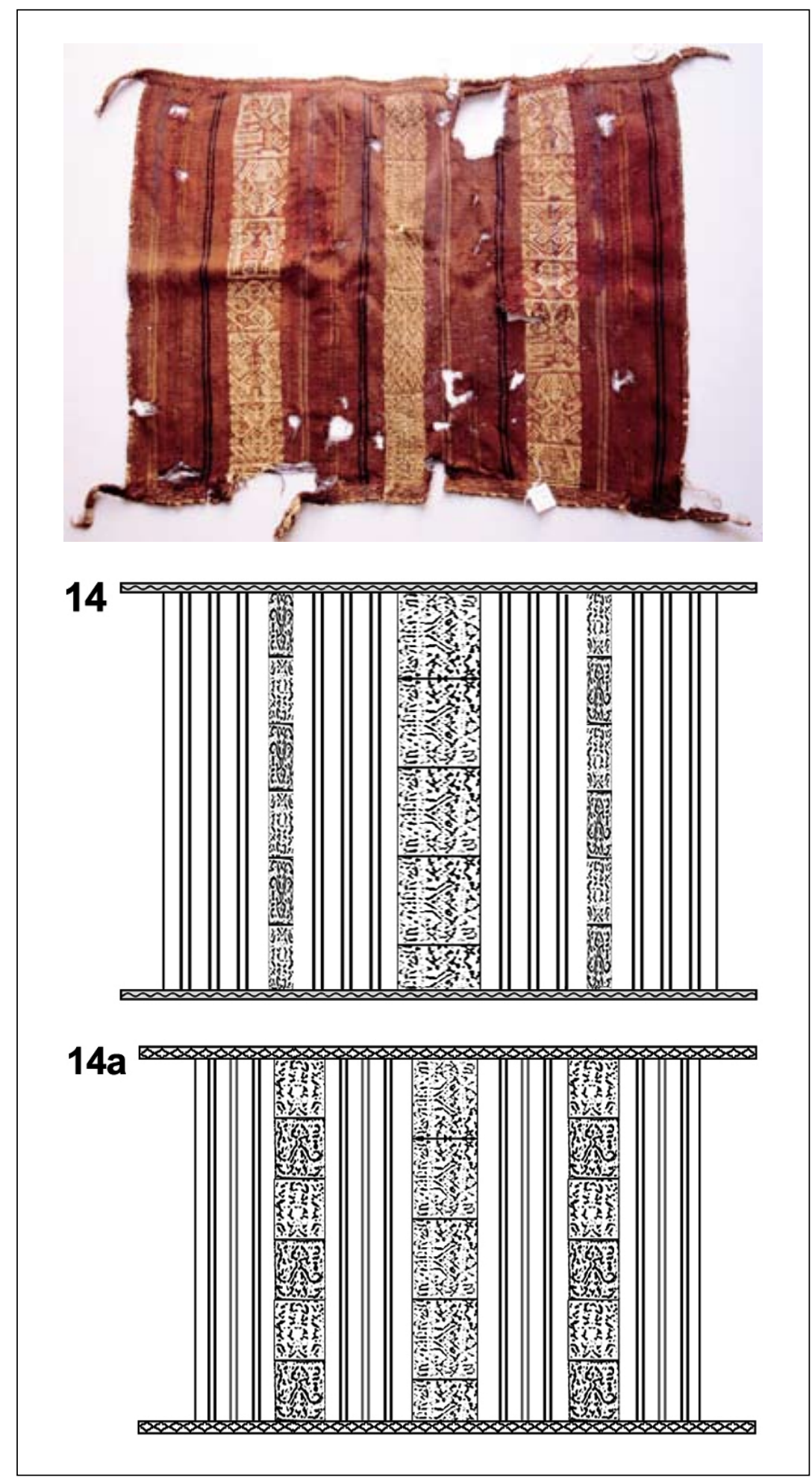

Figura 16. Composición Espacial 14 y 14a. Inkuña del Grupo 2D, procedente del cementerio PLM-3, tumba 156, º 2022. Colección MASMA.

Spacial Composition 14 and 14a. Inkuña from Group 2D, coming from cemetery PLM-3, grave 156, $N^{o}$ 2022. MASMA Collection. 


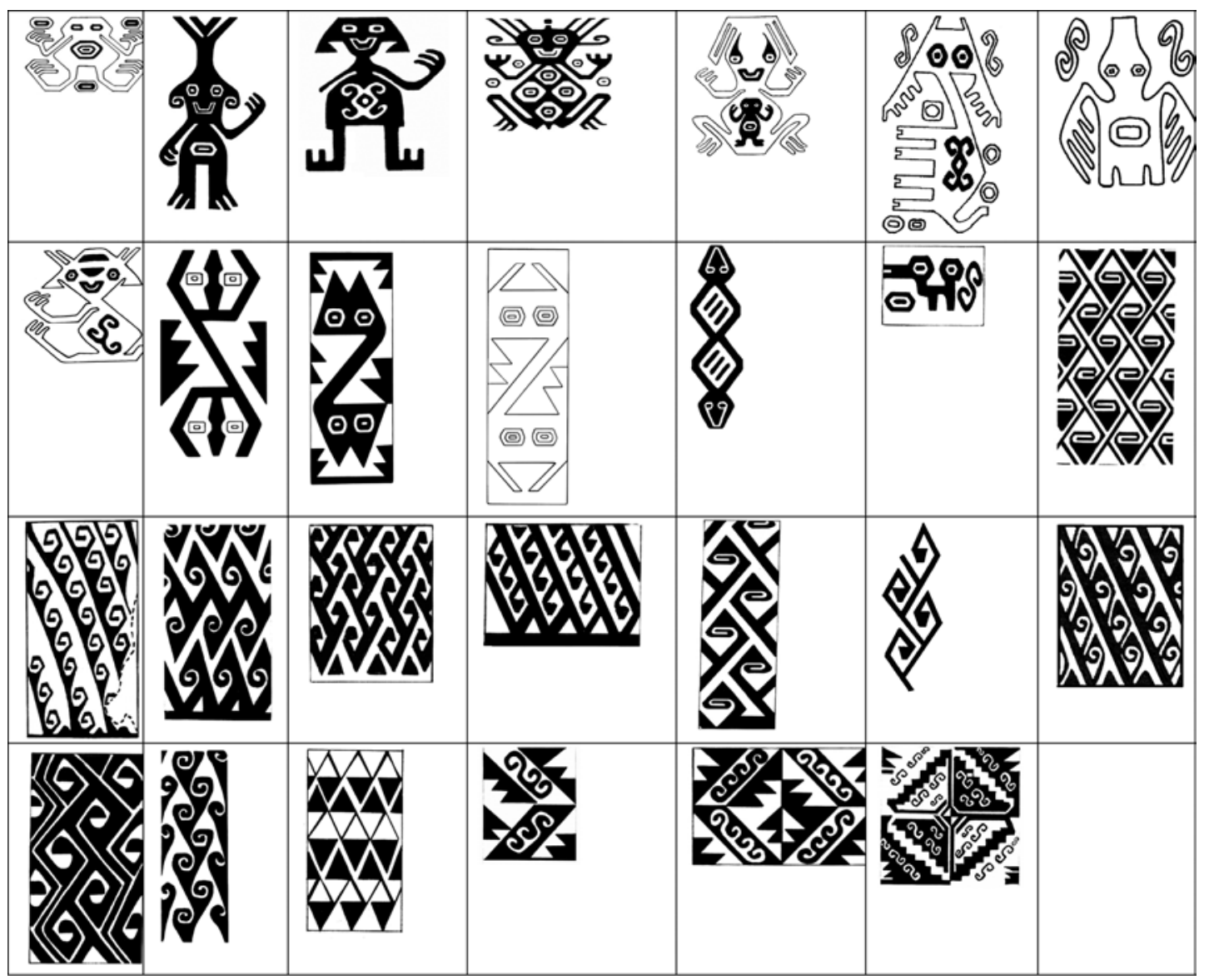

Figura 16a. Motivos decorativos más frecuentes de las inkuñas del Grupo 2D.

Most frequent decorative motifs of inkuñas from Group $2 D$.

La numeración de las Figuras entre paréntesis corresponde a Horta (2005).

- figura antropomorfa con extremidades flectadas hacia arriba (Figura 16)

- figura antropomorfa erguida sobre piernas (Figura 47)

- figura antropomorfa erguida sobre piernas (Figura 54)

- figura antropomorfa de piernas flectadas (Figura 67)

- figura antropomorfa de piernas flectadas (Figura 70)

- camélido de cuatro patas (Figura 182)

- pájaro (Figura 158)

- felino antropomorfizado (Figura 143)

- serpiente bicéfala de cuerpo diagonal (Figura 106)

- serpiente bicéfala de cuerpo diagonal (Figura 102)

- serpiente bicéfala de cuerpo diagonal (Figura 103)

- serpiente bicéfala de cuerpo vertical (Figura 122)

- zoomorfo n/i (Figura 200)

- ganchos (Figura 276)

- ganchos (Figura 287)

- ganchos (Figura 284)

- ganchos (Figura 278)

- ganchos (Figura 288)

- ganchos (Figura 275)

- ganchos (Figura 267)

- ganchos (Figura 292)

- ganchos (Figura 280)

- ganchos (Figura 277)

- ganchos (Figura 286)

- franja diagonal aserrada con voluta triple (Figura 321)

- franja diagonal aserrada, en imagen espejo (Figura 327)

- patrón geométrico cuatripartito (Figura 357) 
Inkuñas Grupo 2E

\begin{tabular}{lccl}
\hline \multicolumn{1}{c}{ Zona/Sitio } & N ${ }^{\circ}$ Pieza & Tumba & \multicolumn{1}{c}{ Asociaciones } \\
\hline Costa/PLM-3 (MASMA) & S/R1 & S/Ref. & $?$ \\
Costa/PLM-3 (MASMA) & 2299 & 182 & PO.G2 \\
Costa/PLM-3 (MASMA) & 2188 & 174 & NO DEC. \\
Costa/PLM-3 (MASMA) & 950 & 70 & PO.G2/NO DEC. \\
Costa/PLM-3 (MASMA) & 638 & 47 & SM.G2, G4/NO DEC. \\
Costa/PLM-8 (CMBE) & 2994 & $20 \times 3$ & $?$ \\
Costa/PLM-4 (MASMA) & 9543 & 175 & $?$ \\
Valle/Az-8 (CMBE) & 321 & N2/2 & SM.G5/Indet./NO DEC. \\
\hline
\end{tabular}

Inkuñas Grupo 2F

\begin{tabular}{lccl}
\hline \multicolumn{1}{c}{ Zona/Sitio } & $\mathrm{N}^{\circ}$ Pieza & Tumba & \multicolumn{1}{c}{ Asociaciones } \\
\hline Costa/PLM-3 (CMBE) & 994 & S/R & \\
Costa/PLM-3 (MASMA) & 42 & 3 & PO.G1-G2/GB.G2/NO DEC. \\
Costa/PLM-3 (MASMA) & 938 & 69 & SMB.G3-G7/NO DEC. \\
Costa/PLM-3 (MASMA) & 657 & 49 & PO.G1-G2/GB.G4 \\
Costa/PLM-3 (MASMA) & 802 & 60 & SMB.G2/NO DEC. \\
Costa/PLM-3 (MASMA) & 896 & 66 & SMB. \\
Costa/PLM-3 (MASMA) & 1505 & 125 & PO.G1, G2, G5/NO DEC. \\
Costa/PLM-3 (MASMA) & 2327 & 186 & PO.G1 \\
Costa/PLM-3 (MASMA) & 2329 & 186 & PO.G1 \\
Costa/PLM-3 (MASMA) & 2328 & 186 & PO.G1 \\
\hline
\end{tabular}

listados generalmente en una gran variedad de combinaciones de colores; en un número menor de casos se verificó la utilización del listado Pocoma; el resto del cuerpo es ocupado por tres franjas (o excepcionalmente cuatro) delgadas de igual ancho y dispuestas en forma equidistante: una franja central, y las otras dos aproximadamente al centro de cada mitad, de $1 \mathrm{a} 3 \mathrm{~cm}$ de ancho, decoradas por urdimbres transpuestas o complementarias rojo y crema sobre morado, rojo sobre azul, y crema sobre rojo, siendo esta última combinación la más frecuente. Los espacios intermedios son completamente listados en diversos colores artificiales o naturales, de tal forma que en la mayoría de los casos no es posible distinguir un color de fondo continuo para la pieza. Los diseños de este tipo de inkuña se pueden observar en la Figura 18a.

\section{G (número total = 5)}

Inkuñas con orillas de urdimbre terminadas en tramas en torzal que se prolongan en asas y forman una línea ondulada delimitada por paralelas. El cuerpo de la inkuña se organiza según la Composición Espacial 17 (Figura 19) que consiste en una franja central, y una al centro de cada mitad, de $1 \mathrm{a} 2 \mathrm{~cm}$ de ancho, decoradas por urdimbres complementarias blanco sobre rojo y azul delimitadas por una lista roja a un lado y verde al otro. El fondo o resto del cuerpo es completamente listado por listas lisas de colores café oscuro y café claro (al modo del Grupo $1 \mathrm{G}$ con "lista con cría"), no existiendo listados laterales diferenciales. Los diseños de este tipo de inkuña se pueden observar en la Figura 19a.

Inkuñas Grupo 2G

\begin{tabular}{lcrl}
\hline \multicolumn{1}{c}{ Zona/Sitio } & N $^{\circ}$ Pieza & Tumba & \multicolumn{1}{c}{ Asociaciones } \\
\hline $\begin{array}{l}\text { Costa/PLM-3 } \\
\text { (MASMA) }\end{array}$ & 659 & 49 & SMB.G2/PO.G1-G2/GB.G4 \\
$\begin{array}{l}\text { Costa/PLM-3 } \\
\text { (MASMA) }\end{array}$ & $949 \mathrm{~B}$ & 70 & PO.G2/NO DEC. \\
$\begin{array}{l}\text { Costa/PLM-3 } \\
\text { (MASMA) }\end{array}$ & 362 & 27 & NO DEC. \\
$\begin{array}{l}\text { Costa/PLM-3 } \\
\text { (MASMA) }\end{array}$ & 1469 & 122 & NO DEC. \\
$\begin{array}{l}\text { Valle/Az-8 } \\
\text { (CMBE) }\end{array}$ & 227 & B'2/1 & SM.G5, G6 (fechado TL: \\
& & & $1.350 \pm 65$ d.C.) \\
\hline
\end{tabular}




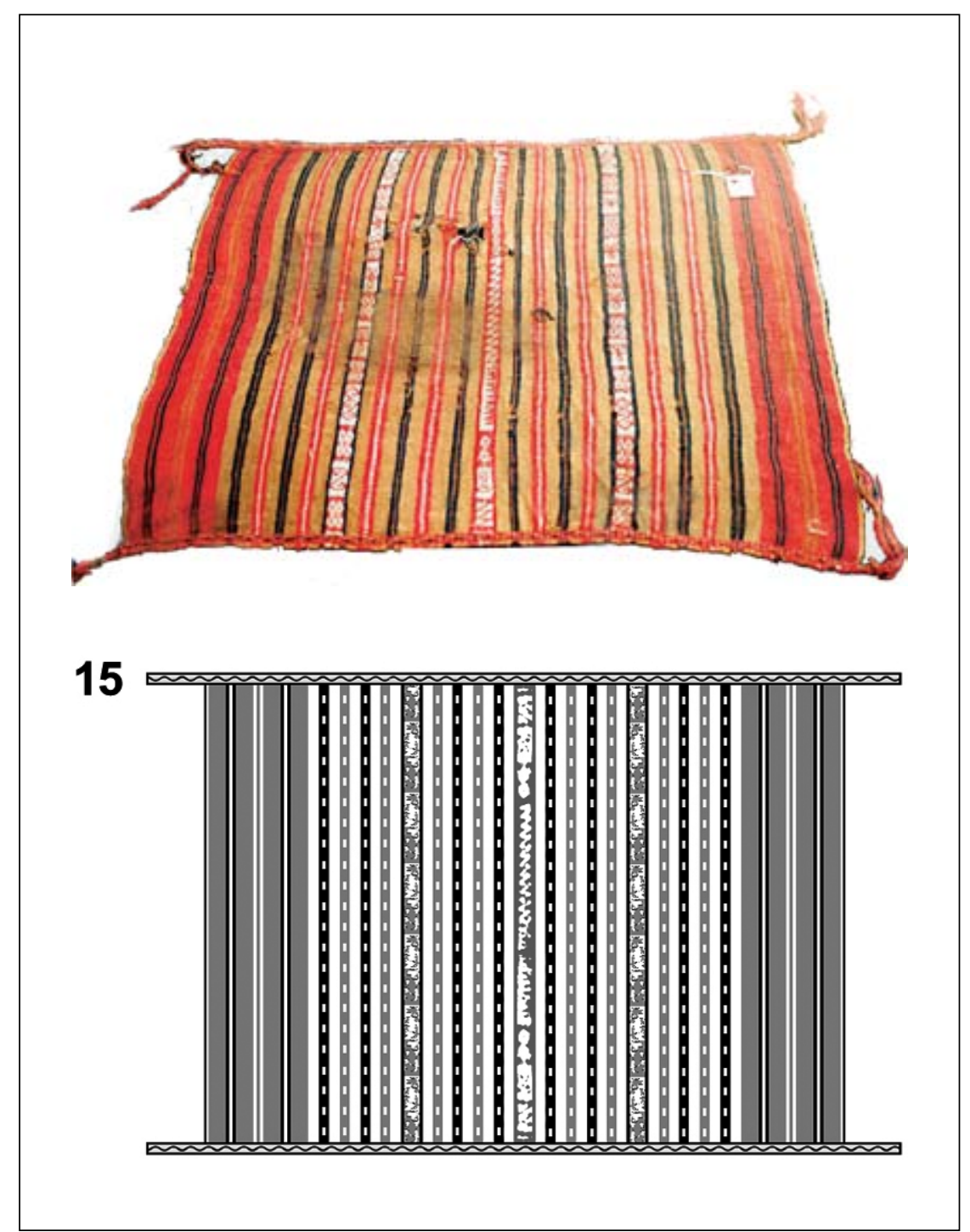

Figura 17. Composición Espacial 15. Inkuña del Grupo 2E, procedente del cementerio PLM-3, sin tumba. Colección MASMA. Spacial Composition 15. Inkuña from Group 2E, coming from cemetery PLM-3, without context. MASMA Collection.

\section{H (número total = 5)}

Inkuñas con orillas de urdimbre terminadas en tramas en torzal que se prolongan en asas y forman una línea ondulada delimitada por paralelas, aunque también hay rombos amarillo ocre. El cuerpo de estos tejidos se organiza según las composiciones espaciales 18 y 18 a (Figura 20), que presentan en el centro de la pieza un sector listado de ancho variable, en cuyo eje existe una franja con diseños por urdimbres complementarias; a ambos lados de dicho bloque central se disponen amplios sectores monocromos, que sólo son interrumpidos por la presencia de eventuales listados laterales diferenciales de $6-10 \mathrm{~cm}$ con diversas combinaciones cromáticas no pautadas. Las inkuñas 2887A y 2722 -ambas de Playa Miller-3- poseen adicionalmente urdimbres de algodón, hecho que se ha observado en forma ocasional en relación con otros textiles de fines del Intermedio Tardío. En la Figura 20a se pueden observar los íconos detectados en las inkuñas de este grupo. 


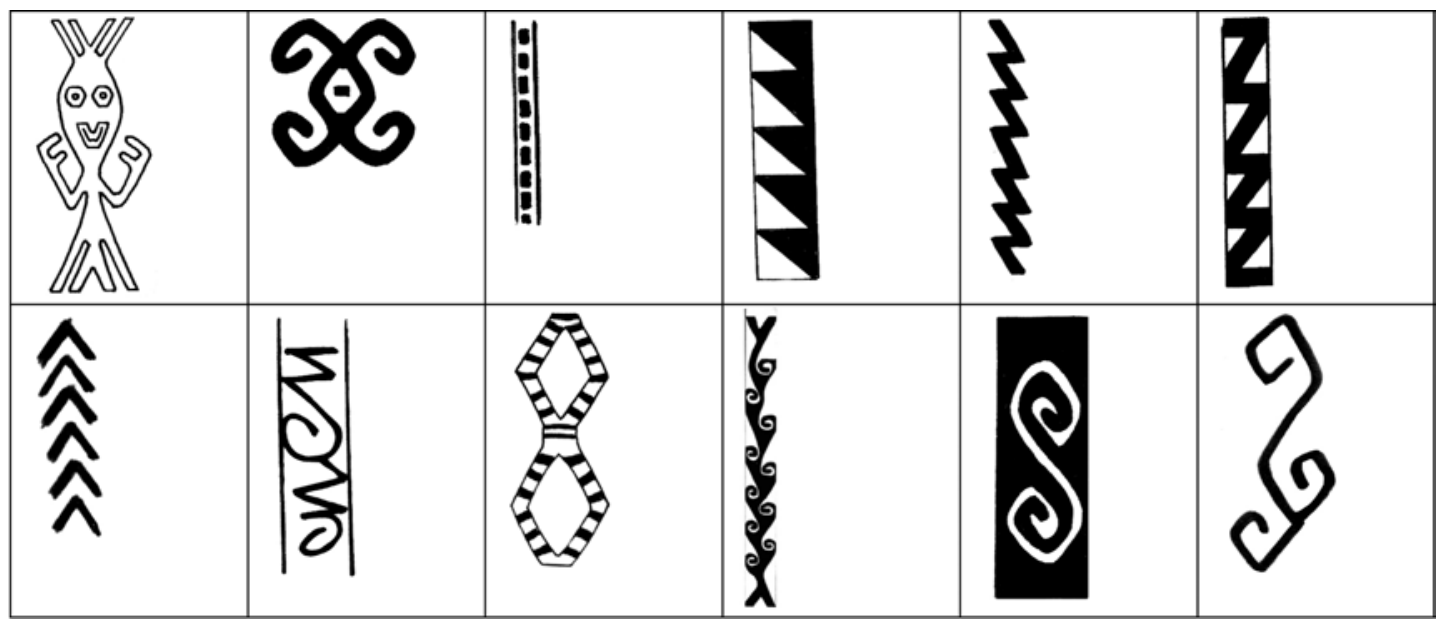

Figura 17a. Motivos decorativos más frecuentes de las inkuñas del Grupo 2E.

Most frequent decorative motifs of inkuñas from Group $2 E$.

La numeración de las Figuras entre paréntesis corresponde a Horta (2005).

- figura antropomorfa erguida sobre piernas (Figura 50)

- rombo con cuatro ganchos (Figura 206)

- línea punteada (Figura 220)

- aserrado (Figura 228)

- línea aserrada (Figura 227)

- letra "Z" (Figura 226)

- chevrón (Figura 235)

- zigzag con ganchos (Figura 240)

- rombo de borde segmentado (Figura 249)

- ganchos (Figura 261)

- voluta "S" individual (Figura 296)

- voluta "S" con prolongación (Figura 304)

Inkuñas Grupo 2H

\begin{tabular}{|c|c|c|c|}
\hline Zona/Sitio & $\mathrm{N}^{\mathrm{o}}$ Pieza & Tumba & Asociaciones \\
\hline Costa/PLM-3 (CMBE) & 2722 & 10 & NO DEC. \\
\hline Costa/PLM-3 (MASMA) & $\mathrm{S} / \mathrm{R}$ & $\mathrm{S} / \mathrm{R}$ & \\
\hline Costa/PLM-3 (CMBE) & 990 & Sup. & \\
\hline Costa/PLM-3 (CMBE) & $2887 \mathrm{a}$ & 9 & SMB.G4, G7/PO.G4/GB.G4/NO DEC. (fechado TL: $1.245 \pm 70$ d.C.) \\
\hline Costa/PLM-3 (CMBE) & 892 & $C^{\prime} 25 / 1$ & SMB.G6/Indet. \\
\hline
\end{tabular}

\section{Definición de Estilos Según Cada Tipo de Inkuña}

Inkuña estilo Cabuza (Grupo 1A; Figura 2). Hemos podido observar asociado a cerámica Cabuza a este tipo de inkuñas, que tienen la particularidad de no presentar terminaciones de tramas en torzal en las orillas de urdimbre: rasgo característico de la inkuña de Arica. Si a esto agregamos la total ausencia de iconografía de estos tejidos, debemos concluir que se trata de una tradición textil sin raigambre local, ajena a los estilos de Valles Occidentales. Minkes, en su tesis doctoral referida a textiles del valle del Osmore, Ilo, Perú, da cuenta de un Tipo 2 conformado por cuatro inkuñas (o "pañuelos") con la misma composición espacial y características de estilo de nuestro Grupo 1A; la semejanza estilística se ve reforzada por el hecho adicional de que 


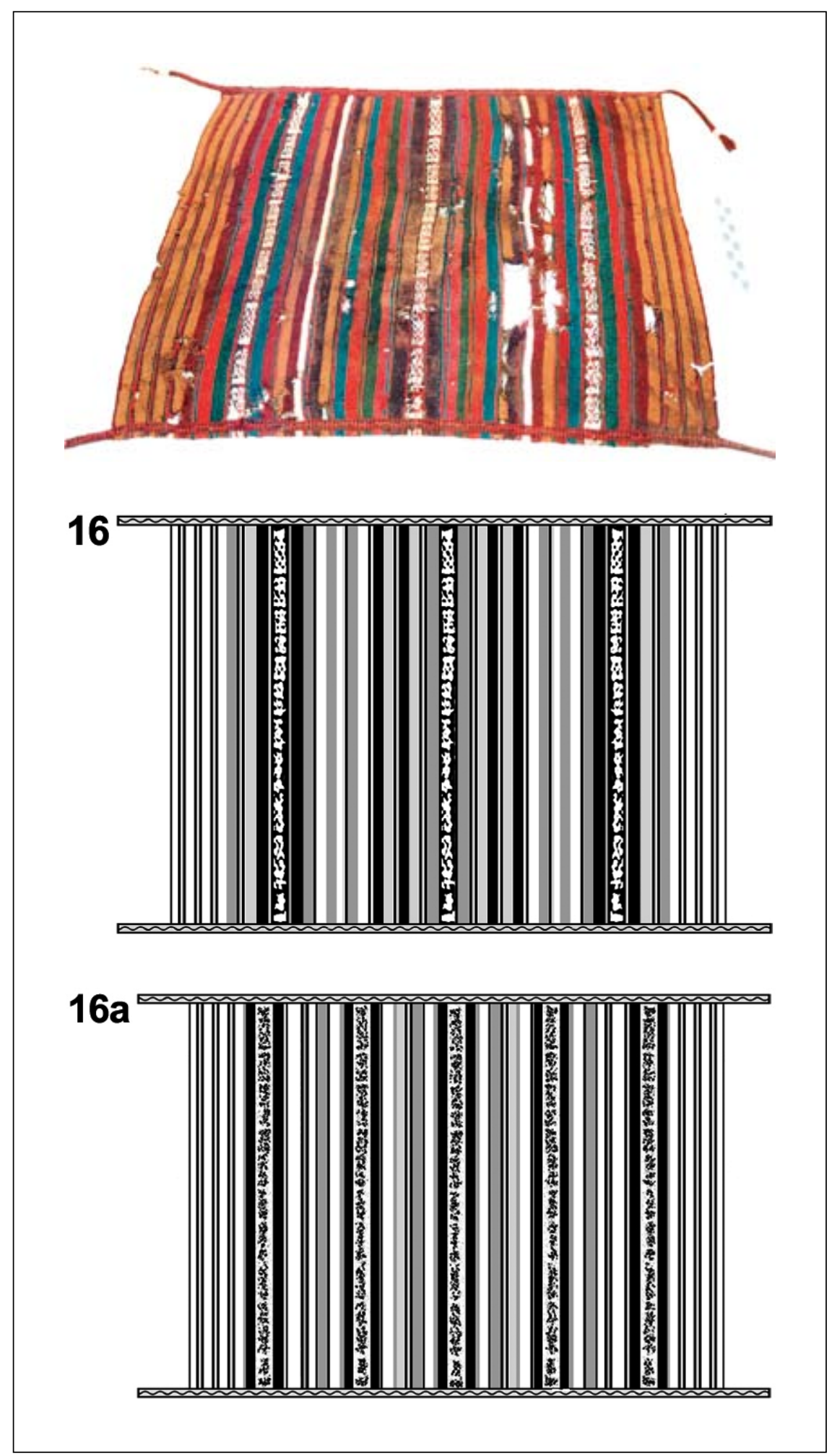

Figura 18. Composición Espacial 16 y 16a. Inkuña del Grupo 2F, procedente del cementerio PLM-3, tumba 3, No 42. Colección MASMA.

Spacial Composition 16 and 16a. Inkuña from Group 2F, coming from cemetery PLM-3, grave 3, $N^{\circ} 42$. MASMA Collection. 


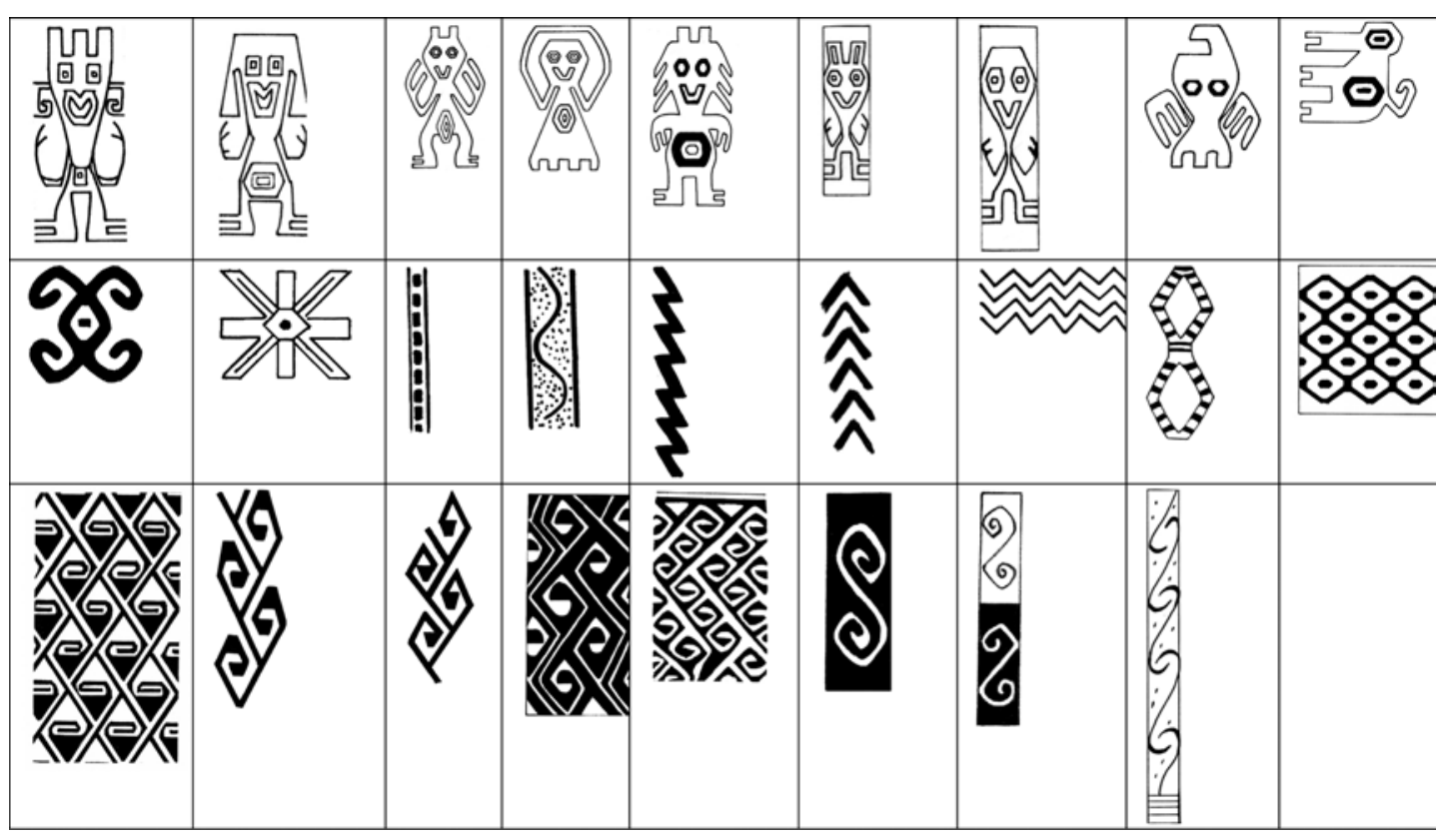

Figura 18a. Motivos decorativos más frecuentes de las inkuñas del Grupo 2F.

Most frequent decorative motifs of inkuñas from Group $2 F$.

La numeración de las Figuras entre paréntesis corresponde a Horta (2005).

- figura antropomorfa erguida sobre piernas (Figura 23)

- figura antropomorfa erguida sobre piernas (Figura 24)

- figura antropomorfa erguida sobre piernas (Figura 32)

- figura antropomorfa erguida sobre piernas (Figura 62)

- figura antropomorfa erguida sobre piernas (Figura 36)

- figura antropomorfa erguida sobre piernas (Figura 35)

- figura antropomorfa erguida sobre piernas (Figura 34)

- pájaro (Figura 157)

- zoomorfo n/i (Figura 201)

- rombo con cuatro ganchos (Figura 206)

- hexágono radiado de ocho ejes (Figura 213)

- línea punteada (Figura 220)

- línea ondulada (Figura 241)

- línea aserrada (Figura 227)

- chevrón (Figura 235)

- zigzag horizontal (Figura 243)

- rombo de borde segmentado (Figura 249)

- panal de abejas (Figura 258)

- ganchos (Figura 276)

- ganchos (Figura 265)

- ganchos (Figura 267)

- ganchos (Figura 280)

- ganchos (Figura 295)

- voluta "S" individual (Figura 296)

- voluta "S" en sucesión vertical (Figura 297)

- voluta "S" con prolongación (Figura 304)

- voluta "S" lineal (Figura 312) 


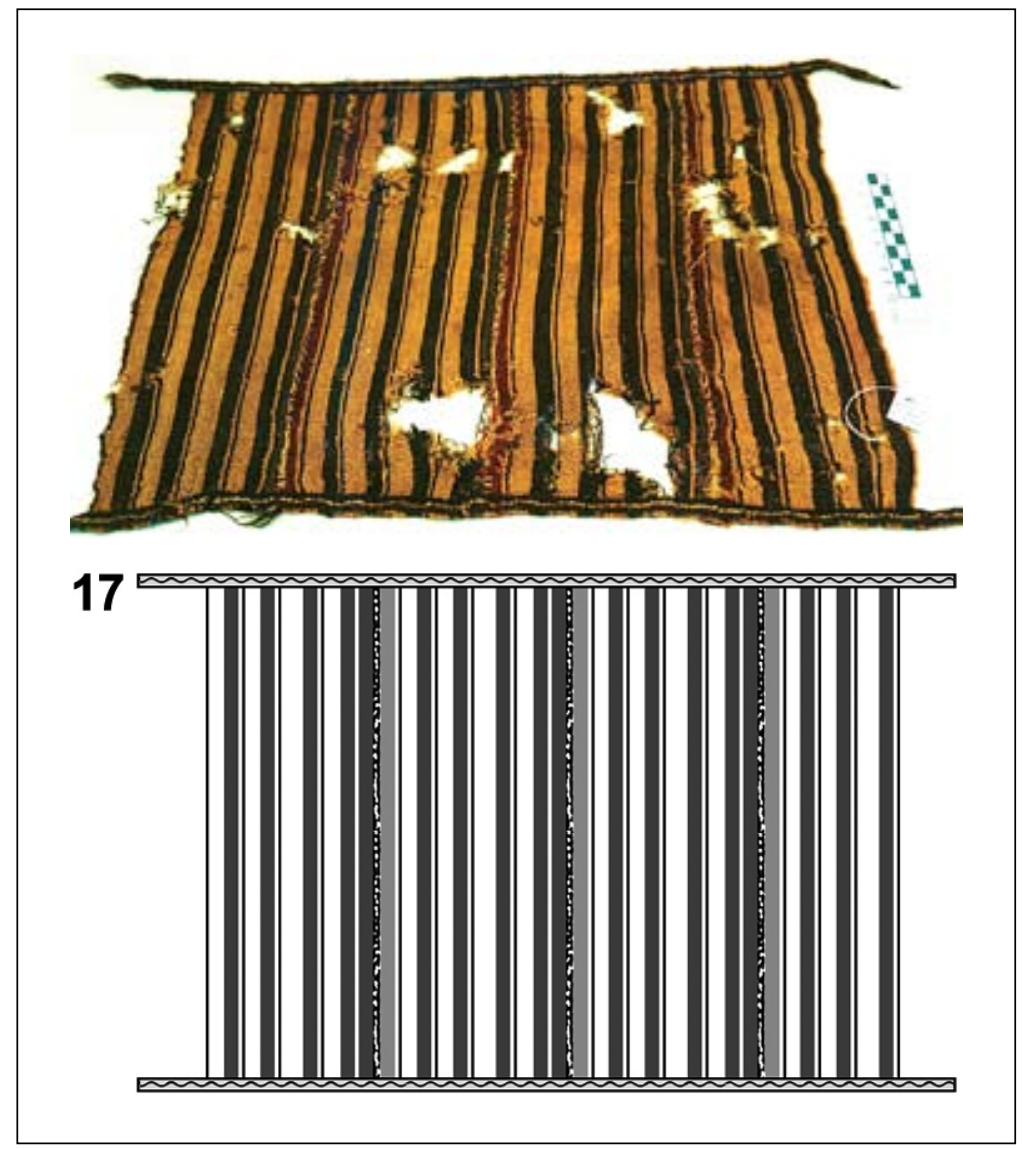

Figura 19. Composición Espacial 17. Inkuña del Grupo 2G, procedente del cementerio PLM-3, tumba 49, No 659. Colección MASMA. Spacial Composition 17. Inkuña from Group 2G, coming from cemetery PLM-3, grave 49, $N^{o}$ 659. MASMA Collection.

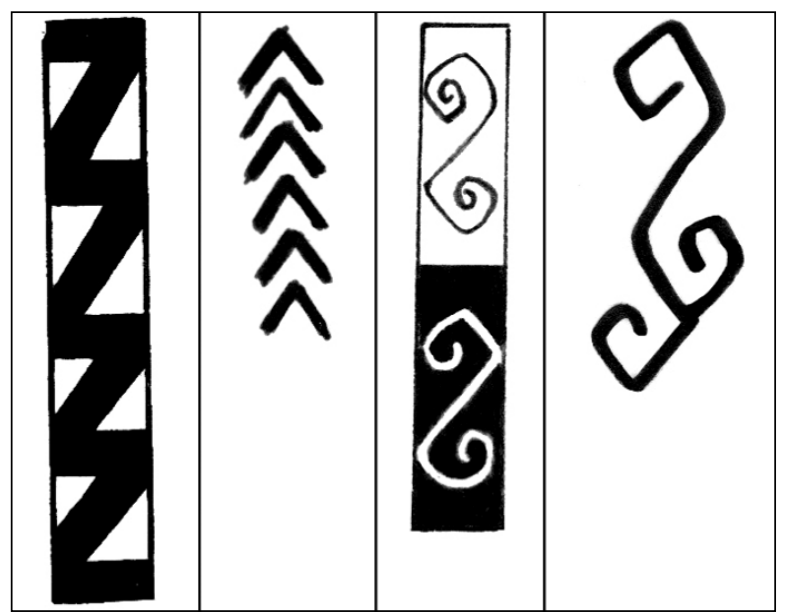

Figura 19a. Motivos decorativos más frecuentes de las inkuñas del Grupo 2G. Most frequent decorative motifs of inkuñas from Group $2 G$.

La numeración de las Figuras entre paréntesis corresponde a Horta (2005).

- letra "Z" (Figura 226) • voluta "S" en sucesión vertical (Figura 297)

- chevrón (Figura 235) • voluta "S" con prolongación (Figura 304) 


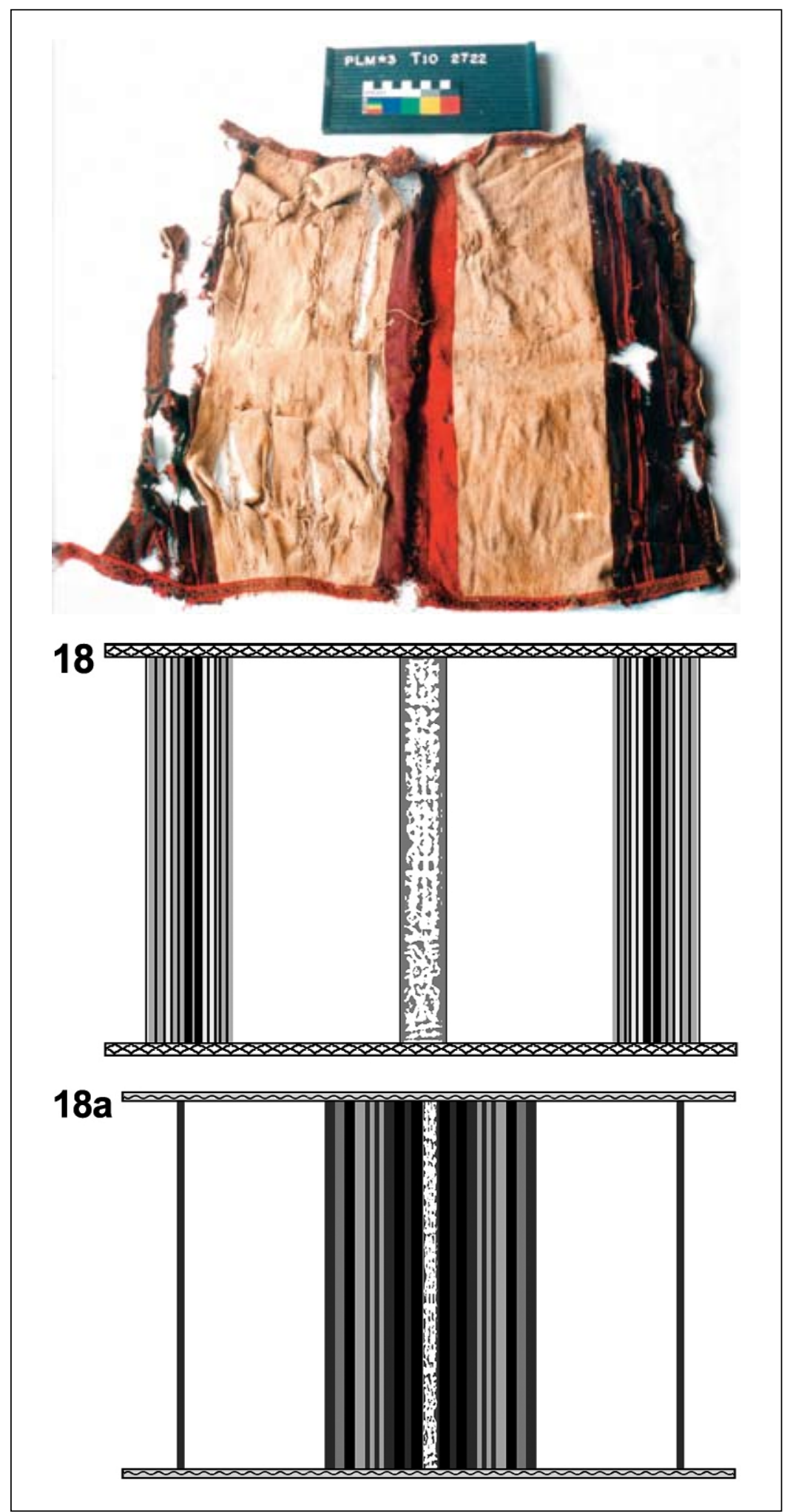

Figura 20. Composición Espacial 18 y 18a. Inkuña del Grupo 2H, procedente del cementerio PLM-3, tumba 10, № 2722. Colección MBE. Spacial Composition 18 and 18a. Inkuña from Group $2 \mathrm{H}$, coming from cemetery PLM-3, grave 10, $N^{\circ} 2722$. MBE Collection. 


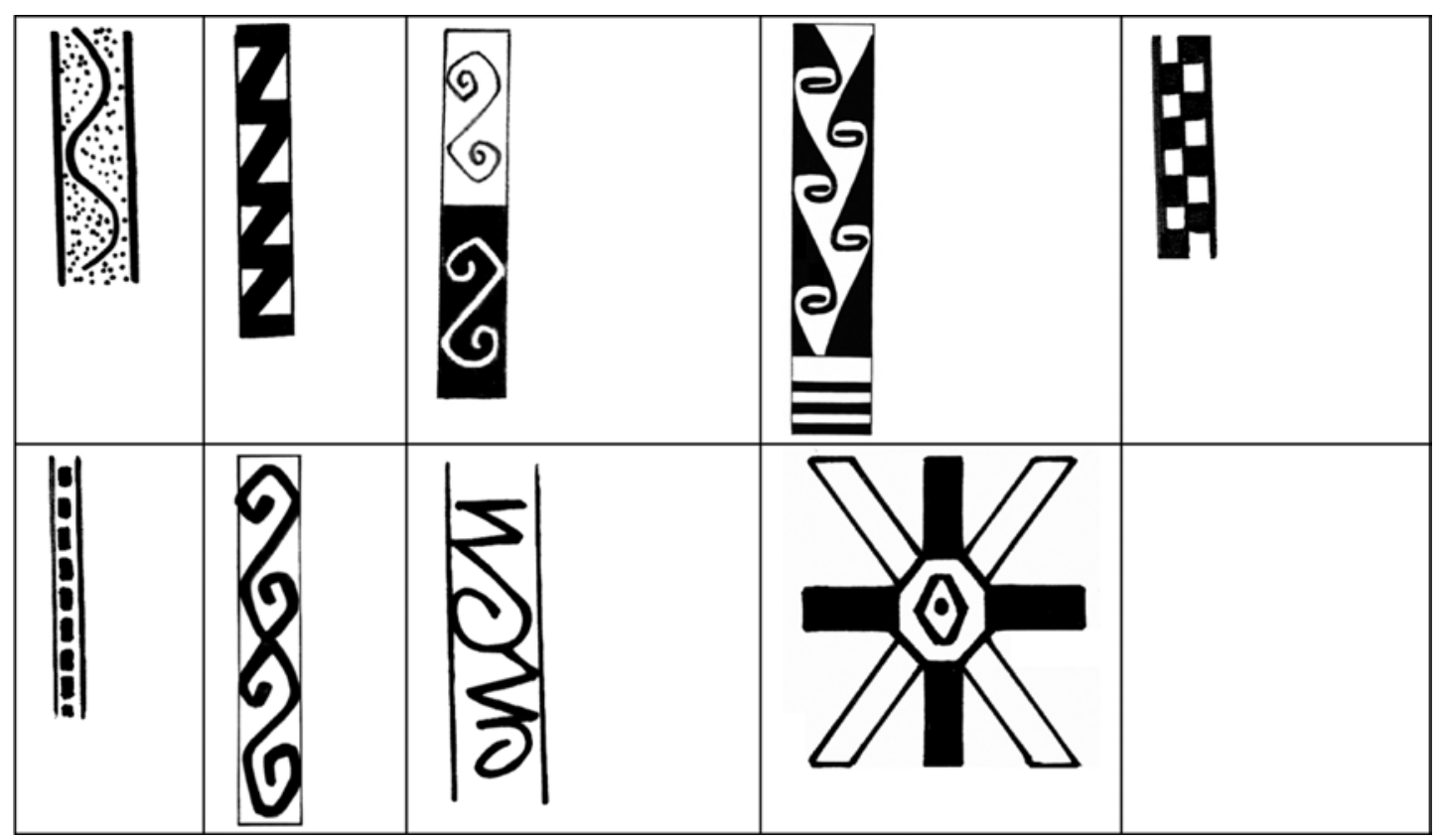

Figura 20a. Motivos decorativos más frecuentes de las inkuñas del Grupo 2H.

Most frequent decorative motifs of inkuñas from Group $2 \mathrm{H}$.

La numeración de las Figuras entre paréntesis corresponde a Horta (2005).

- línea ondulada (Figura 241)

- letra "Z" (Figura 226)

- voluta "S" en sucesión vertical (Figura 297)

- ganchos (Figura 264)

- línea ajedrezada simple (Figura 224)

- línea punteada (Figura 220)

- volutas "S" unidas verticalmente (Figura 307)

- zigzag con ganchos (Figura 240)

- hexágono radiado de ocho ejes (Figura 212)

este tipo de inkuñas provienen del cementerio El Descanso cercano a Chiribaya Baja, cuyo material cultural pertenecía a población Ilo-Tumilaca/Cabuza (Minkes 2005:174).

Inkuña estilo Maytas (Grupos 1C, 1D; Figuras 4 y 5). A juzgar por la ausencia de terminaciones de la inkuña 1245 de Az-71 -lo que la acerca al grupo Cabuza-, así como la presencia de asas compuestas por 3 trenzas, y su aparición en sitios con connotaciones tempranas o Maytas como Az-6, Az-71 y PLM-9, en donde ya presentan terminación de tramas en torzal, estas inkuñas parecen corresponder al estilo textil Maytas. Por su parte, el Grupo 1D, tiende a decorar el centro y las mitades de la inkuña con listas punteadas, soluciones técnicas, colores y terminaciones semejantes al del Grupo 1C. De igual manera está presente en sitios tempranos como Az-3, Az-71, Az-75 y PLM-9 donde se asocia a cerámica Maytas-Chiribaya, aunque en una oportunidad lo encontramos también en PLM-3 asociado a cerámica Pocoma y Gentilar. El fechado 1.215 d. C., obtenido del contexto de una inkuña de Az-75, se encuentra acorde con el rango temporal conocido para la tradición alfarera Maytas en Valles Occidentales (Uribe 1999).

Inkuña estilo San Miguel (Grupos 1E y 2B; Figuras 6, 14 y 14a). La inkuña San Miguel presenta, por una parte, la Composición Espacial 12 que consiste en tres franjas decoradas, destacándose la central por su mayor ancho (fenómeno análogo a la composición espacial de la chuspa de estilo San Miguel, que fue definida en un trabajo anterior por Horta 
y Agüero 2000). Por otra parte, la Composición Espacial 12a también caracteriza a este estilo de inkuñas, la cual consiste en tres franjas de igual ancho, equidistantemente dispuestas sobre un fondo monocromo, que -tanto en este caso como en el de la Composición Espacial 12- sólo es interrumpido en cada costado de la pieza por un listado lateral diferencial.

Dicho listado lateral corresponde a tres listas individuales y lisas en amarillo ocre, morado, verde o azul oscuro sobre un fondo rojo, lográndose un manifiesto contraste cromático con el verdadero color de fondo de la inkuña, que en el caso de las inkuñas San Miguel es generalmente morado oscuro. La esencia de los dos tipos de composiciones espaciales mencionadas, es el equilibrio imperante entre las superficies decoradas y las superficies llanas o "pampas".

La mayoría de los motivos decorativos de estas inkuñas son los mismos de las chuspas del Grupo 1A (Horta y Agüero 2000), vale decir, composiciones geométricas, patrones geométricos, "voluta $\mathrm{S}$ triple al interior de franja diagonal aserrada" simple y en imagen-espejo, "composición de siluetas de serpientes bicéfalas en esquema ampliado" (Figura 14a), obviamente en los colores de lo que hemos dado en llamar "policromía San Miguel" (crema sobre rojo guinda, morado, ocre, verde o azul oscuro. El ritmo composicional más frecuente es B-A-B, o también A-A-A.

Entre los rasgos técnicos característicos de la inkuña San Miguel destaca la terminación en trama en torzal de las urdimbres en algunos de los colores imperantes en la pieza, y su prolongación desde las esquinas a modo de "asas". El diseño conformado es en la amplia mayoría de los casos un rombo amarillo entre líneas rojas paralelas.

En estos tipos de inkuñas San Miguel se hace un gran despliege de colores teñidos. La pampa o color de fondo de la pieza es siempre teñida (morado, rojo oscuro o granate), al igual que los hilados de urdimbres de las franjas decoradas. El fechado obtenido del sitio Az-8, tumba N2/4, cae bien dentro del rango de la primera mitad del Intermedio Tardío (1215 d.C.) en concordancia con una etapa de experimentación que se ha observado en la cerámica San Miguel (Uribe 1999:209).

El Grupo 1E de inkuñas representa una forma distinta de cubrir el espacio textil (listas delgadas polícromas sobre un color claro de fondo; ver Figura 6, Composición Espacial 5) y, por otra parte, prescinde de todo tipo de diseño; sin embargo, el listado lateral diferencial y el diseño de las tramas en torzal emparentan estilísticamente a este grupo con la tradición textil San Miguel.

Inkuña estilo San Miguel-Pocoma (Grupos 2A, 2A', 2D; Figuras 12, 12a, 13, 16, 16a). Este estilo de inkuña representa la misma fusión estilística de rasgos San Miguel y Pocoma, que fuese observado en el caso de las chuspas del Grupo 1A (Horta y Agüero 2000). En el caso específico de la inkuña esto se traduce en una innovación espacial: se listan las "pampas" o espacios llanos que quedaban entre las tres franjas decoradas (ver Figura 16 con Composiciones Espaciales 14 y 14a). Esto se hace con tres pares de listas en ocre, morado y azul oscuro, listado característico al cual hemos denominado "listado Pocoma". Junto con ello, desaparece el listado diferencial de los bordes laterales que vimos en las inkuñas San Miguel.

Es importante destacar que, a pesar del listado de las pampas, se mantiene invariable la composición de un cuerpo dividido por tres franjas decoradas (compárense las Figuras 14 y 16 con las Composiciones Espaciales 12 y 14); el ancho de la franja central suele presentar variaciones, pudiendo ser más ancha que las laterales, o del mismo tamaño. En el primer caso, la franja central se destaca además por un diseño particular y diferente al de las franjas laterales.

En este estilo de inkuñas se detectan varios cambios importantes en términos composicionales respecto de la inkuña de estilo San Miguel Clásico. Surge una de las composiciones espaciales más difundidas entre las inkuñas de fines del Intermedio Tardío: se trata de las Composiciones Espaciales 11 y 11a (Figuras 12 y 13), en las cuales el centro de la pieza se deja sin decorar, de modo que tenemos un centro llano morado o rojo oscuro, desde el cual se disponen simétricamente dos o más franjas decoradas por lado, además del "listado Pocoma" intermedio (Grupos 2A y 2A').

En las inkuñas de estilo San Miguel-Pocoma se mantienen algunos motivos San Miguel (patrón geométrico, "voluta $\mathrm{S}$ triple al interior de franja diagonal aserrada" en su variante simple y en imagen-espejo, ganchos en módulos), a la vez que se incorporan el pájaro de pico grueso y el "camélido de cuatro patas" en sus diferentes variantes (Figura 12a), así como figuras antropomorfas erguidas sobre pies y otras con las piernas flectadas 
(Figura 16a). En lo cromático se sigue utilizando la "policromía San Miguel" en las franjas decoradas, aunque ocasionalmente es posible observar en una misma pieza el uso simultáneo de "policromía San Miguel" y dos combinaciones de colores estables (rojo y crema, café y crema), que hemos llamado "bicromía Pocoma-Gentilar".

En este estilo de inkuñas no hay listado lateral diferencial, puesto que todo el fondo o "pampa" sólo es interrumpido por la presencia alternada de franjas decoradas y sectores listados con los colores recurrentes del "listado Pocoma" (azul marino, amarillo ocre y morado) (Grupo 2D).

El grueso de los fechados obtenidos por medio de la asociación contextual de las inkuñas de los Grupos 2A y 2D, nos entregan un rango amplio -entre el 1.200 y el 1.400 d. C.- el cual es acorde con el período de madurez del estilo San Miguel y la aparición de los rasgos Pocoma (Uribe 1999:209). Por su parte, el fechado de $960 \pm 80$ d.C. para la tumba M4/1 ha sido evaluado como discordante, considerándose que su ubicación real en la serie es del orden de 1.250 d.C. (Espoueys et al. 1995).

Inkuña estilo Pocoma (Grupos 1B, 2C; Figuras 3, 15 y 15a). Tal como ya se vio, la esencia de su composición espacial es tres, cuatro o cinco franjas decoradas, dispuestas simétricamente y equidistantemente sobre un fondo café claro; dichas franjas presentan el mismo ancho, de forma que no hay predominio de ninguna de ellas, ni por tamaño ni por diseño especial (Figura 15 con la Composición Espacial 13). Se da un equilibrio perfecto entre franjas decoradas polícromas y fondo monocromo, sin dominio de uno sobre el otro. En rigor, no hay listado lateral diferencial, puesto que en los costados de la pieza se utilizan los mismos colores artificiales empleados en las franjas decoradas. De esta manera, el contraste cromático se produce entre lo decorado con diseño y el color de fondo (café claro) subyacente a él, y no entre el color de fondo del listado lateral y el resto del cuerpo, como ocurre en la inkuña San Miguel, al igual que en ciertas piezas San Miguel-Pocoma. No obstante, entre las inkuñas del Grupo 2C han sido identificadas todas las posibilidades de listados laterales: en tres pares de listas (listado Pocoma), en listado por contraste y en tres listas llanas de diferentes colores.

Entre los diseños y motivos más frecuentes de las inkuñas Pocoma destacan: una línea ondulada lograda por medio de la técnica de urdimbres flotantes, el rombo con cuatro ganchos, la voluta "S" simple y con prolongaciones (Figura 15 y 15a). Igualmente hay que destacar la presencia de un motivo observado en textiles del sur del Perú: un rombo segmentado, que es logrado con la técnica de urdimbres transpuestas (ésta última, de muy baja frecuencia en los textiles de Arica). Otro rasgo Pocoma es la bicromía rojo/crema para las franjas decoradas. El ritmo de las franjas decoradas puede ser, indistintamente, B-A-B o A-A-A. Una inkuña de este grupo era parte de un contexto fechado en $1.310 \pm 75$ d.C., lo cual coincide con el tiempo consignado para la aparición estilística Pocoma en la cerámica Arica (Uribe 1995, 1999).

Inkuña estilo Pocoma-Gentilar (Grupos 1G, 2E; Figuras 8, 17 y 17a). La inkuña de estilo PocomaGentilar se caracteriza por el uso de una serie de motivos que no son utilizados por la iconografía San Miguel (chevrón, volutas de cabezas entrelazadas, etc.), aunque también figuran en menor grado algunos compartidos (ganchos en módulos y ganchos continuos, pájaro de pico grueso, rombo con cuatro ganchos, antropomorfo monocéfalo con extremidades flectadas hacia arriba; ver Figura 17a).

Por otra parte, a nivel de lo cromático se opera un cambio sustancial. Las inkuñas Pocoma-Gentilar no utilizan la "policromía San Miguel" en las franjas decoradas; por el contrario, los colores de los diseños se reducen a los de la "bicromía Pocoma-Gentilar" (rojo/crema; café/crema).

Igualmente, también ha sido posible detectar entre las inkuñas Pocoma-Gentilar la adopción de otra de las composiciones espaciales características de fines del Intermedio Tardío, que consiste en listar el espacio textil con listas individuales de variados colores y no sólo pareadas, como en el caso del "listado Pocoma".

El Grupo $1 \mathrm{G}$ es la variante simple, sin decoración figurativa del Grupo 2E. Siempre exhibe un listado lateral diferencial en los costados de la inkuña, en una gran gama de posibilidades, ya sea como tres listas llanas, como tres listas en pares o en forma de listas impares de diferentes colores.

Inkuña de estilo Costero (Grupo 2H; Figuras $20 \mathrm{y}$ 20a). Esta denominación es provisoria y obedece a dos situaciones; por una parte, los ejemplares de este grupo provienen hasta aquí exclusivamente de cementerios costeros y, por otra parte, su composición 
espacial básica difiere completamente de la tradición textil Arica. Los diseños geométricos simples que se pueden observar en la Figura 20a, también dan cuenta del alejamiento de los patrones decorativos de los textiles San Miguel, Pocoma o Gentilar. Por estas razones, y también debido a su pequeño número, creemos que se trata de ejemplares intrusivos en la muestra.

Inkuña de estilo Listado Especial (Grupos 1H, 2G; Figuras 9, 19 y 19a). Los ejemplares del Grupo $1 \mathrm{H}$, organizados según la Composición Espacial 8 y 8a, corresponden a este estilo. En el material del cementerio Playa Miller-3 pudimos observar la presencia de 11 inkuñas, así como una de Playa Miller-4, que presentaban todo el cuerpo decorado con el característico tipo de listado en colores naturales que previamente habíamos observado en 2 inkuñas de Azapa-8, en el material de la CMBE.

Tal como ya se señaló y se aprecia en la Figura 9, el listado mencionado consiste en una lista gruesa café oscura acompañada de una lista delgada del mismo color dispuestas rítmicamente sobre un fondo café claro, en un interesante juego de figura y fondo. Hemos utilizado la denominación "lista con cría" para designar dicha forma de listado, adoptando el término de Cereceda (1990, $\mathrm{s} / \mathrm{f}$ ). En investigaciones previas habíamos advertido que doce bolsas-fajas provenientes de los sitios Playa Miller-3, 4 y 9 presentaban este mismo tipo de listado en sus caras no expuestas, en contraste con la decoración figurativa y geométrica de los anversos (Horta 1998a) ${ }^{5}$.

Algunas piezas exhiben listado lateral diferencial, y otras no. El diseño de la trama en torzal que adorna las orillas de urdimbres es, por lo general, una simple línea serpenteante, y el rombo de las inkuñas San Miguel y Pocoma-Gentilar se observa sólo ocasionalmente.

Este mismo tipo de listado es el que exhibe el pequeño número de inkuñas del Grupo $2 \mathrm{G}$ (Figura 19), las cuales presentan además una decoración estructural discreta, en forma de motivos geométricos simples (chevrón, voluta "S", letra "Z" en sucesión vertical; Figura 19a), dispuestos al interior de tres franjas extremadamente delgadas y repartidas equidistantemente en el cuerpo de la pieza. Cada uno de estos motivos (así como la forma característica de disponerlos en el centro de una franja mitad roja/mitad verde), son posteriormente elementos recurrentes de la decoración de tejidos incaicos, de manera que suponemos que estas inkuñas podrían estar representando la adopción por parte de la población local de patrones altiplánicos incanizados. El fechado por termoluminiscencia de $1.350 \pm 65$ d.C. que nos entrega el contexto de una inkuña del Grupo 2G, ubica la vigencia de este estilo en la segunda mitad del Intermedio Tardío.

Inkuña de estilo Listado Profuso (Grupos 1F, 1I, 1J, 2F; Figuras 7, 10, 11, 18 y 18a). Esta denominación también tiene carácter provisorio, con la esperanza de que nuevas investigaciones puedan establecer con más precisión la identidad cultural de sus tejedores y portadores. La característica más general de los diversos estilos de inkuñas de fines del Intermedio Tardío, con presencia casi exclusiva en la costa de Arica, es el listado completo o parcial de sus cuerpos (véanse Composiciones Espaciales 15, 16, 16a, 17 entre las decoradas figurativamente, y Composiciones Espaciales 6, 7, 8, $8 \mathrm{a}, 9,10$, para las tejidas sólo con listados). Aparte de esta característica básica, presentan un sin fin de combinaciones aleatorias entre diferentes tipos de listados, en los colores naturales y artificiales utilizados en ellos, así como combinaciones entre listados y franjas decoradas con diseños, etc., lo que dificulta a primera vista la segregación del material textil en subgrupos al interior de una macro-definición composicional.

Las inkuñas del Grupo 1F prácticamente no presentan rasgos emparentados con los estilos San Miguel o San Miguel-Pocoma, y caben en el conjunto de tendencias estilísticas de finales del Intermedio Tardío, que se caracterizan por listar el espacio verticalmente con colores artificiales, permitiendo así que el color de fondo (café claro) destaque en el conjunto. También se utiliza el color blanco en forma de delgadas líneas equidistantemente dispuestas en el espacio, por medio de las cuales se consigue dar golpes de luz al tejido. El único resabio de las composiciones Pocoma es la evidencia de una inkuña de este grupo que exhibe lateralmente el listado Pocoma (pieza 988 de Playa Miller-3).

Lo señalado anteriormente tiene plena vigencia para las inkuñas de los grupos $1 \mathrm{I}$ y $1 \mathrm{~J}$, con la salvedad de que en ellas se empieza a notar una marcada tendencia a omitir todo tipo de decoración figurativa y a enfatizar el uso de colores naturales; éstos van ganando un espacio cada vez mayor al interior 
del textil en desmedro de los colores artificiales. Por otra parte, en rigor, el uso del listado lateral diferencial desaparece, al no presentar contraste cromático con el color de fondo de la pieza. En cuanto a los motivos no figurativos observados en inkuñas de estos grupos, podemos mencionar bloques punteados y líneas ajedrezadas como única forma de decoración.

Las Composiciones Espaciales 16 y $16 \mathrm{a}$-que caracterizan al Grupo 2F en la Figura 18- consisten en un cuerpo listado de manera tal, que puede observarse un color de fondo continuo café claro por debajo de las franjas decoradas con diseños o punteados que difieren del punteado de los Grupos 1C y 1D, puesto que los del estilo Listado Profuso son más anchos. En este grupo la decoración queda segregada mayoritariamente a tres franjas muy delgadas, con diseños en miniatura.

El fechado por termoluminiscencia de 1.470 d.C. obtenido en relación con una pieza del Grupo 1I es perfectamente coherente con el inicio del período Tardío en el Norte Grande de Chile.

Como resumen de lo expuesto hasta aquí, consignamos en la Tabla 2 la presencia porcentual de cada estilo textil definido en nuestra muestra.

\section{Funciones de la Inkuña Etnográfica}

De acuerdo a reseñas acerca de inkuñas etnográficas utilizadas aún hoy por pastores andinos, podemos conocer interesantes detalles tanto de los aspectos formales como del valor y significado asignado a estas particulares prendas, denominadas también "mantas pequeñas" o "telas rituales"
(Flores Ochoa 1997; Šolc 1969; Tschopik 1968; Zorn 1984, 1987).

Zorn (1987), establece básicamente siete tipos de inkuñas de acuerdo con sus composiciones espaciales, y tres o cuatro funciones anexas a ellas:

(1) para contenidos rituales o para llevar y guardar coca (unkhuña misa o Tipo 4; tiqlla unkhuña o Tipo 3; k'uchu unkhuña sin tipo establecido),

(2) para marcar ganado (vaca unkhuña o Tipo 5; unkhuña camélida o Tipo 2),

(3) para acarrear comida y cualquier otra función de las mencionadas (q'asi unkhuña o Tipo 1).

No deja de sorprender que en relación con los tipos 6 y 7 no mencione ni el nombre indígena ni la función de éstos. Al mismo tiempo, manifiesta que las inkuñas "con una creciente diferenciación del espacio están destinadas sólo para un uso especializado, que incluye llevar la coca y el guardar los artículos rituales" (Zorn 1987:519), lo cual se traduce en una diferenciación clara entre inkuñas con divisiones espaciales más complejas y a la vez decoradas con diseños geométricos, y sus pares más simples en tejido llano. De ésto se deduce que la función ritual tiene más valor que la cotidiana y, por lo mismo, la función ritual amerita una factura más cuidada y con diseños más complejos, exigiendo a la vez una función exclusiva para ese tipo de inkuña.

Por su parte, Šolc (1969) indica -de acuerdo a las observaciones realizadas durante su estadia en la isla Suriqui del lago Titicaca- a la inkuña como parte de la vestimenta masculina, señalando que:

Tabla 2. Presencia porcentual por estilo textil en la muestra utilizada. Textile style percentages found in the analyzed sample.

\begin{tabular}{llcc}
\hline \multicolumn{1}{c}{ Estilo } & \multicolumn{1}{c}{ Grupo } & Número de Inkuñas & Porcentaje (\%) \\
\hline Cabuza & $1 \mathrm{~A}$ & 4 & 2,7 \\
Maytas-Chiribaya & $1 \mathrm{C}, 1 \mathrm{D}$ & 12 & 8,1 \\
San Miguel & $1 \mathrm{E}, 2 \mathrm{~B}$ & 22 & 15 \\
San Miguel-Pocoma & $2 \mathrm{~A}, 2 \mathrm{~A}, 2 \mathrm{D}$ & 28 & 19 \\
Pocoma & $1 \mathrm{~B}, 2 \mathrm{C}$ & 12 & 8,1 \\
Pocoma-Gentilar & $1 \mathrm{G}, 2 \mathrm{E}$ & 17 & 11,6 \\
Listado especial & $1 \mathrm{H}, 2 \mathrm{G}$ & 17 & 11,6 \\
Costero & 2H & 30 & 20,4 \\
Listado Profuso & $1 \mathrm{~F}, 1 \mathrm{I}, 1 \mathrm{~J}, 2 \mathrm{~F}$ & 30 \\
\hline
\end{tabular}


es de origen muy antiguo y corresponde a un paño cuadrado [...] La cantidad de coca que se puede guardar en el tari, con la que pueden ligarlo facilmente, fue aceptada como medida y todavía es común medir las cantidades de coca por taris (Šolc 1969:102, el énfasis es nuestro).

O también en otra sección señala:

La coca es guardada por cada uno en un paño de lana de color nogal, con rayas más oscuras y claras. Este paño lo anudan por sus cuatro puntas y lo guardan en el bolsillo del saco o los pantalones, o atrás de la faja ancha [...] Su tamaño está aproximadamente normalizado (cerca de $40 \times 40 \mathrm{~cm}$ ), de tal modo que se llena de coca, pues se le ha considerado como una unidad en el comercio al detalle. El comprador puede pedir un tari o la mitad de un tari de coca; un tari equivale más o menos a la concavidad formada por la mano más grande... (Šolc 1969:187).

Aparte de esta clara asociacion de la inkuña al individuo aymara masculino, asi como a su carácter de contenedora de coca, dicho autor menciona también otras variantes de uso para esta pieza textil. Una de ellas es envolver el almuerzo de mediodía que los hombres llevan a sus faenas de pesca en el lago (Šolc 1969:59), y la otra es servir en este tipo de textiles la comida a invitados en ocasiones festivas (Šolc 1969:71).

Sin lugar a dudas, la información entregada por este autor entraña gran valor para la arqueología; por una parte, no sólo entrega datos útiles para vincular a nuestro tipo de textil con determinadas funciones, sino que además se puede colegir de su somera descripción, que los aymaras del lago Titicaca en el siglo XX poseen básicamente dos tipos de taris, cada uno para una diferente función y, por lo mismo, cada tipo presenta distinta decoración. Esto es lo que se desprende de la mención descriptiva de la inkuña como contenedora de hojas de coca ("paño de color nogal, con rayas más oscuras y claras"), y como contenedora de alimentos ("paño de lana parda") (Šolc 1969:59). Por otra parte, sus observaciones incluyeron también establecer el tamaño estandar del tari, lo cual puede arrojar luces sobre las dimensiones normalizadas de las piezas arqueológicas.

Finalmente, entre la vestimenta actual de la comunidad de Coroma (altiplano sur de Bolivia) también figura la unkhuña o tari, y es mencionada como "la prenda que envuelve el q'ipi de textiles" (Bubba 1997:391).

\section{Funciones de la Inkuña Arqueológica}

Por nuestra parte, hemos podido establecer en base a la muestra analizada tres funciones o usos básicos avalados por el registro arqueológico:

- inkuñas depositadas en la tumba conteniendo hojas de coca, y ocasionalmente también un trozo de llipta. Para lograr este uso se ataban sus cuatro esquinas como un pañuelo. Esta función presenta el mayor número de evidencias con hallazgos en Playa Miller-3 (Skottsberg 1924), Playa Miller-2 (en 13 tumbas excavadas por Mostny en 1942 se encontraron siete inkuñas y todas sin excepción contenían hojas de coca), Azapa-6 (Focacci 1990), Playa Miller-9 (cuya tumba 17 contenía siete inkuñas conteniendo coca; Focacci 1982), en una tumba de Estuquiña, valle de Moquegua, Perú (Clark 1993) y en Chiribaya Baja cementerio 1 (Clark et al. 1993). Generalmente estos "atados" son depositados junto al fardo; también pueden encontrarse en el interior del fardo, en el regazo, por debajo de algún hombro (Bird 1943), o por encima de ellos (Clark 1993; Minkes 2005).

- inkuñas cubriendo enteramente la cabeza del difunto y, por lo tanto, tapándole la cara; el resto del cuerpo es cubierto por textiles de mayor tamaño, tales como túnicas o mantas y amarrado con cuerdas de fibra vegetal o de camélido. Dicha utilización de la inkuña parece ser parte de un rito funerario particular observado aisladamente en un número menor de fardos de diferentes cementerios con contextos de fines del Intermedio Tardío, tanto de Azapa (Az-6, Az-8) como de la costa (PLM-9). Respecto a este último sitio, Ulloa señala que en dos de un total de 26 tumbas se encontraron párvulos con las cabezas cubiertas por inkuñas (Ulloa 1981a:122); Clark menciona la misma forma de utilización en el caso de una tumba de Estuquiña 
que contenía a un adolescente probablemente femenino (Clark 1993).

- inkuñas amarradas como pañuelos conteniendo objetos diversos; esta situación es absolutamente minoritaria en el material analizado. Podemos mencionar un hallazgo aislado de Playa Miller-3, en donde excepcionalmente el "atado" contenía ovillos de lana de camélido en colores naturales y también fibra sin hilar, y un caso similar del cementerio 1 de Chiribaya Baja, donde la inkuña que formaba parte de la ofrenda envolvía implementos de tejer (huso, wichuña o naveta, peine, portahilos, aguja y tupu) (Clark 1993). Por otra parte, también podemos consignar un hallazgo excepcional en el cementerio de Azapa-15 (período Tardío), en donde se registró una inkuña conteniendo arcilla roja compacta. Tal vez se pudiese tratar de $t a k u$, sustancia utilizada por los pastores andinos en la ceremonias de marcación del ganado, tal como es mencionado por Zorn (1987) de acuerdo a uno de los usos menos comunes de la inkuña en contextos actuales (inkuña marcadora de ganado).

En el curso de la revisión bibliográfica pudimos detectar sólo un caso de inkuñas dispuestas como paños cubriendo el piso de una tumba; ésto es mencionado por Skottsberg para la tumba VI de la "necrópolis de Arica", perteneciente a un párvulo (Skottsberg 1924:63). Debido a su frecuencia tan restringida no la consideramos como una posible función pautada en relación con los ritos funerarios del norte de Chile.

De este modo, las funciones apoyadas por las evidencias arqueológicas nos entregan un panorama disímil del de las evidencias etnográficas, las cuales sustentan el carácter heterogéneo de las funciones actuales de la inkuña: "para guardar y cargar objetos pequeños, alimentos (crudos o cocidos) o coca, o bien son empleadas como altar en las ceremonias" (Zorn 1987:498), o también más someramente como "tela pequeña para guardar cosas" (Zorn 1987:490).

Tampoco podemos dejar de mencionar la definición que Ludovico Bertonio da en su diccionario en lengua aymara, en cuanto aporta información sobre la función de dicha prenda dos o tres siglos después de la desaparición de la inkuña del Intermedio Tardío. Tal como se verá, contamos con más de una definición para el término.
HUNCUÑA: el paño donde llevan algo, o la mantellina que traen las indias en la cabeza, que también suele servir de llevar (Bertonio 1984 [1612]:163).

ISCAYO, ONCUÑA: toca o mantellina, es vocablo de los Pacajes (Bertonio 1984 [1612]:182).

TOCA: cualquier cosa que las mujeres se ponen en la cabeza para cubrirla, excepto sombreros. SUNTTUKHALLU, ÑANACA, UNCUÑA (Bertonio 1984 [1612]:450).

En base a estas definiciones vemos que entre los aymaras de comienzos del siglo XVII la inkuña tenía un uso general como prenda "donde llevan algo", y un uso más restringido y nuevo de "toca" o "mantellina" como parte del atuendo de cabeza femenino. Cabe aquí llamar la atención sobre el hecho de que tanto Guaman Poma como Murúa presentan dibujos de mujeres incas nobles con ñañaca o toca sobre la cabeza, lo cual indica que tal atuendo ya tenía vigencia en tiempos incaicos ${ }^{6}$; al mismo tiempo, no se puede descartar la idea de que la ñañaca también haya sido parte de la indumentaria de las mujeres de alto rango de los señoríos altiplánicos, de hecho Bertonio traduce el vocablo tari como "mantellina de las mujeres Pacajes" (Bertonio 1984 [1612]:338; el énfasis es nuestro). Todo esto indica que en tiempos de Bertonio la inkuña era usada de modo diferente dependiendo del sexo del sujeto: a todos, sin excepción de género, les habría servido para llevar objetos, pero sólo las mujeres podían usarlas alternativamente como mantilla de cabeza ${ }^{7}$.

Desafortunadamente, no nos ha sido posible establecer la asociación entre la inkuña arqueológica y el sexo del individuo enterrado con ellas. Esto se debe a que en los inicios de las investigaciones arqueológicas de Arica, en la amplia mayoría de los casos, los cuerpos fueron depositados separados de sus contextos culturales, desvinculando los restos óseos de las ofrendas funerarias. En muchos casos se perdió la información del número de tumba, a la cual pertenecía el cuerpo. Por otra parte, para Playa Miller-3 específicamente no fueron conservados los restos óseos, sólo los objetos que conformaban las ofrendas, puesto que no se trató de excavaciones, sino de una serie de rescates del material arqueológico del sitio.

De este modo, resta aún establecer el uso según sexo para el material arqueológico de las 
inkuñas, lo cual no es posible abordar con la información fragmentada que tenemos hoy en día. Investigaciones futuras con la participación de bioantropólogos podrían llenar estas lagunas del conocimiento actual ${ }^{8}$.

Tal como se ha podido observar en parráfos anteriores, la función predominante de la inkuña arqueológica en el contexto funerario está estrechamente ligada a la coca, no habiéndose registrado en nuestra muestra ningún hallazgo de inkuñas relacionadas con alimentos, y el número de recurrencias con implementos de tejer ha sido minoritario. Su función como una suerte de "paño de misa" utilizado en la presentación de ofrendas tampoco ha podido ser avalada por el registro arqueológico, aunque no se puede descartar la idea de que fuera del contexto funerario las inkuñas hubiesen podido cumplir dicha función.

A pesar de las claras diferencias en el uso (contenedora de coca) y función (integrar parte de la ofrenda funeraria) de las inkuñas arqueológicas y etnográficas, hemos podido constatar que la función prehispánica de contener hojas de coca sobrevive ampliamente en el ámbito de las ceremonias de pastores andinos actuales (Šolc 1969; Tschopik 1968; Zorn 1987).

También es interesante destacar, que entre las composiciones espaciales de las inkuñas etnográficas podemos observar varias que ya figuraban en tiempos prehispánicos. Por una parte, existe la qasi unkhuña que equivale a una amplia "pampa" monocroma o a nuestra Composición Espacial 1 en la Figura 2; la entera listada o Composición Espacial 8, 8a, 16, 16a, 17 en las Figuras 9, 18, 19; la inkuña con un amplio centro vacío o Composición Espacial 2, 11, 11a en las Figuras 3, 12, 13; la con tres franjas decoradas sobre un fondo monocromo o Composición Espacial 12, 12a en la Figura 14; la de cuerpo bicromo (Figuras 21b y 21d); la de cuerpo cuatripartito (Figura 21c). Estos dos últimos tipos son especialmente interesantes porque respecto a ellos Zorn (1987) afirma: "Las más "especializadas" telas bicolores (tiqlla) y las cuatripartitas ( $\left.k^{\prime} u c h u\right)$ sirven para conservar la coca o guardar contenidos rituales. Resulta impensable el colocar fiambre en una manta cuatripartita" (Zorn 1987:517).

\section{Conclusiones}

La observación en detalle de las diversas composiciones espaciales, de los colores, diseños y terminaciones de la muestra de inkuñas nos ha permitido definir diferentes tipos al interior de este universo textil. Para ello establecimos rasgos o atributos diagnósticos que hacen posible segregar a dichas prendas en configuraciones de rasgos estables o estilos textiles. Los estilos San Miguel, Pocoma y Gentilar eran conocidos hasta aquí en base al análisis de la cerámica de la cultura Arica (Bird 1943; Dauelsberg 1972; Uhle 1919; Uribe 1995, entre otros); de acuerdo con los avances experimentados en las últimas décadas por las investigaciones centradas en el textil arqueológico, actualmente estamos en condiciones de utilizar con seguridad el estilo textil -a la par con las definiciones estilísticas de la cerámica- como fuente de información que nos permita afiliar culturalmente el contexto funerario de una determinada tumba (Agüero 2000; Agüero y Horta 1997; Horta 1996, 1997, 1998b, 2005; Horta y Agüero 2000; Ulloa 1981a, 1981b; Ulloa et al. 2000, entre otros).

Al mismo tiempo, y en base a esta misma muestra establecemos su función primordial como textil contenedor de hojas de coca, para el período referido al Intermedio Tardío; esto marca diferencias frente al uso actual de esta prenda por parte de pastores de tierras altas, aunque entre ellos existen tres tipos que se reservan para tareas de llevar y guardar coca (Zorn 1984, 1987).

Por otra parte, el estudio de los textiles funerarios de Playa Miller-3 nos entrega importante información adicional acerca de la contemporaneidad de los grupos clasificatorios establecidos en base a nuestra muestra. Al respecto, las evidencias del contexto de la tumba 60 de dicho cementerio indican la presencia simultánea de siete grupos de inkuñas compartiendo la ofrenda: piezas 800 y 805 (Grupo 2A), 806 (Grupo 2A'), 801 y 807 (Grupo 2C), 804 (Grupo 2D), 802 (Grupo 2F). Esto reafirma la contemporaneidad de los estilos San Miguel, Pocoma y Listado Profuso.

A su vez, la tumba 47 contenía 11 inkuñas, de las cuales siete pudieron ser clasificadas por nosotras: piezas 635 (Grupo 1E), 636a y 637 (Grupo 1H), 636b (Grupo 2C), 638 (Grupo 2E), 640 (Grupo 1F), 641 (Grupo 1I), 643 (pieza excepcional, sin determinación de estilo; ver Figura 21a). Esto reafirma la contemporaneidad de los estilos San Miguel, Pocoma, Pocoma-Gentilar, Listado Especial y Listado Profuso. La tumba 70 del mismo cementerio pone en evidencia la contemporaneidad de otros dos grupos: $2 \mathrm{G}$ y $2 \mathrm{E}$ (piezas 949 b y 950 , 


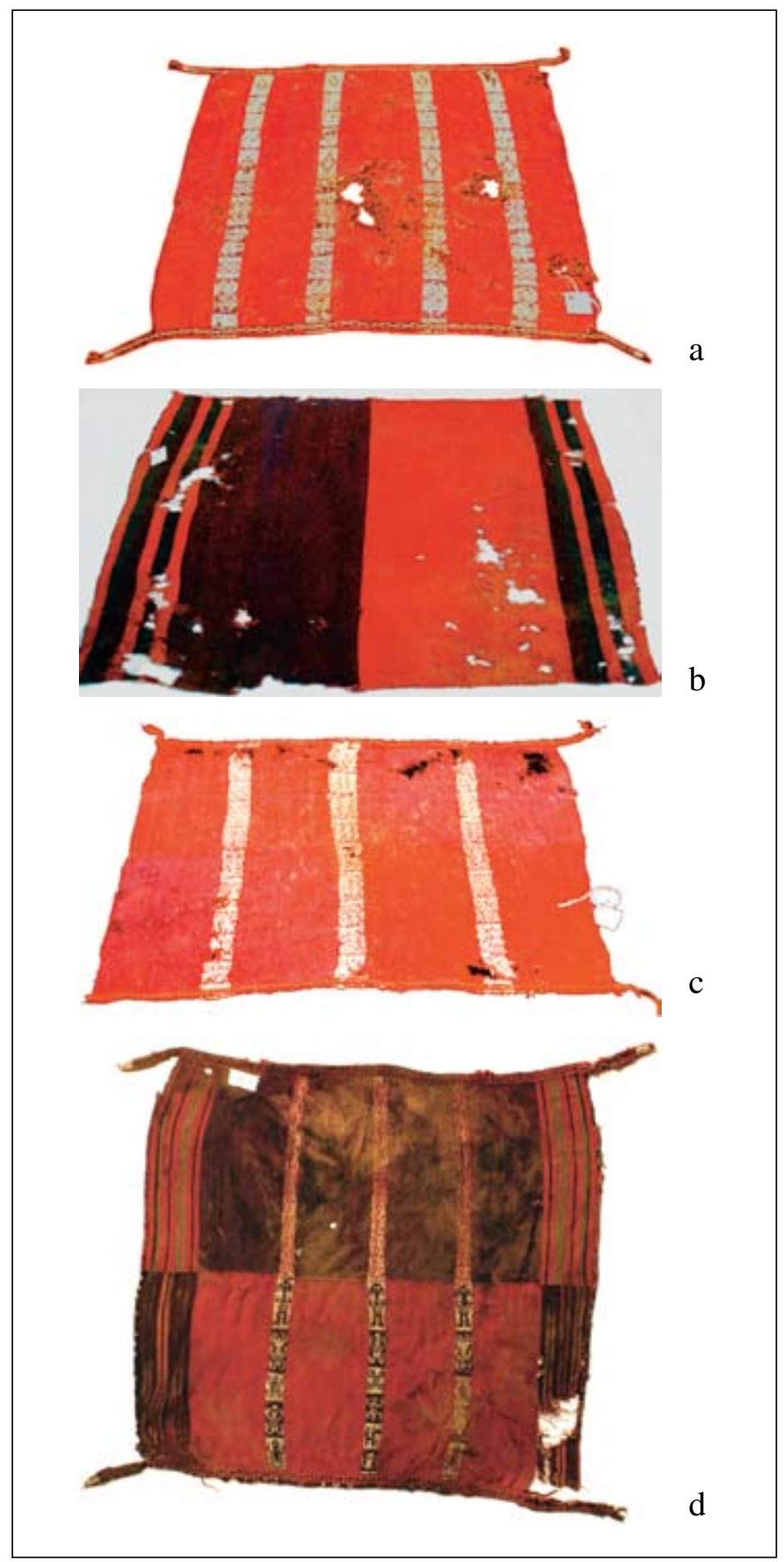

Figura 21. Ejemplares excepcionales -y de muy baja frecuencia- que escapan a las composiciones espaciales establecidas en base a la observación de la muestra de este estudio: (a) Inkuña 643 de Playa Miller-3, tumba 47. Colección MASMA; (b) Inkuña 4540 de Azapa-71, tumba 5. Colección MASMA; (c) Inkuña 442 de Playa Miller-3, tumba 32. Colección MASMA; (d) Inkuña 2885 de Playa Miller-3, tumba 9. Colección MBE.

Exceptional examples - of very low frequency-outside the spacial compositions established for this study: (a) Inkuña 643, cemetery PLM-3, grave 47, MASMA Collection; (b) Inkuña 4540, cemetery Azapa-71, grave 5, MASMA Collection; (c) Inkuña 442, cemetery PLM-3, grave 32, MASMA Collection; (d) Inkuña 2885, cemetery PLM-3, grave 9, MBE Collection. 
respectivamente), o de los estilos Pocoma-Gentilar y Listado Especial. Todo esto demuestra la contemporaneidad indiscutible de varios de los estilos definidos a través del testimonio de las inkuñas de Playa Miller-3; al mismo tiempo, pensamos que probablemente la ausencia de otros -como son los Grupos 1A, 1C y 1D- podría estar apuntando a diferencias existentes entre la población del valle versus la de la costa.

Aparte de lo señalado, el número de inkuñas depositadas en las tumbas del litoral aumenta llamativamente respecto de su presencia en tumbas de cementerios del valle, $\mathrm{y}$-lo que es aún más sugerente desde el punto de vista del surgimiento de la estratificación social en una sociedad de rango- también se ha detectado una marcada concentración de inkuñas en un número limitado de tumbas de ciertos cementerios costeros. Es el caso de Playa Miller-3, en donde el 92\% del total de inkuñas depositadas como ofrendas se encuentra en sólo un $34 \%$ de las tumbas de dicho cementerio (Horta 1999). Si bien cada uno de estos fenómenos observados traspasan los objetivos específicos que guiaron el presente trabajo, y por lo tanto quedan como tareas para investigaciones futuras, no podemos dejar de destacar el hecho que las evidencias textiles surgen aportando una cuota nada desdeñable de información contextual, que en el caso específico de la tradición textil ariqueña puede arrojar nueva luz en relación con las diferencias culturales o étnicas entre la población de pescadores asentados en el litoral, y aquella de agricultores que cultivaban los valles interiores.

Agradecimientos. Ambas autoras tenemos una enorme deuda de gratitud con Oscar Espoueys, quien nos confiara generosamente su colección textil, permitiéndonos estudiarla sin restricciones. Asimismo, vayan nuestros agradecimientos por la colaboración y el espíritu de trabajo en equipo que demostraron los colegas Julie Palma, Mauricio Uribe y Claudia Prado. Agradecemos también al plantel del Museo Arqueológico San Miguel de Azapa por la colaboración que siempre nos ha prestado en el curso del estudio de sus colecciones arqueológicas; deseamos destacar en forma especial la excelente disposición del personal de Registro, Teresa Cañipa y Gustavo Espinosa. Tampoco podríamos olvidar agradecer a la dibujante Paulina Chávez el trabajo paciente y dedicado de las composiciones espaciales y los íconos textiles, así como a los evaluadores de nuestro manuscrito por la dedicación que demostraron en su revisión.

\section{Referencias Citadas}

Adelson, L. y A. Tracht

1983 Aymara Weavings. Ceremonial Textiles of Colonial and $19^{\text {th }}$ Century Bolivia. Smithsonian Institution Traveling Exhibition Service, Washington.

Agüero, C.

2000 Las tradiciones altiplánicas y de valles occidentales en la textilería arqueológica del valle de Azapa. Chungara Revista de Antropología Chilena 32:217-233.

Agüero, C. y H. Horta

1997 Los textiles del período Intermedio Tardío del valle de Azapa y costa de Arica. Informe final Proyecto FONDECYT 1960113. Manuscrito en posesión de las autoras.

Bertonio, L.

1984 [1612] Vocabulario de la Lengua Aymara. CERES, IFEA, MUSEF, Cochabamba.

Bird, J.

1943 Excavations in Northern Chile. Antropological Papers, American Museum of Natural History 38:173-318.

Brugnoli, P. y S. Hoces de la Guardia 1989 Arte Mayor de los Andes. Catálogo exhibición del Museo Chileno de Arte Precolombino, Santiago.

Bubba, C.

1997 Los rituales a los vestidos de María Titiqhawa, Juana Palla y otros fundadores de los ayllu de Coroma. En Saberes y Memorias en los Andes. In memoriam Thierry Saignes, editado y compilado por T. Bouysse-Cassagne, pp. 377-400.
Instituto de Altos Estudios de la América Latina, París Instituto Francés de Estudios Andinos, Lima.

Cassman, V.

1997 A Reconsideration of Prehistoric Ethnicity and Status in Northern Chile: The Textile Evidence. Doctoral Dissertation, Department of Anthropology, Arizona State University, Tucson. Tempe University Microfilms, Ann Arbor.

Cereceda, V.

s/f Las talegas de Isluga: apuntes para una semiología del textil andino. (Datos sobre espacio y formas). Versión en español mecanografiada e inédita.

1990 A partir de los colores de un pájaro. Boletín del Museo Chileno de Arte Precolombino 4:57-104.

Clark, N.

1993 The Estuquiña Textile Tradition. Cultural Patterning in Late Prehistoric Fabrics, Moquegua, far Southern Peru. Tesis de Doctorado inédita. Washington University, Department of Anthropology, Tomo I y II.

Clark, N., P. Palacios y N. Juárez

1993 Proyecto Textil III. Informe Preliminar. Chiribaya Baja: cementerio 1. Fardos y Textiles. Informe Interno. Programa Contisuyu, Ilo, Perú.

Dauelsberg, P.

1972 La cerámica de Arica y su situación cronológica. Chungara 1:15-25. 
Durston, A. y J. Hidalgo

1997 La presencia andina en los valles de Arica, siglos XVI-

XVIII: Casos de regeneración colonial de estructuras archipielágicas. Chungara 29:249-273.

Espoueys, O., M. Uribe, A. Román y A. Deza

1995 Nuevos fechados por termoluminiscencia para la cerámica del período Medio del valle de Azapa (I Parte). Actas del XIII Congreso Nacional de Arqueología, pp. 31-54. Sociedad Chilena de Arqueología/ Instituto Investigaciones Antropológicas, Antofagasta.

Flores Ochoa, J.

1997 La missa andina. Arqueología, Antropología e Historia en los Andes. Homenaje a M. Rostworowski, editado por R. Varón Gabai y J. Flores Espinoza, pp. 717-728. IEP, Lima.

Focacci, G.

1982 Excavaciones en el cementerio de PLM-9. Documentos de Trabajo 2:126-213, Instituto de Antropología y Arqueología, Universidad de Tarapacá, Arica.

1990 Excavaciones en Az-6. Fase Cabuza. Chungara 24/25:69124.

González-Holguín, D.

1952 [1608] Vocabulario de la Lengua General de todo el Perú Llamada Lengua Qqichhua o del Inca. Universidad Nacional Mayor de San Marcos, Lima.

Hidalgo, J.

2004 Pescadores del litoral árido de valles y quebradas del norte de Chile y su relación con agricultores, siglos XVI y XVII. En Historia Andina en Chile, editado por J. Hidalgo, pp. 431-469. Editorial Universitaria, Santiago.

Hidalgo, J. y G. Focacci

1986 Multietnicidad en Arica, siglo XVI. Evidencias etnohistóricas y arqueológicas. Chungara 16/17:137-147.

Hidalgo, J. y A. Durston

1998 Reconstitución étnica colonial en la sierra de Arica: el cacicazgo de Codpa, 1650-1780. Actas del IV Congreso Internacional de Etnohistoria. Fondo Editorial Pontificia Universidad Católica del Perú, Lima.

Hoces de la Guardia, S. y P. Brugnoli

2006 Manual de técnicas textiles andinas. Terminaciones. Proyecto Fondo Nacional del Libro, Consejo de la Cultura, Mineduc, Santiago.

Horta, $\mathrm{H}$.

1996 Introducción al estudio iconográfico de textiles arqueológicos de Arica. Boletín de la Sociedad Chilena de Arqueología 22:17-18.

1997 Estudio iconográfico de textiles arqueológicos del valle de Azapa, Arica. Chungara 29:81-108.

1998a Las bolsas-fajas del extremo norte de Chile: símbolo de estatus durante el período Intermedio Tardío. Manuscrito en posesión de la autora.

1998b Catálogo de motivos decorativos de los textiles arqueológicos de Arica. Boletín del Comité Nacional de Conservación Textil 3:145-167, Santiago.

1999 Presencia de inkuñas en cementerios de la costa de Arica y del valle de Azapa (1000-1470). Ponencia presentada en la XIII Reunión Anual del Comité Nacional de Conservación Textil, Arica. Manuscrito en posesión de la autora.

2005 Arte textil prehispánico. Diseños de los tejidos de la cultura Arica (1000-1470 d. C.). Serie Colección Estudios Regionales y Locales de la Universidad Bolivariana, sede Santiago. Imprenta LOM, Santiago.
Horta, H. y C. Aguero

2000 Definición de chuspa: textil de uso ritual durante el período Intermedio Tardío, en la zona arqueológica de Arica. Actas del XIV Congreso Nacional de Arqueología Chilena. Tomo 2 (Comunicaciones). Contribución Arqueológica 5:45-82, Museo Regional de Atacama.

Minkes, W.

2005 Warp the Dead. The Funerary Textile Tradition from the Osmore Valley, South Peru, and its Social-Political Implications. Tesis doctoral publicada por la Universidad de Leiden, Facultad de Arqueología, Leiden.

Mostny, G.

1942 Informe sobre excavaciones en Arica. Boletín del Museo Nacional de Historia Natural Tomo XX:79-125.

1944 Excavaciones en Arica. Boletín del Museo Nacional de Historia Natural Tomo XXII:135-145.

Murra, J.

1972 El Control Vertical de un Máximo de Pisos Ecológicos en la Economía de las Sociedades Andinas. Universidad Hermilio Valdizán, Huánuco, Perú.

1976 Los límites y las limitaciones del Archipiélago Vertical en los Andes. En Homenaje al R. P. Gustavo Le Paige S.J., editado por J.M. Casassas. Universidad del Norte, Antofagasta.

Santoro, C. y L. Ulloa, editores

1985 Culturas de Arica. Instituto de Antropología y Arqueología, Universidad de Tarapacá, Arica.

Skottsberg, C.

1924 Notes on the old Indian Necropolis of Arica. Meddelende fran Geografiska Föreningen i Goteborg, vol. III. Suecia.

Šolc, V.

1969 Los Aymaras de las Islas del Titicaca. Instituto Indigenista Interamericano. Serie Antropología Social 12, México.

Tschopik, H.

1968 Magia en Chucuito. Instituto Indigenista Interamericano. Ediciones Especiales 50, México.

Uhle, $\mathrm{M}$.

1919 Fundamentos étnicos de la región de Arica y Tacna. Boletín de la Sociedad Ecuatoriana de Estudios Históricos Americanos 4, vol. II, Quito.

Ulloa, L.

1981a Estilos decorativos y formas textiles de poblaciones agromarítimas en el extremo norte de Chile. Chungara 8:109-136.

1981b Evolución de la industria textil prehispánica en la zona de Arica. Chungara 8:97-108.

Ulloa, L., V. Standen y V. Gavilán

2000 Estudio de una prenda textil asociada al Inca en la costa norte de Chile (Camarones 9): las "mantas" que envuelven los cuerpos. Chungara Revista de Antropología Chilena 32:259-261.

Uribe, $M$.

1995 Cerámica arqueológica de Arica (extremo norte de Chile): primera etapa de una reevaluación tipológica. Actas del XIII Congreso Nacional de Arqueología de Chile, pp. 81-96. Universidad de Antofagasta, Antofagasta.

1999 La cerámica de Arica 40 años después de Dauelsberg. Chungara Revista de Antropología Chilena 31:189-228.

Zorn, E.

1984 Textiles in Herder's ritual bundles of Macusani, Peru. En The Junius B. Bird Conference on Andean Textiles, editado por A. Pollard Rowe, pp. 289-307. The Textile Museum, Washington, D.C.

1987 Un análisis de los tejidos en los atados rituales de los pastores. Revista Andina 5:489-526. 
Notas

1 Este estudio fue realizado por las autoras en el marco de dos diferentes proyectos de investigación: (1) Proyecto Fondecyt 1930202: "Cronología y secuencia de dos cementerios claves del valle de Azapa, Arica: períodos Medio y Desarrollos Regionales"; (2) Proyecto Fondecyt 1960113: "Estudio comparativo cultural y biológico entre cementerios del litoral y el interior, pertenecientes al período Intermedio Tardío del extremo norte de Chile". En ambos proyectos, dirigidos por Oscar Espoueys, colaboró un equipo multidisciplinario de investigadores, que incluía arqueólogos y antropólogos físicos.

2 Lo referido se observa en el trabajo de J. Bird (1943: Plate 126), en el cual vemos la fotografía de una inkuña que presenta cuerdas agregadas arriba y abajo, en el centro de la terminación de trama en torzal, con el claro propósito de convertirla en taparrabo.

3 Nos basaremos en la definición iconográfica elaborada por una de las autoras de este trabajo en su libro Arte Textil Prehispánico. Diseños de los tejidos de la cultura Arica (1000-1470 d.C.) (Horta 2005).

$4 \quad$ Minkes publica en su tesis doctoral (Minkes 2005: fig. 7.37) un ejemplar de estilo Chiribaya que también tuvimos oportunidad de observar en la exhibición del Museo El Algarrobal, cuya composición espacial coincide plenamente con nuestra Composición 12, aunque sus diseños figurativos corresponden a la fase Gentilar de la cultura Arica; por lo mismo, pensamos que se trata de una inkuña Chiribaya Tardía.

5 En el ajuar de la tumba 62 de Playa Miller-3 se detectó un único caso de una túnica completamente decorada con dicho tipo de listado (MASMA, túnica $\mathrm{N}^{\circ}$ 1260).

6 En el diccionario de González-Holguín encontramos las siguientes definiciones para pampacuna o ñañaca: (a) mantellina de india, (b) mantellina de listas de colores: ccuychi ñañaca, (c) mantellina pintada: tocapu o acnopu ñañaca (González-Holguín 1952 [1608]:582).

7 Incluimos este exhaustivo glosario preparado por Clark (1993) en su tesis doctoral, el cual incluye las diferentes denominaciones de la inkuña y sus variantes:

“incuña, un'kuña, unkhuña, huncuña $(Q)$ : a small, square cloth used by women to carry coca leaves or foodstuffs, also used as a groundcloth for ceremonial offerings, until the 20th century the incuña was also used as a woman's head covering; "[The Aymara woman carried] a number of accessory cloths for foodstuffs or coca that also doubled for a headdress (incuña)" (A\&T:32); see sunttu khallu; q'eperina (): woman's small, rectangular carrying cloth; ver huncuña; incuña=tari (A-Pacaje) (A\&T 1983:150); inkuña: (ethngr.) cloth similar to tari (term used by Chilean archaeologists); un paño cuadrado o rectangular tejido a telar, usado en la zona andina con fines utilitarios y rituales; un'kuña: pañuelo cuadrado, de género de lana, en el cual se llevan objetos pequeños, amarrando las puntas del pañuelo (Middendorf 1980); see istalla, histalla -unkuña, un'kuña, uncuña, inkhuña, unkhuña, 'unkhuña (A): aymarization (Charcas) of the Quechua "unku"; "se conocía en los antiguos señoríos aymaras con el nombre de unkuña, en la actualidad en algunas comunidades campesinas de Bolivia pervive con el nombre de "anaku" (como en Yora Departamento de Potosí)" (Money 1983:222); but also "unkhuña $(Q)=$ inkuña: small carrying cloth important in señal qepi bundle (ethngr. - Macusani, Peru - Zorn 1986:291); uncuña (A): la mantellina o tocado de las indias, ídem que uncu y más usado (B-G:86); small cloth used for a woman's coca leaves \& food stuffs, also used as a groundcloth for ceremonial offerings (Schevill 86:129); also for coins, \& for coca divination (E. Franquemont 86:89); \& 'unkhuna=llik lla-like large cloth used by women for carrying (babies, produce, etc.) on back (ethngr. - Cuzco area - APR 1976); inkhuña: similar to ist'alla but without designs, used by both men \& women to carry food (ethngr. - Qollahuaya Bastien 1978:110); see inkuña, huncuña, uncu, mantellina, hamacora; also khallu, sunttu khallu, huncuña, phantta, tari, unkhuñita, estalla" (Clark 1993:1017-1018).

8 Para el extremo sur del Perú contamos con la valiosa información aportada por Clark (1993) respecto al sitio Estuquiña de fines del Intermedio Tardío, en donde fueron encontradas cuatro inkuñas, todas ellas asociadas a hombres. Por otra parte, en relación con el cementerio 1 del sitio Chiribaya Baja, esta misma autora indica la presencia de tres inkuñas igualmente asociadas a fardos masculinos (Clark et al. 1993). 
